University of Massachusetts Amherst

ScholarWorks@UMass Amherst

Masters Theses 1911 - February 2014

1914

\title{
The absorption of certain radicals by leaves in varying stages of decay, and the effect of leaves on the absorption of these radicals by a soil
}

Harry Alfred Noyes

University of Massachusetts Amherst

Follow this and additional works at: https://scholarworks.umass.edu/theses

Noyes, Harry Alfred, "The absorption of certain radicals by leaves in varying stages of decay, and the effect of leaves on the absorption of these radicals by a soil" (1914). Masters Theses 1911 - February 2014. 1219.

https://doi.org/10.7275/pt75-cr46

This thesis is brought to you for free and open access by ScholarWorks@UMass Amherst. It has been accepted for inclusion in Masters Theses 1911 - February 2014 by an authorized administrator of ScholarWorks@UMass Amherst. For more information, please contact scholarworks@library.umass.edu. 


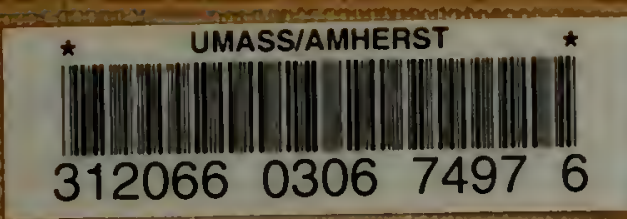

\section{FIVE COLLEGE DEPOSITORY}

The Absorption of Certain Radicals by Leaves in Varying Stages of Decay, and the Effect of Leaves on the Absorption of these Radicals by a Soil

\section{Harry Alfred Noyes}

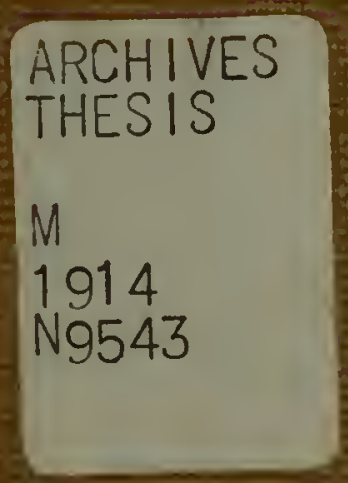

This thesis is not to be loaned outside the library buila'ing. For this purpose, use the copy in the department where the work of the thesis was done. 



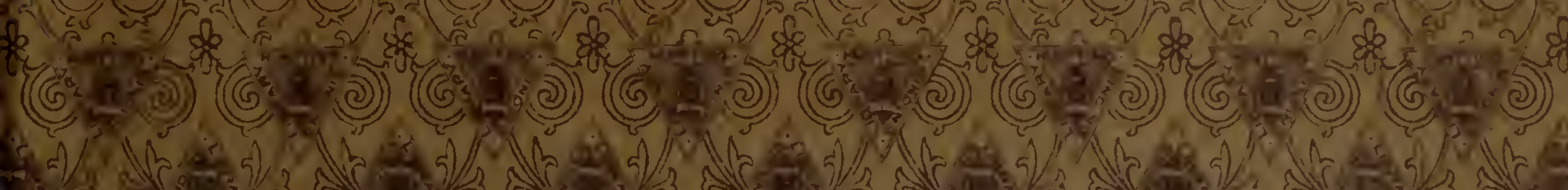

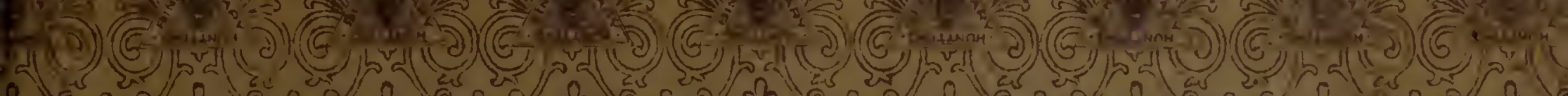

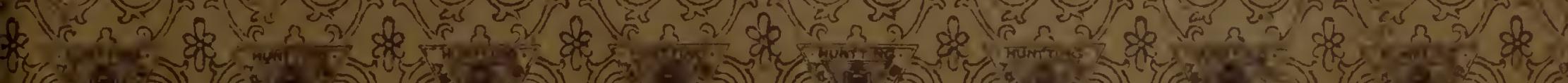

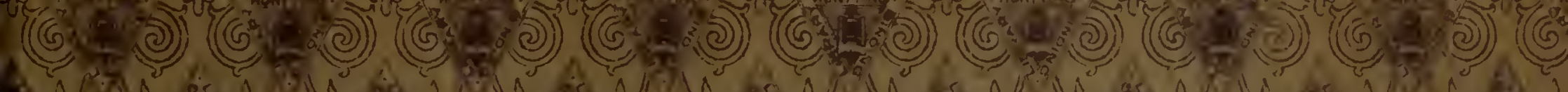
15.

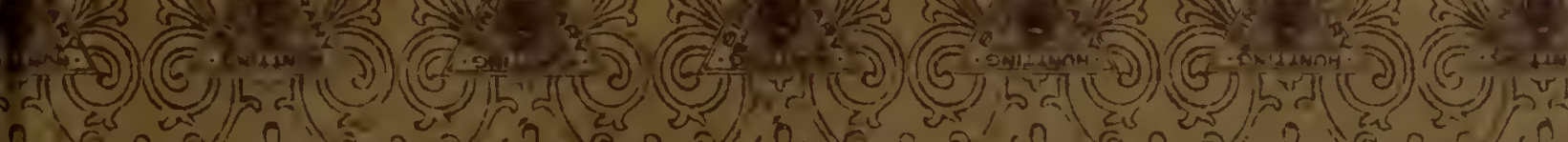

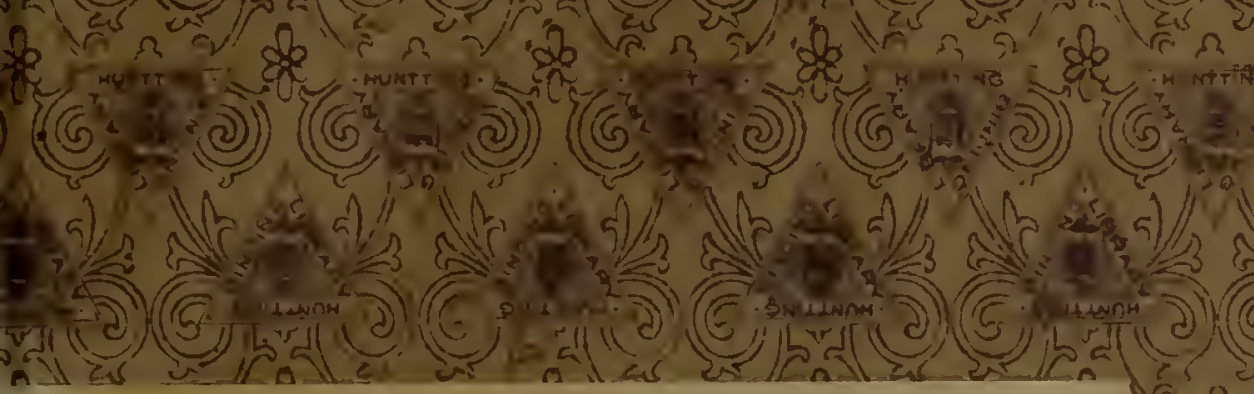

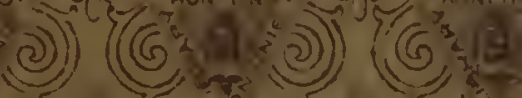
(2)) ) $((6,2)$

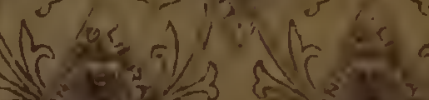
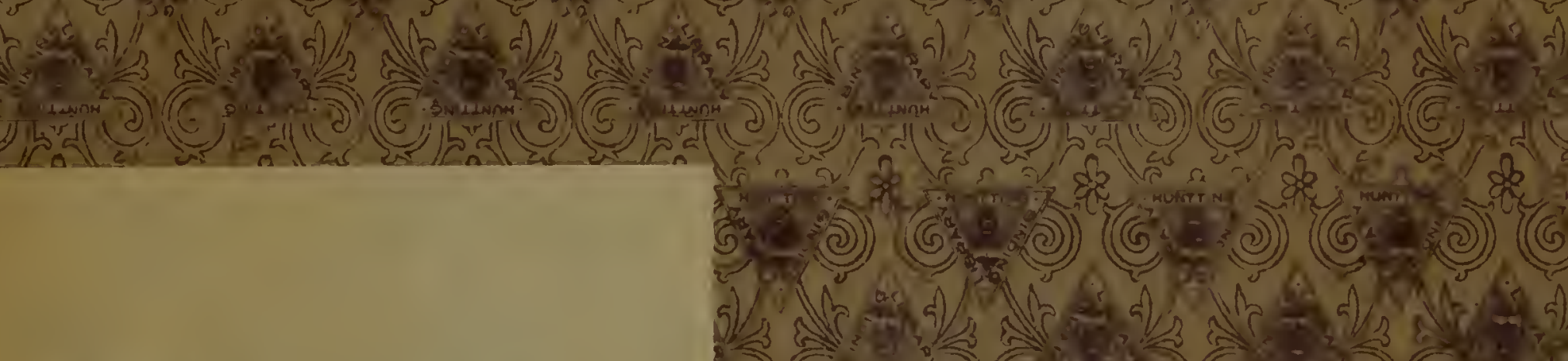

This thesis is not to be loaned outside the library building. For this purpose, use the copy in the department where the work of the thesis - was done.

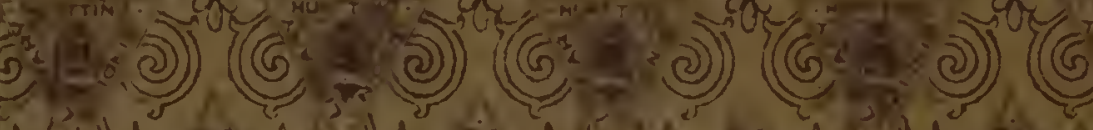

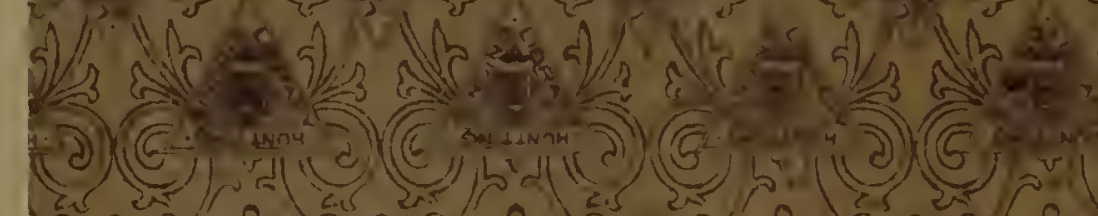
है

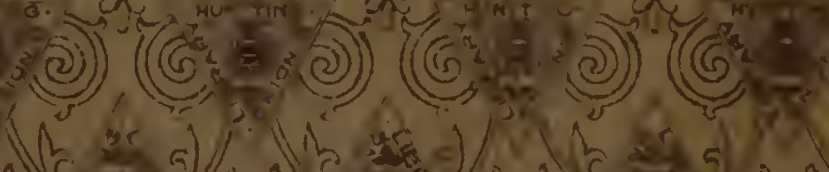

(2)) $(6$

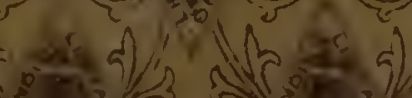

\section{(G)}

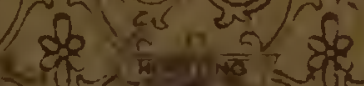

(G)

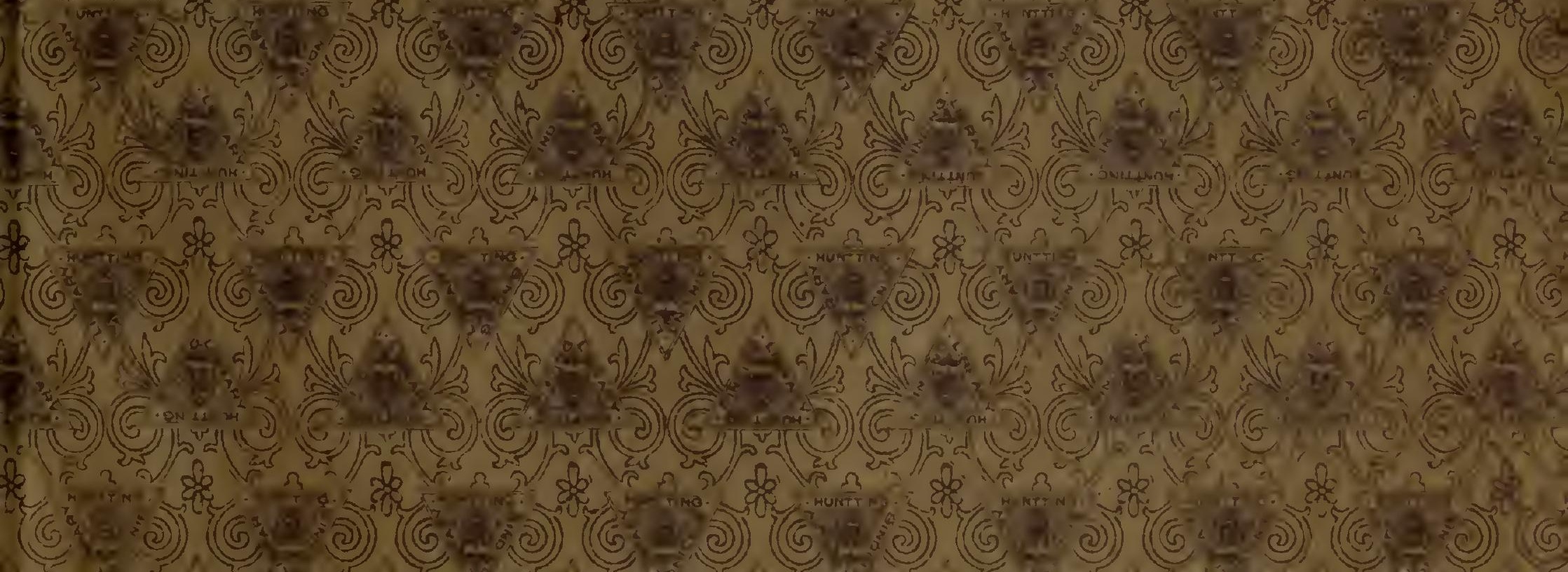



THE ABSORPTION OF CLRTAIN RADICAIS BY LEAVES

IN VARYIIG STAGES OF DECAY, AND THE RFFECT OF IFAVES ON THE ABSORPTION OF THESE RADICALS BY A SOIL.

\author{
A THES IS
}

SUBMITTSD TO THE FACUITY

OF THE

MASSACHUSETTS AGRICULTURAI COLIEGE

$B Y$

HARRY ALFRED INOYES

CANDIDATE FOR THE DEGRETC

$\mathrm{OF}$

HASTER OF SCIENCE

JUNE 1914. 


$$
\begin{gathered}
\frac{\text { LWFARY }}{\text { UNVE STY OF }} \\
\text { MASO } \\
\text { AMETESTS MASS. }
\end{gathered}
$$


The Absorption of Certain Radicals by Leaves

in varying Stages of Decay, and the Effect of Ieaves on the

Absorption of these Radicals by a Soil.

The subject of soil absorption is an old one, dating back to before 1850. The nature of soil absorption has been, and still is, a puzzle, in spite of the vast amount of work that has been done in the last few years. Two theories have been held as the cause of the absorption. The first is that the absorption is chemical, the compounds beigg changed into insoluble ones by double decomposition. The second is that the salts or radicals are physically held, that is, adsorbed by the soil particles. These theories have been held separately and combined. At the present time soil absorption, (of various kinds) is being held for the explanation of as many soil conditions as there are diseases that the patent medicine is claimed to cure. As an example, we have many methods for the determination of soil acidity and humus. It can be very easily claimed, and practically proven from available literature that the reason why some of these methods fail on certain soil types is due to the $a b$ - and adsorption phenomena particular to those soil types. The fact that virgin and cropped soils have been investigated does not exhaust the subject for the cropped soil may be as balanced as the virgin 
$\sqrt{1}$

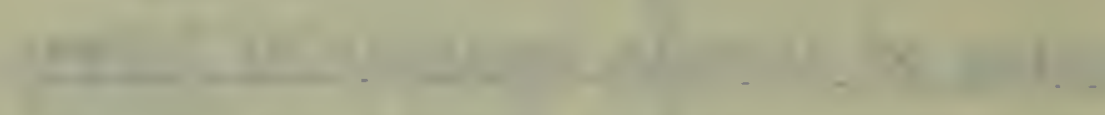

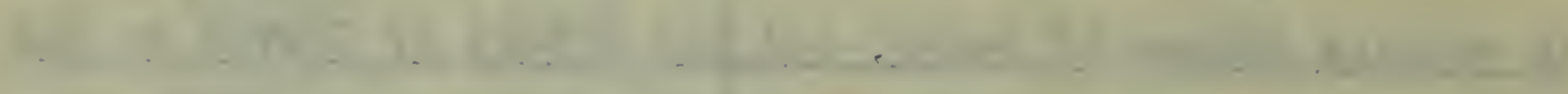

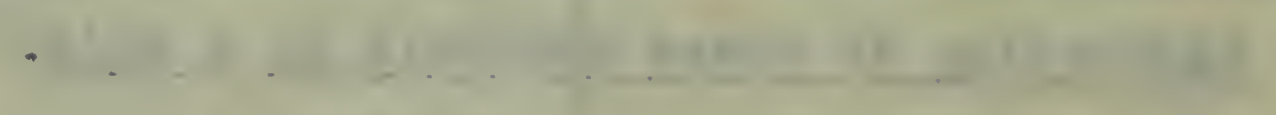

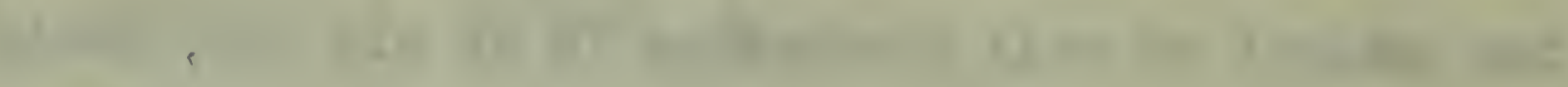

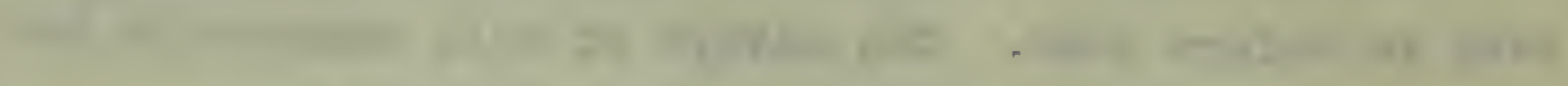

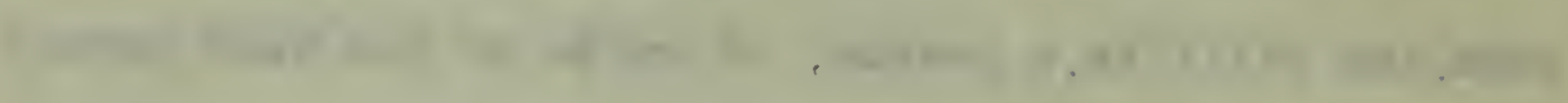

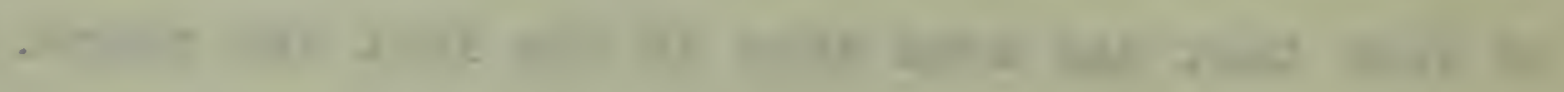

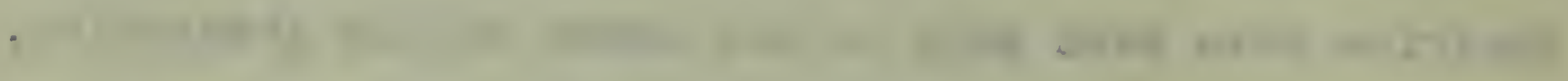

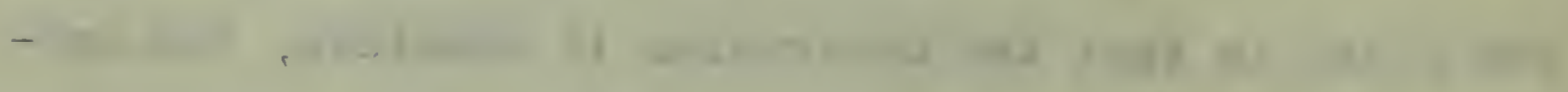

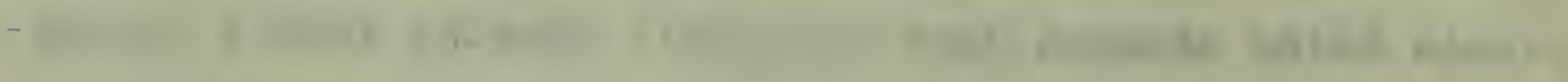

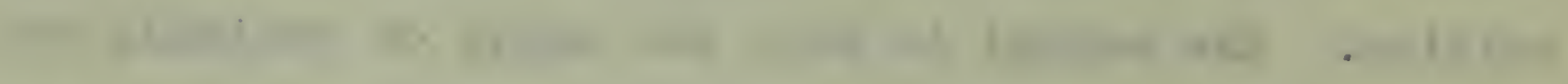

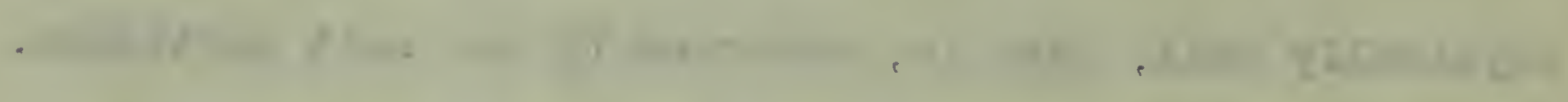
-

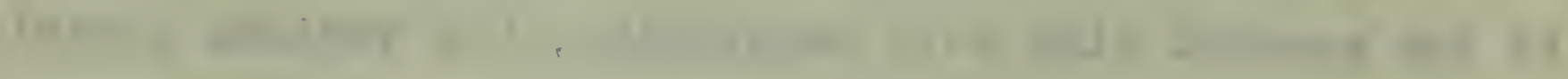

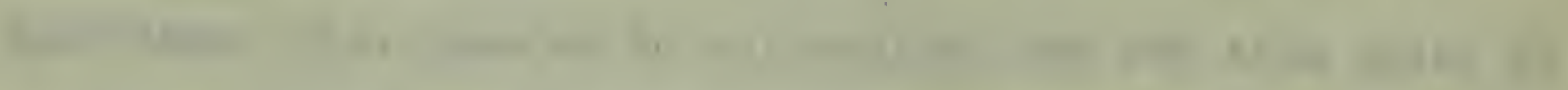

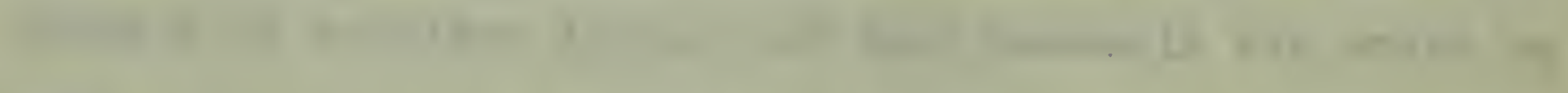

-

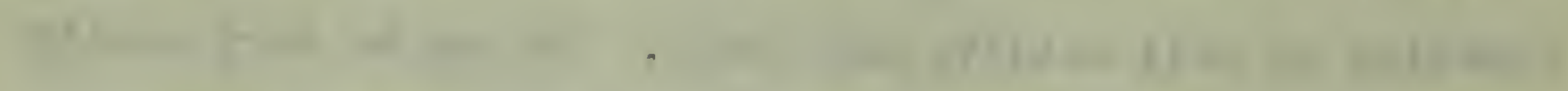

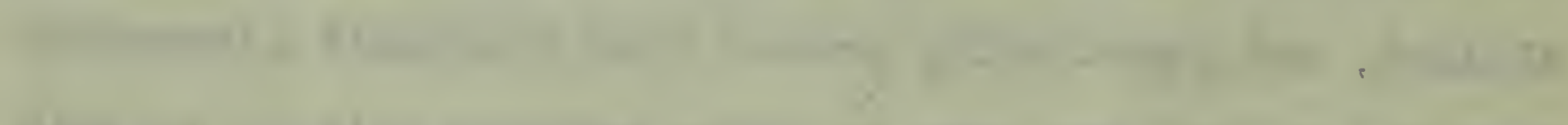

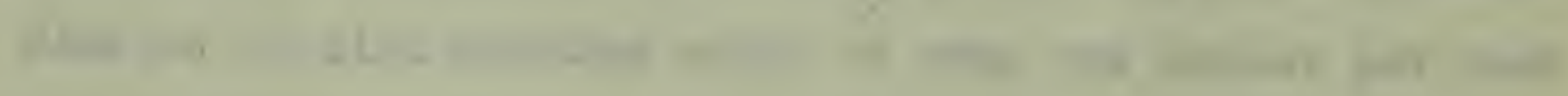

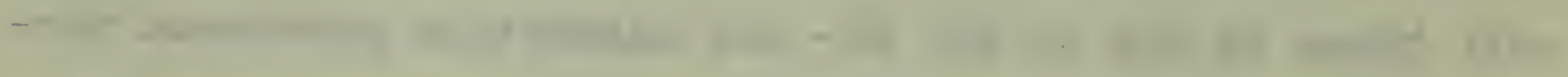

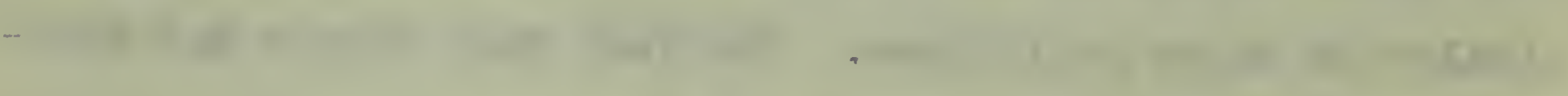

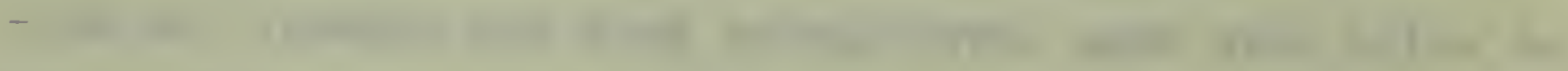

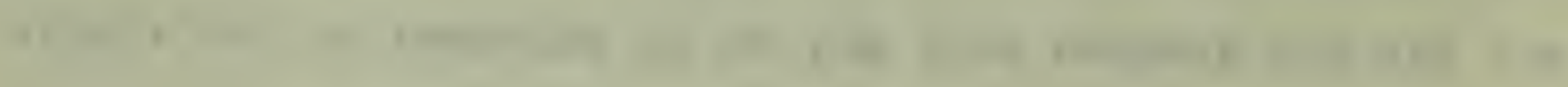


soil, or the virgin soil may be naturally just as much out of balance as the cropped soil. Investigetors are holding, that colloidal bodies, specific compounds, and radicals, are the cause of both the $a b$ - and adsorption when soil is the absorptive medium. Investigations have not advanced to where the subject can be put in perspective, and so the best that we can do, is to obtain aditional data.

\section{The Iiterature.}

Ordinarily the substances in the soil, that are of a humic nature, have not been supposed to play an important part in soil absorption. Very little is known of the aband adsorption of humus forming substances as they decay. and their effect on the absorptive capacity of the soil in their different stages of decay. No literature bearing directly on the subject of this investigation is available.

Way $\left({ }^{1}\right)$ found that when sand $\left(\mathrm{SiO}_{2}\right)$ was put on a filter paper and treated with ammonia the filtrate contained exactly the same amount of ammonia as the solution used. The first filtrate from a soil treated in the same manner contained very little if any ammonia. He took another portion of the soil, burned out the organic matter and

(1) Journal Royal Agricultural Society, Ing. 1850; 313-379 


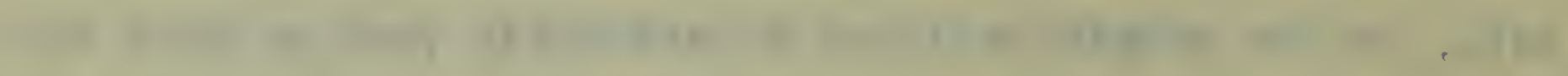
.

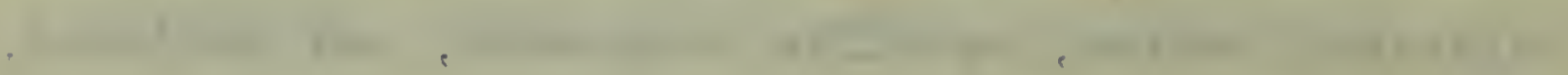

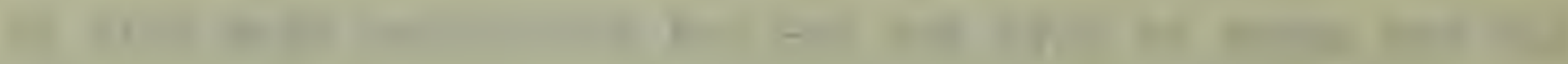

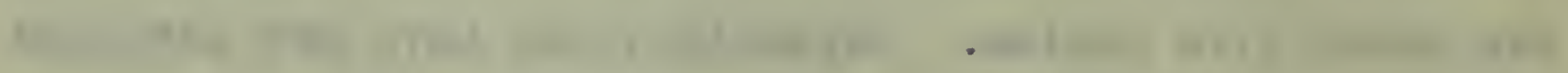

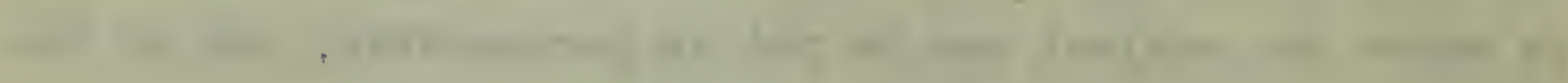

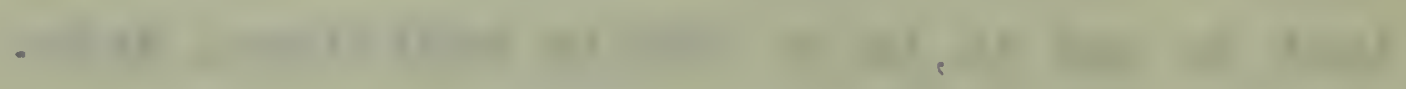

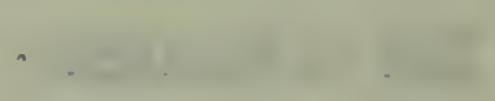

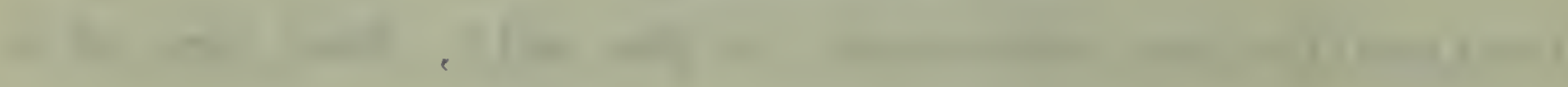

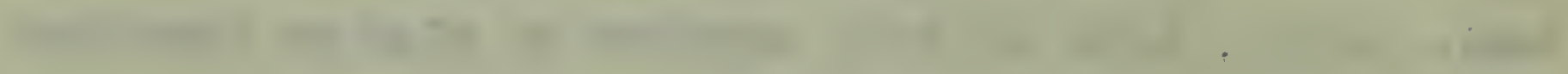

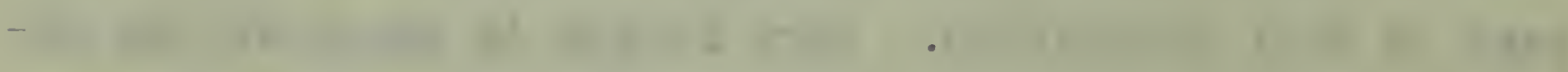
-

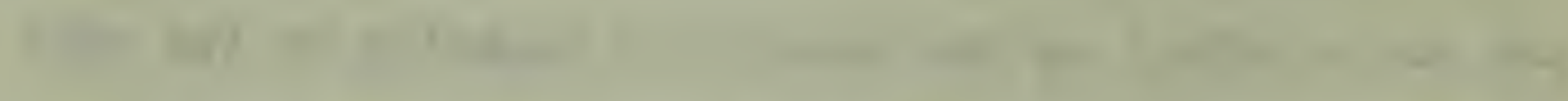

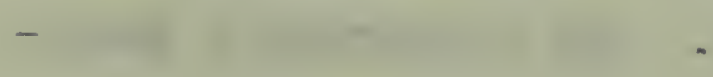

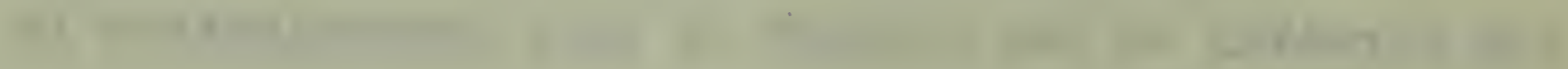

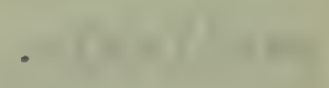

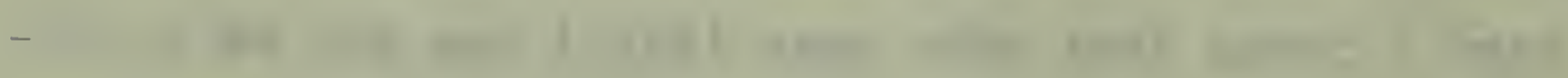

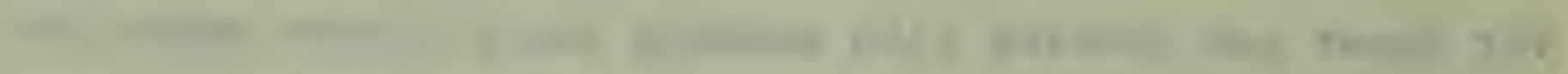

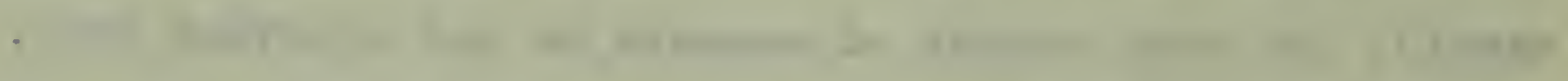

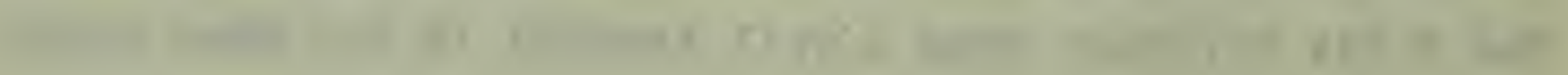

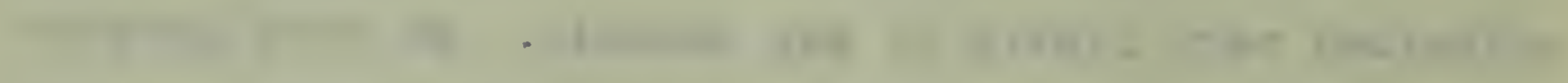

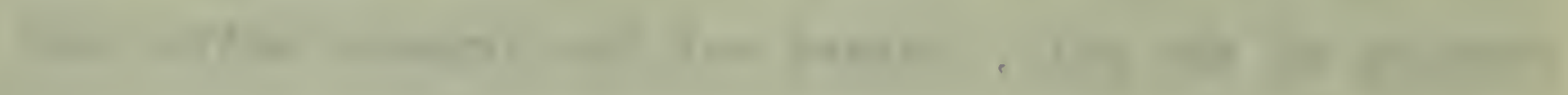
1 


\section{$-3-$}

treated with the ammonia solution. The filtrate contained less ammonia than the original solution. From these experiments Way concluded that the absorption of ammonia by the soil was not due to the organic matter in the soil, but that the clay was the principal constituent concerned with the absorption.

Michaelis and Rone $(1)$ worked on the absorption of sev eral substances using carbon, kaolin, and ferric hydroxide as the absorbing materials. With some substances the maximum absorption (adsorption) took place with a definite hydrogen ion concentration, with other substances the minimum adsorption took place with a definite hydrogen, ion centration. In the third class a continuous change in the amount of absorption occurred on altering the reaction of the medium without the attrinment, at any time, of a definite maximum or minimum hydrogen, concentration.

Warington $(2)$ after giving a fair amount of data on the absorptive action of the oxides of iron and aluminum present in the soilxsays, - "It must not be forgotten that other ingredients of the soil, the humus -.......- have been shown to posses absorptive power.

(1)Bio. Chem. Zeitsch. 1910, Vol. 25; 359.

(2) Journ. Chem. Soc. London.1868; 1-19. 


\section{$-$}

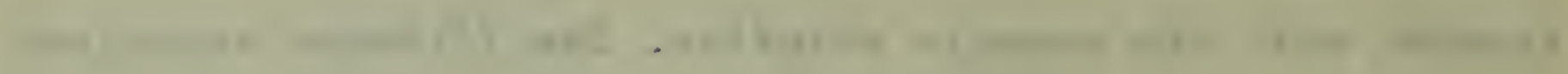

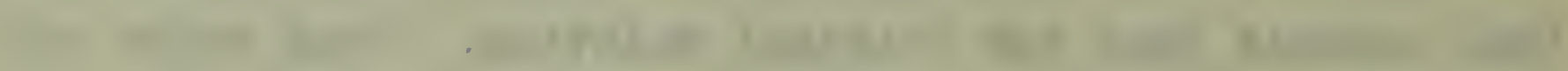

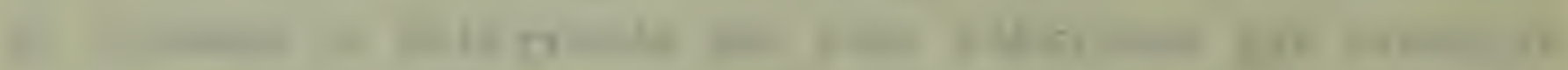

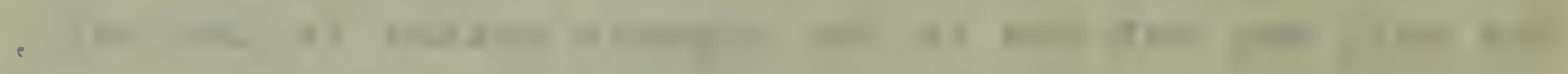

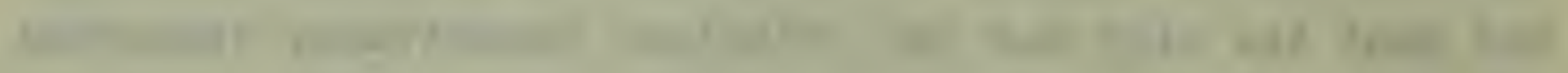

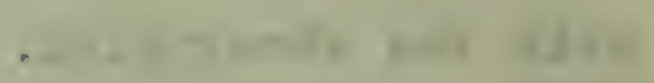

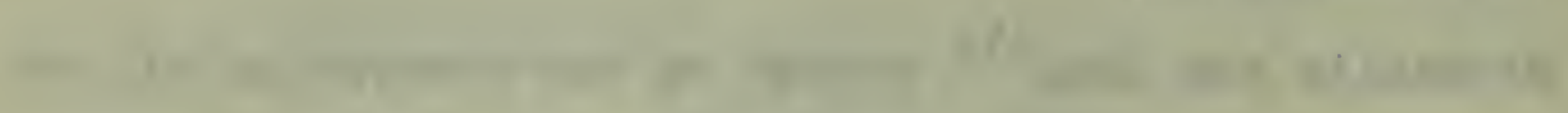

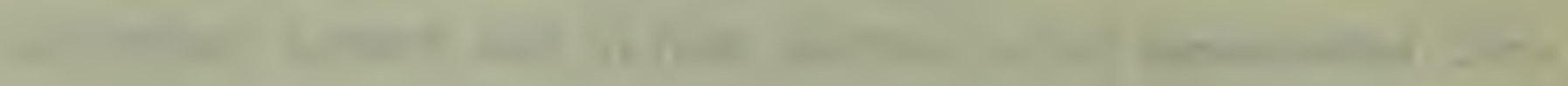

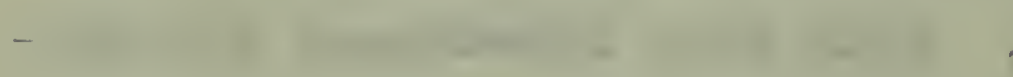

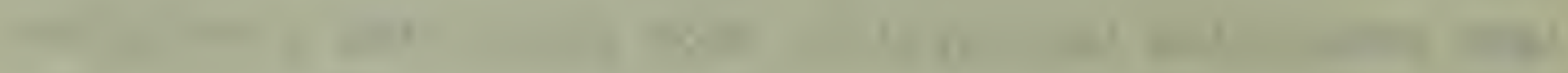

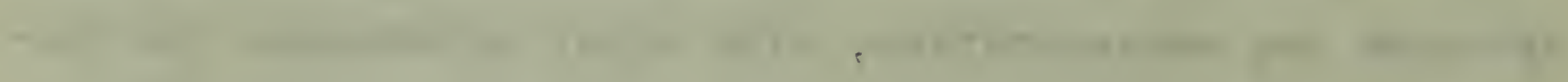

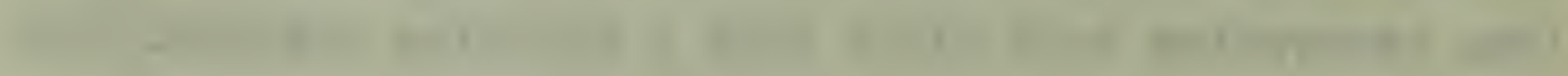
-

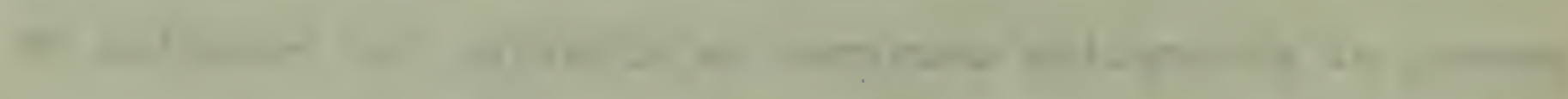

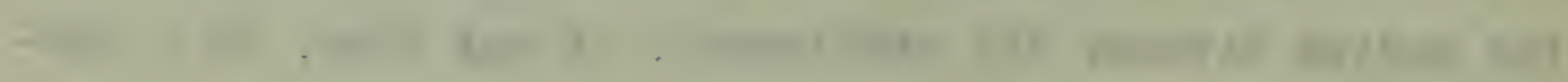

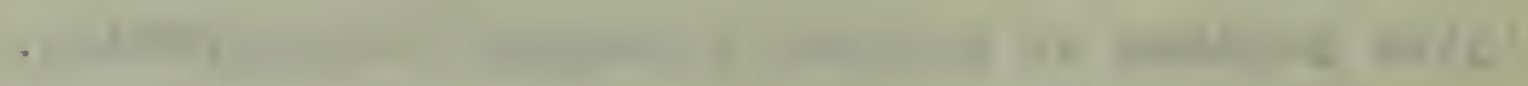

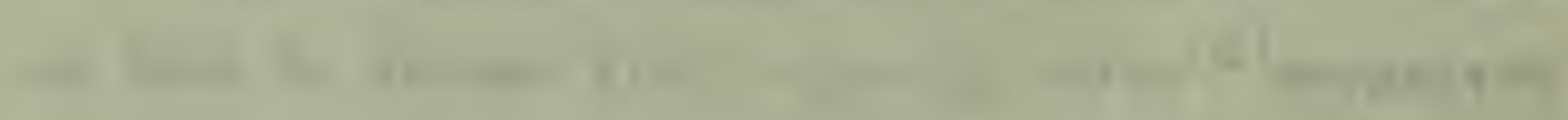

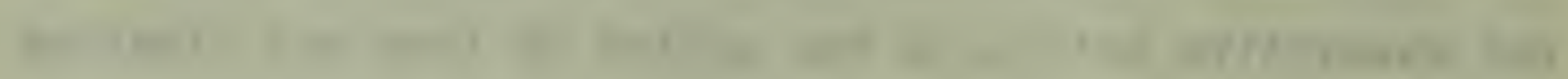

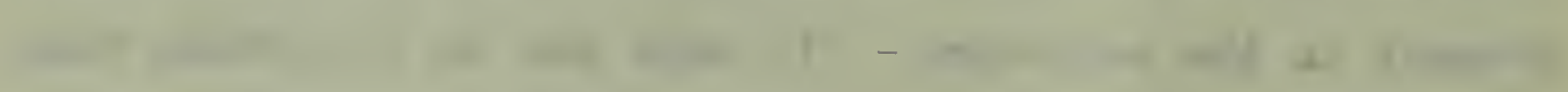

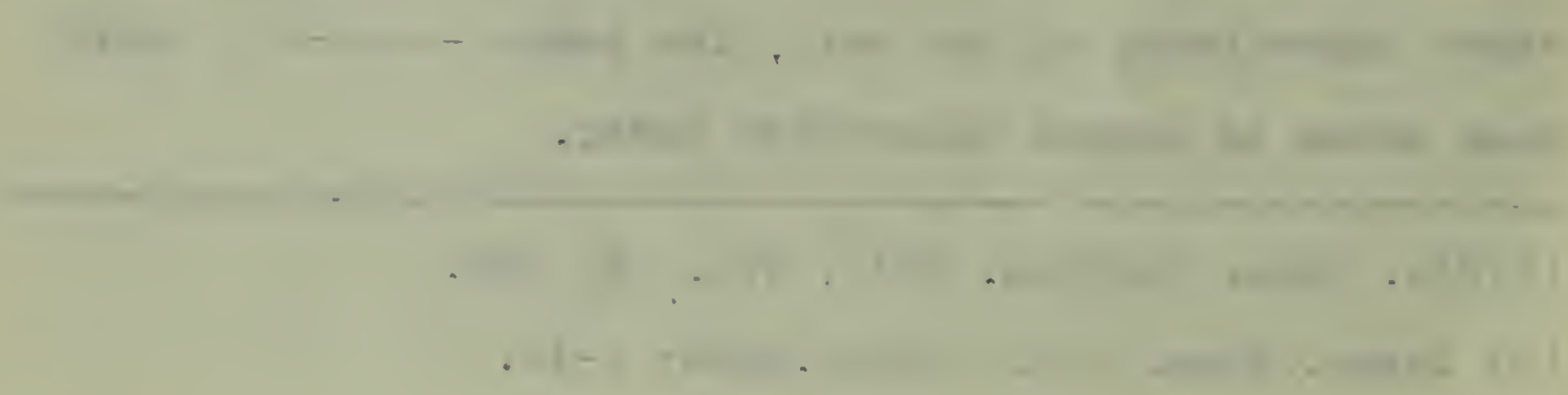




\section{$-4-$}

Q. Iemmermann and I. Fresenius (I) report tests on six soils, including sendy loams and a moor soil, to determine the influence of calcium carbonate on the ammonia absorbing power of the soils. The soils were treated with ammonium carbonate and exposed to the air. The absorption of the amronia was dependant on the soil used, and on the physical and chemical characteristics of the soil. In three of the soils the absorption was increased by a large addition of calcium carbonate, while with a slight addition the reverse was true. "It was concluded that the absorption of ammonia salts depends almost entire Iy on the exchange of bases of the zeolitic combinations in the soil. This is either promoted, retarded, or not affected by the addition of calcium carbonate, according to the chemical character of the soil, and the effect of the calcium carbonate is influenced by the absolute quantity of ammonium carbonate added and by the amount of exchangeable potassium present."

Brehm(2) speaks of colloidal chemistry in relation to soils. His chief colloidal bodies are-humus, slime organisms, colloidal iron and aluminum hydrozides,
(1) Landw. Jahrb. 45 (1913), No. 1; 127-154.
(2) Kolloisd Ztschr. 13 (1913), No. 1; 19-35. 


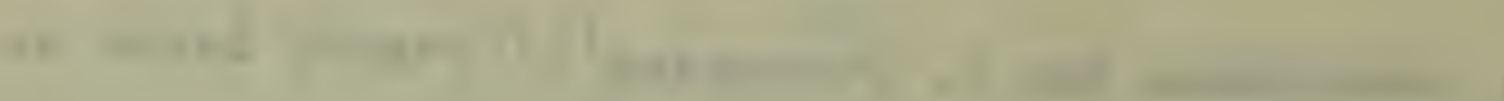

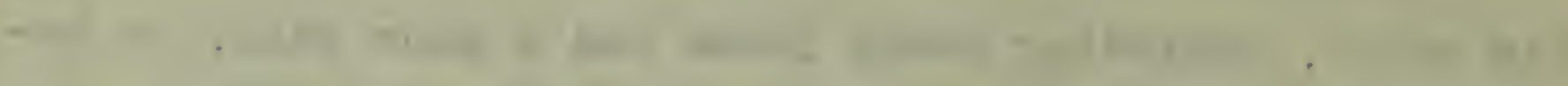

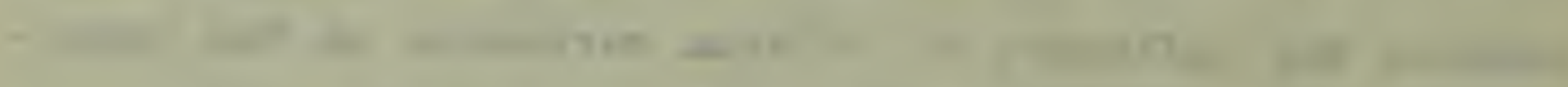

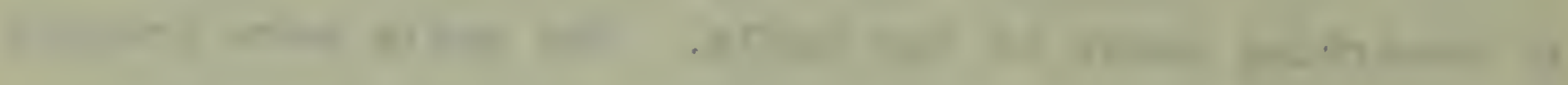

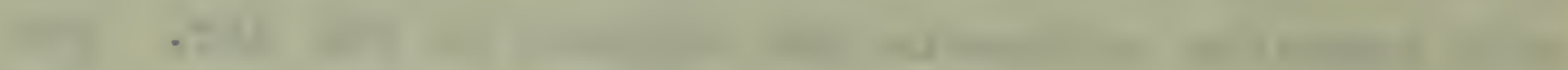

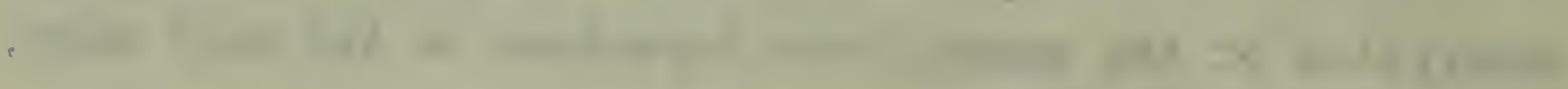

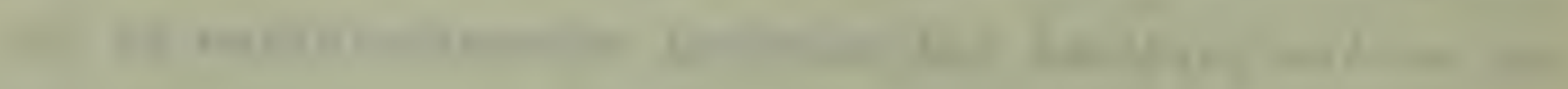

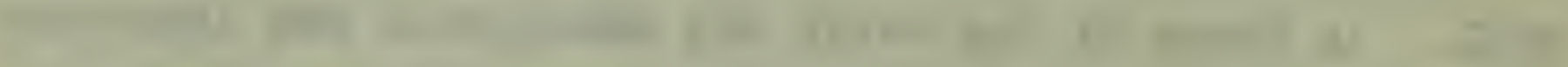

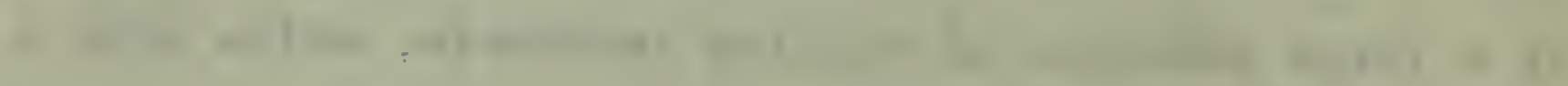

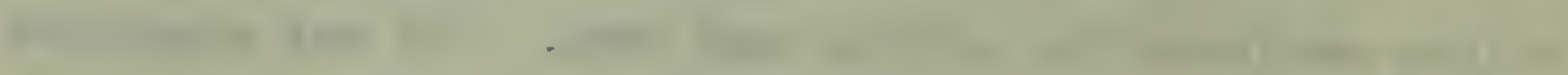

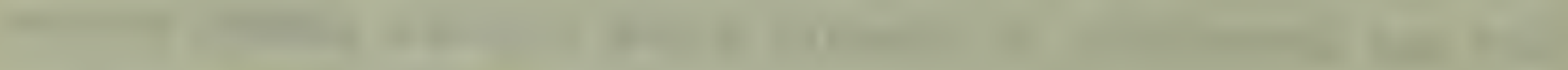

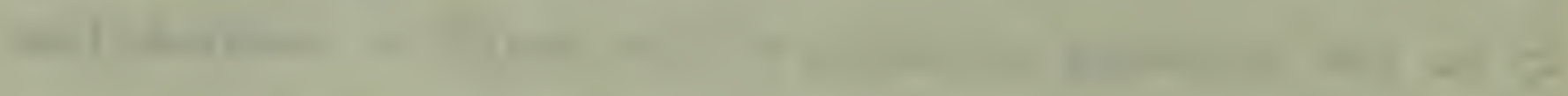

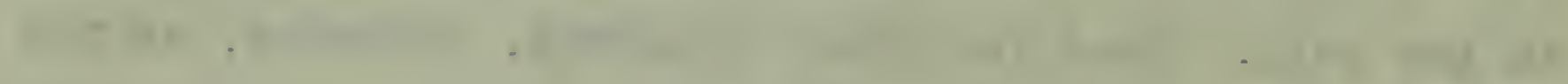
.

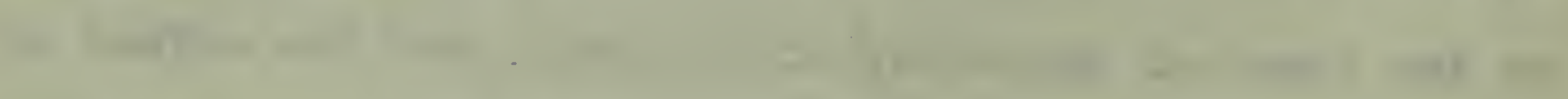

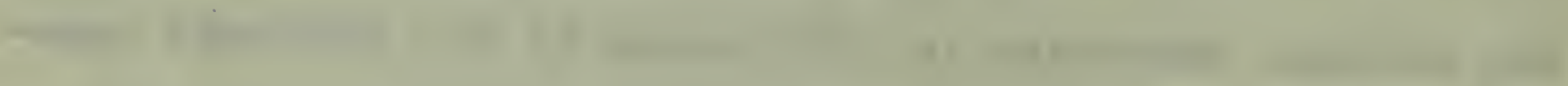

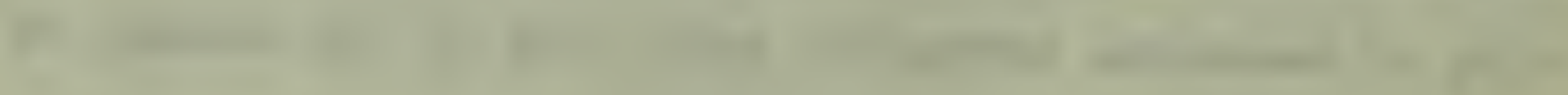
-

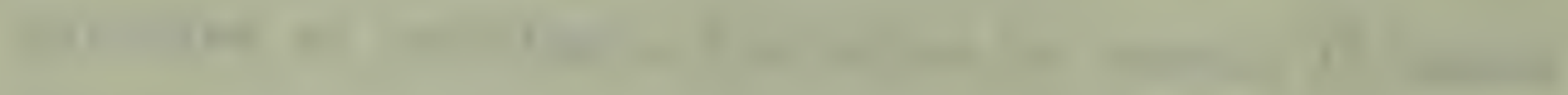

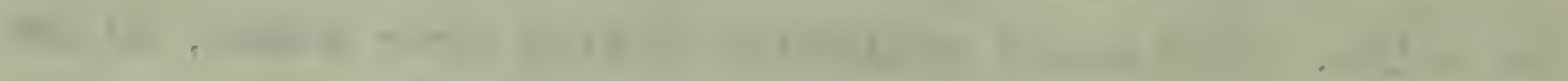

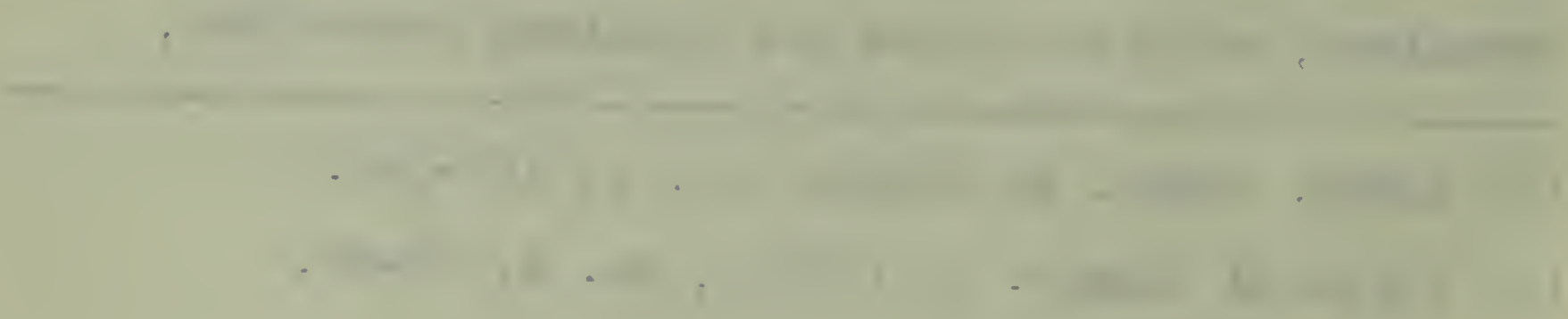


weathered amorphous silicates, bacteria and micro-organisms held in suspension, are held by him as the important factors in the exchange of bases when plant food is added. The food enters into the so called adsorption compounds forming colloidal combinations. The colloidal combinations are called the food bearers of the soil.

Baumann and Gully ${ }^{(1)}$ conducted a detailed investigation on the identity of humic and sphagnum acids -- and the absorptive properties of these substances in relation to acid conditions. They found no free humic acids in peat moss, but that the acid reactions observed are due to the absorbent power of the colloids of the cell-covering of the hyalinesphagnum cells. The general conclusion is drawn that there are no free humis acids in upland soils but that the absorbent properties of the sphagnum bring about conditions which indicate the presence of acids. B. Tacke and H. süchtig et al (2). set out to investigate the work of Baumann and Gully. The part of their work which is of interest here is abstracted in the Experiment Station Record as follows.-

" Starch and Cellulose, as neutral colloidsłiberated no noteworthy amounts of acetic acid or mineral acid

(1) Exp. Sta. Rec. Vol. 23; 715.

(2) Landw. Jahr. 4I, (1911); 717-754. Exp. Sta. Rec 26,720. 


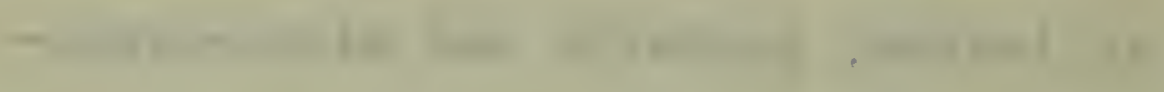

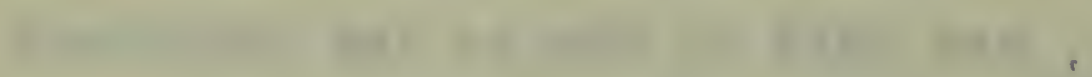

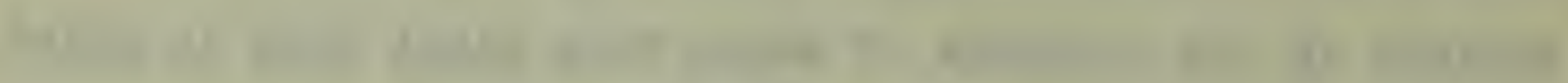

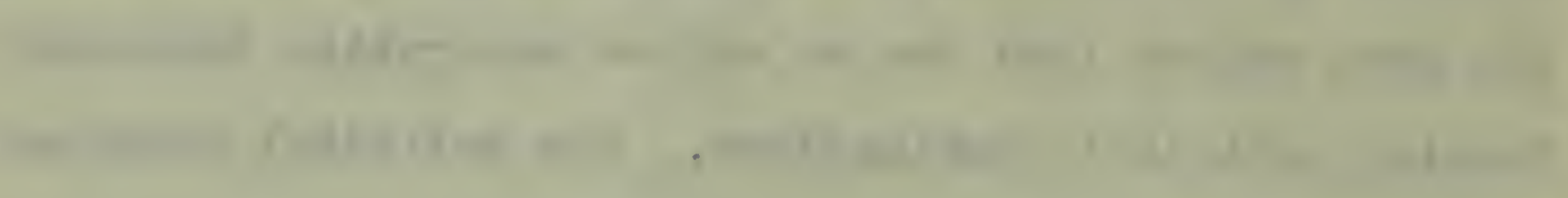

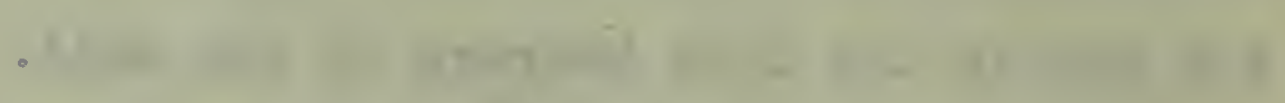

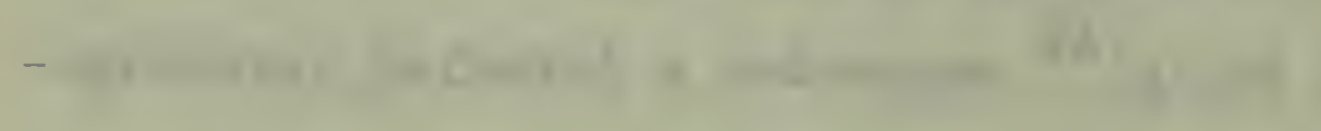

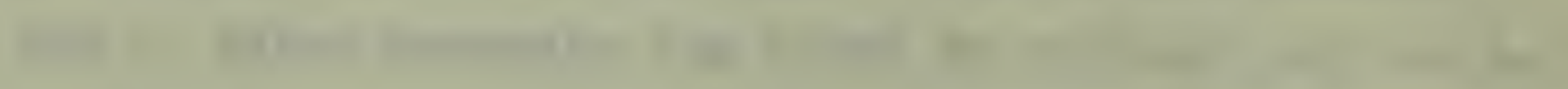

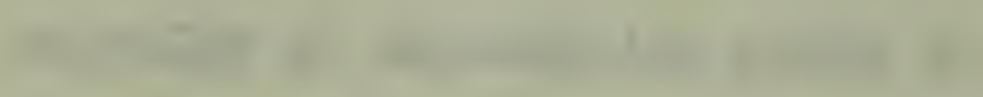

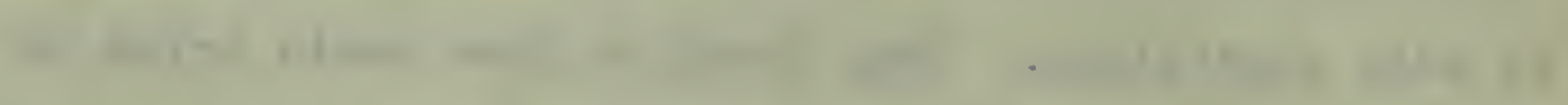

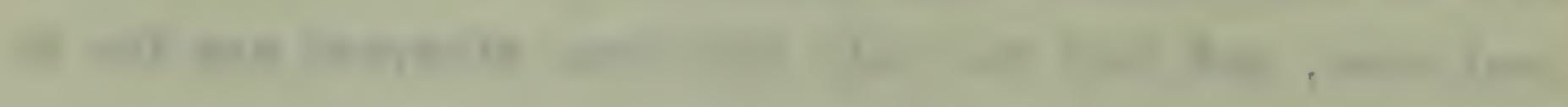

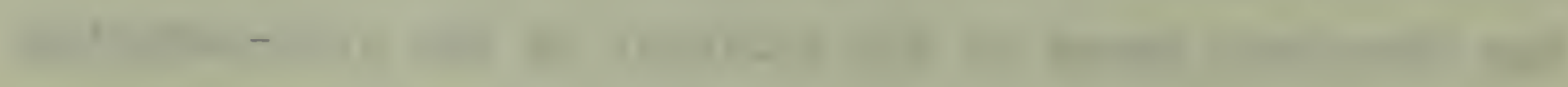

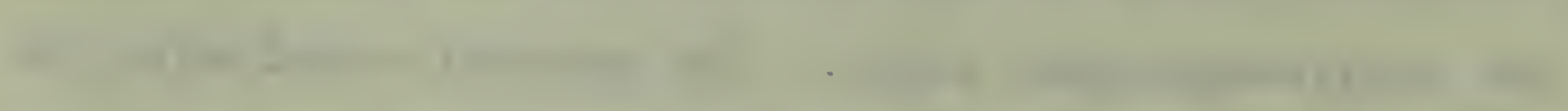

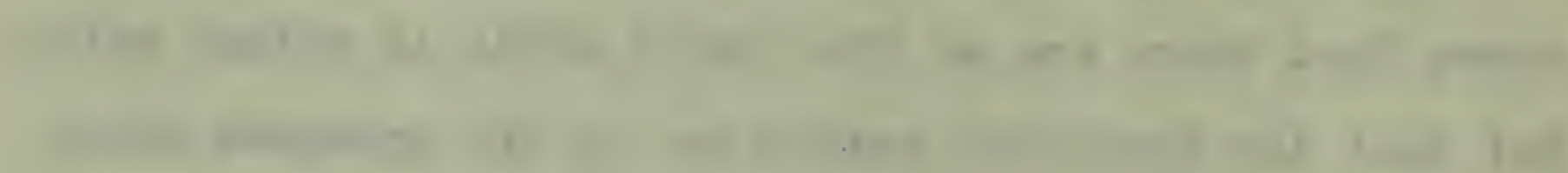
-

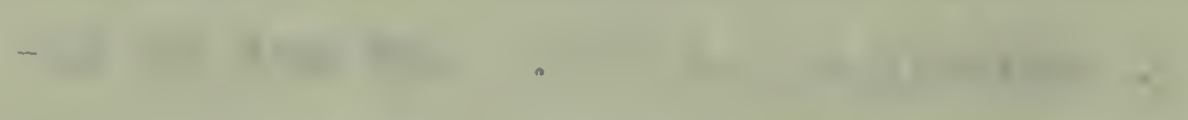

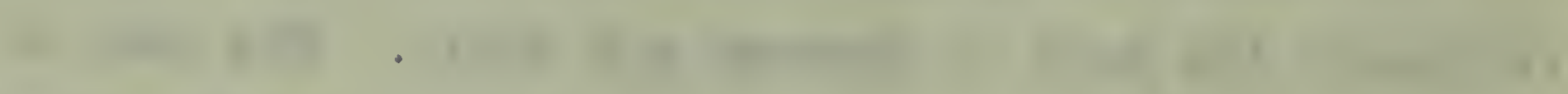

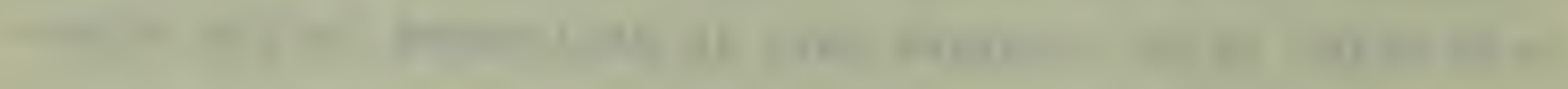

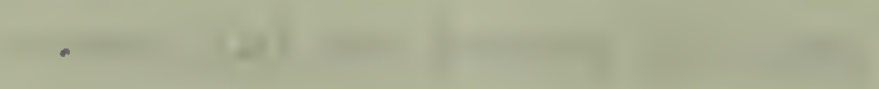

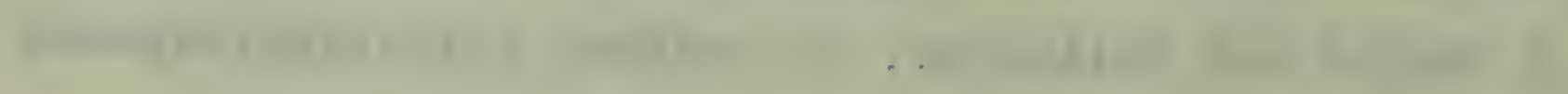

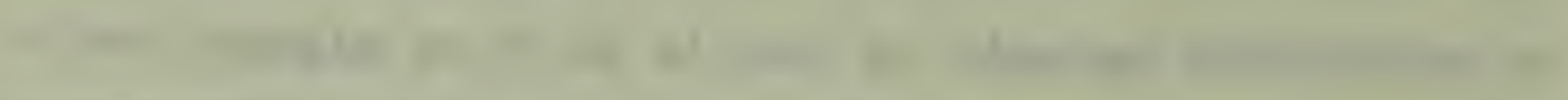

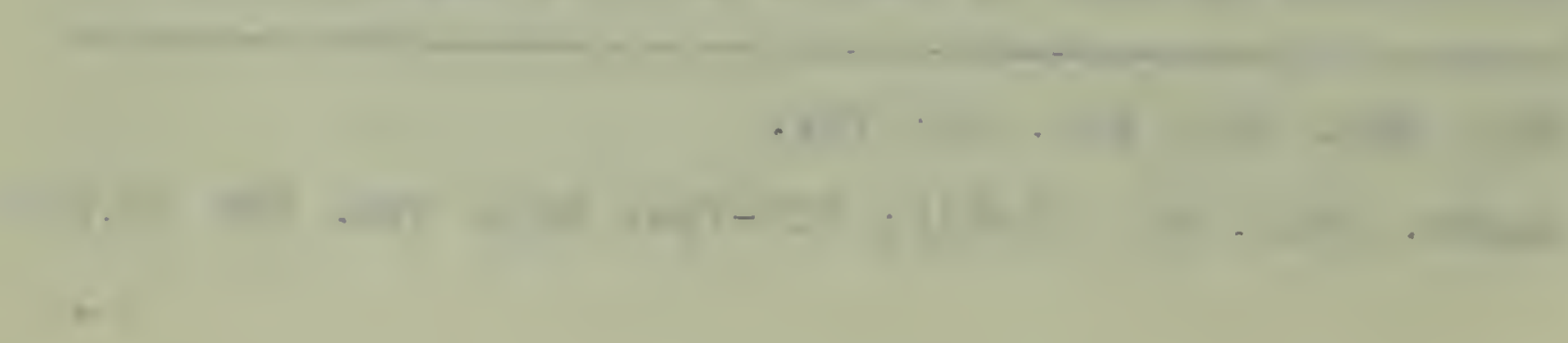




\section{$-6-$}

from the salts of the alkalies or the alkaline earths. Peat moss on the other hand, liberated considerable amounts of acetic acid from the acetates and small amounts of oxalic acid fromcalcium oxalate. No effect of the colloidal character of the peat moss was noticeable in the reactions of these salts.

Peat moss decomposed solutions of iron chloride, decreasing the concentration to such an extent that nearly all the iron was precipitated from a 0.001 -normal solution. Peat moss adsorbedthe iron from a colloidal solution of ferric hydroxide, decreasing the concentration so that all the iron was adsorbed from a 0.01-normal solution. Gelatin and starch adsorbed very small, and as compared with the peat moss, substantially smaller amounts of iron from dilute solutions of ferric chloride. Gelatin adsorbed very much amaller amounts of iron from ferric hydroxide solutions than peat moss and adsorbed no iron from a 0.5-normal solution but did adsorb water. The adsorption of iron by peat moss was accompanied by the evolution of hydrogen suggesting a possible chemical reaction. Neutralizing the soil acids with calcium carbonate checked the evolution of hydrogen almost complete 1y. There was no relation between the extent of the evolution of hydrogen and the adsorption of iron from ferric and colloidal ferric hydroxide. The colloidal 


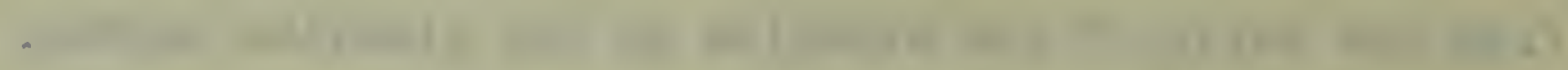

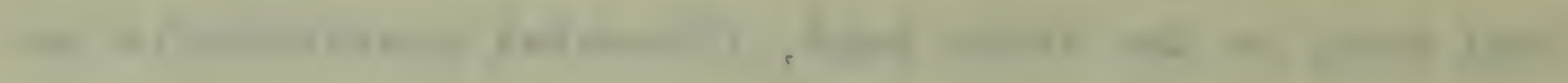

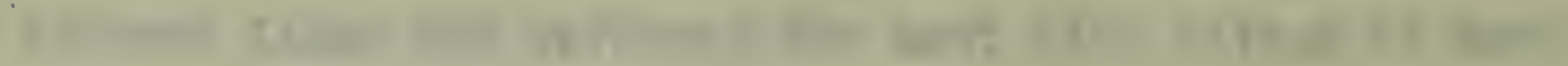

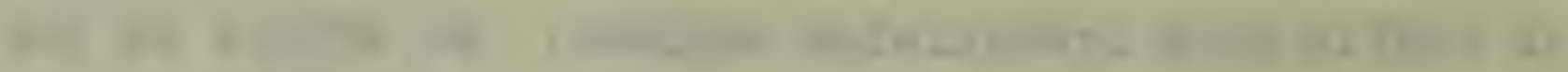

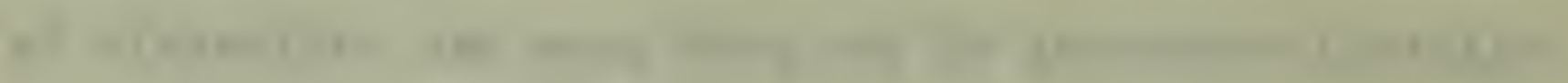

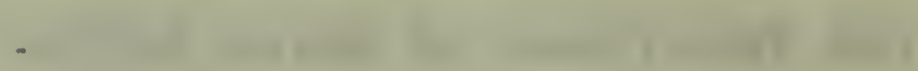

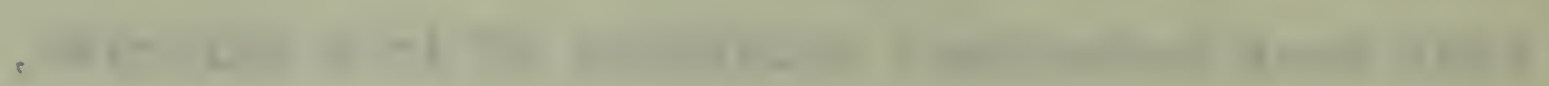

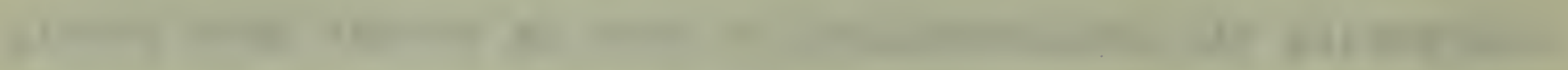

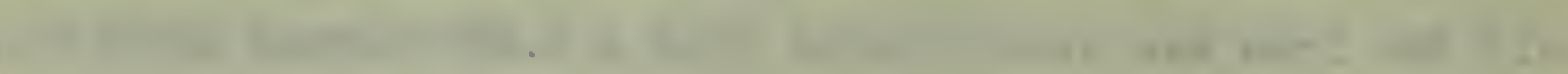

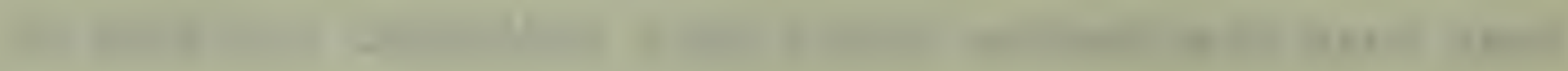

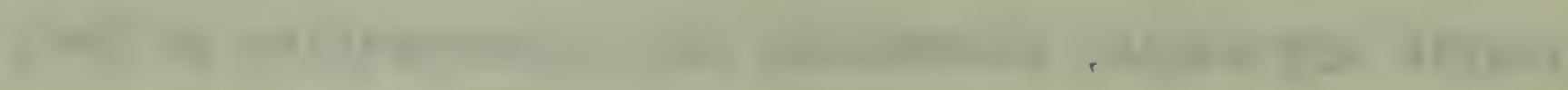
.

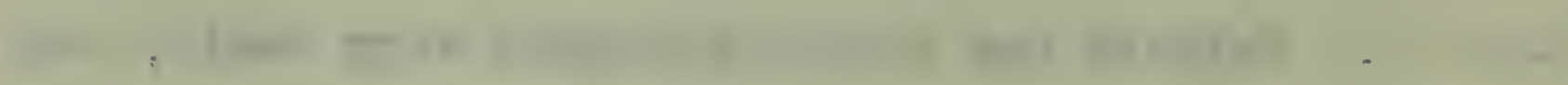

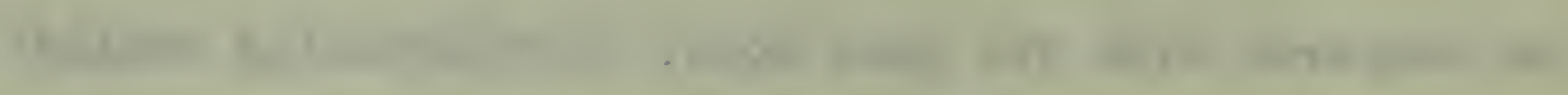

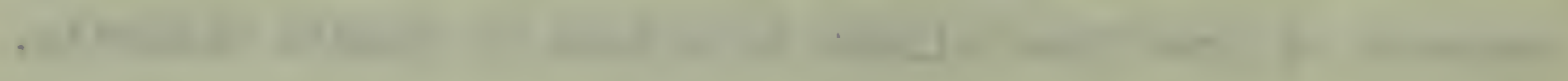

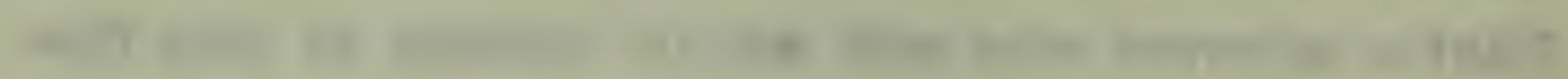

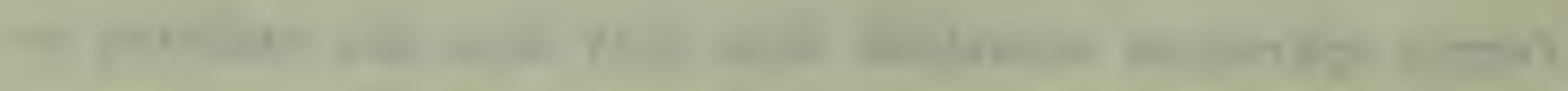

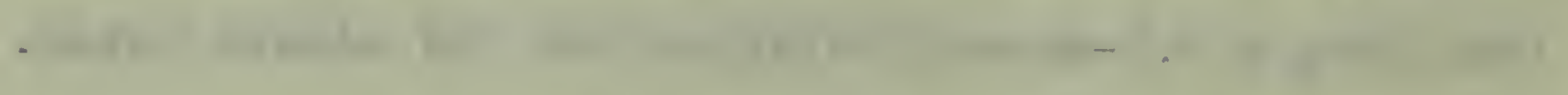

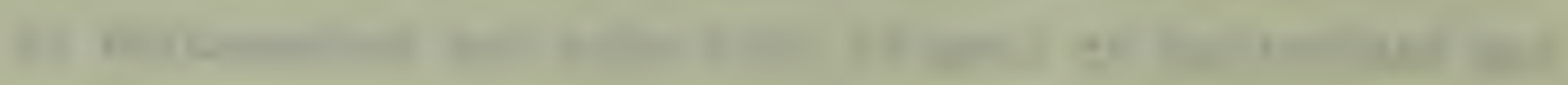

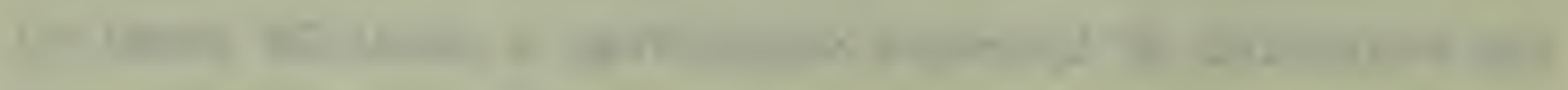

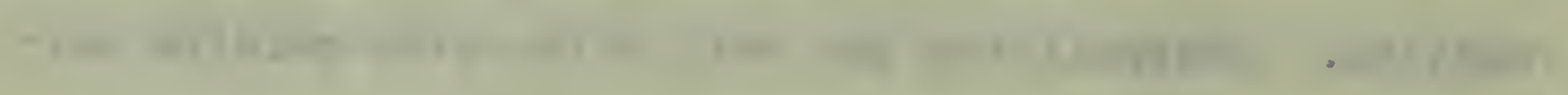

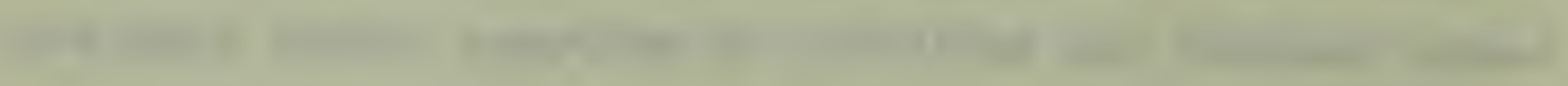

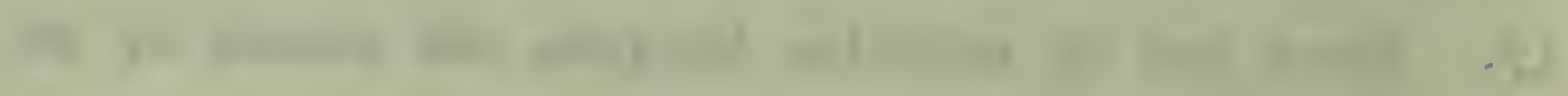

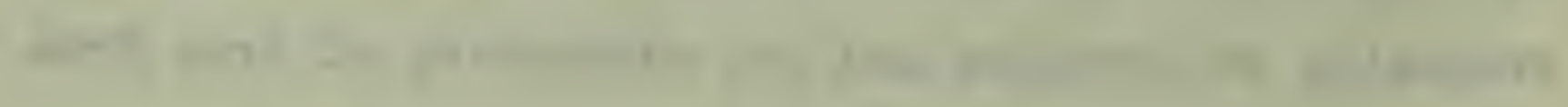

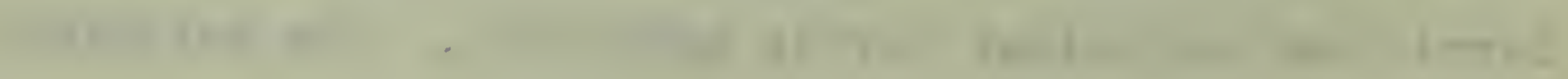


character of the peat moss had no effect on the evolution of hydrogen."

Brustlein (I) reports humus as capable of removing free ammonia from a water solution of the same.

A. Petit (2) found that a forest soil, although very rich in humus, was incapable of absorbing phosphoric acid from a solution of monocalcium pinosphate, but thaton the contrary it jielded a more or less constant proportion of its phosphoric acid to the solution."

The absorption of monocalcium phosphate by a soil was considered by Dumont ${ }^{(3)}$ to depend on the extent of the relation of humus to calcium carbonate, and not on the amount of calcium carbonate present in the soil.

Marcellin Bertholet (4) speaks of the soluble and the insoluble compounds of potassium and sodium replacing each other in the soluble and the insoluble compounds according to their proportions and the relative strength of the mineral, organic, and humic acids present. Soluble potassium may be rendered insoluble by humic acid and thus stored for a time, being made available by the double decomposition and the spontaneous combustionor oxidation of the organic matter; the potassium being converted to the

(1) Jahresbericht der Agricultur Chemie. 1859-1860; 1 .

(2) Compt. Rend. Acad. Sci. (Paris)155; 921-923.

$\begin{array}{lllllll}(3) & " & & & & & \end{array}$

(4) $"$ " " $" ~ " 14 i ; 433-445$. 


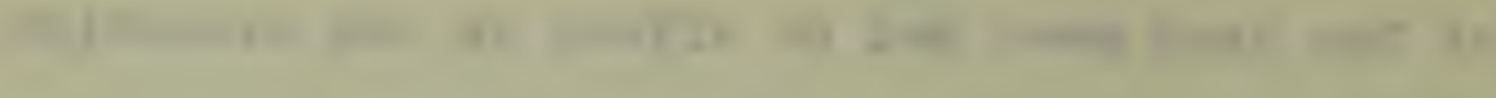

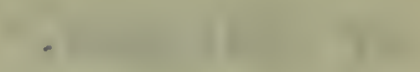

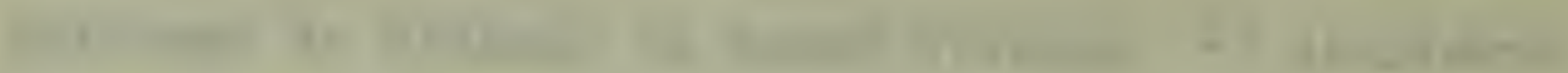

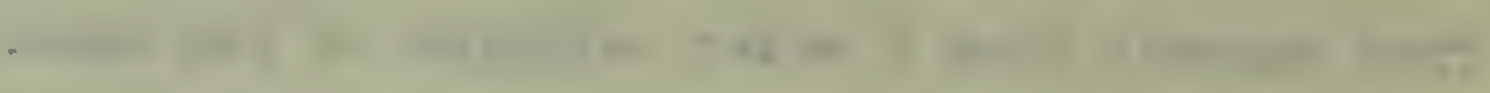

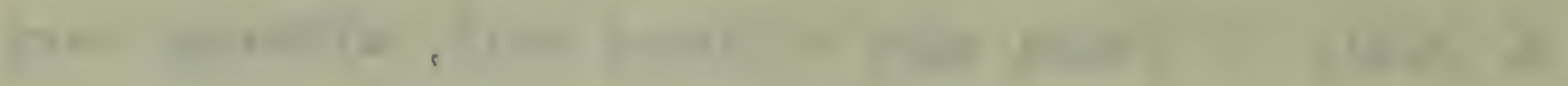

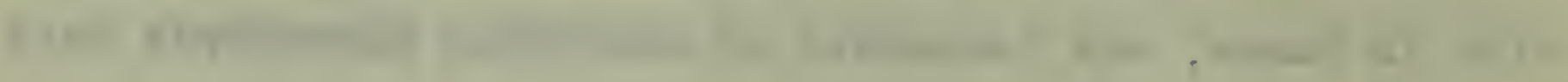

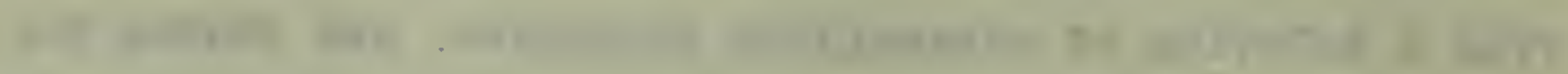

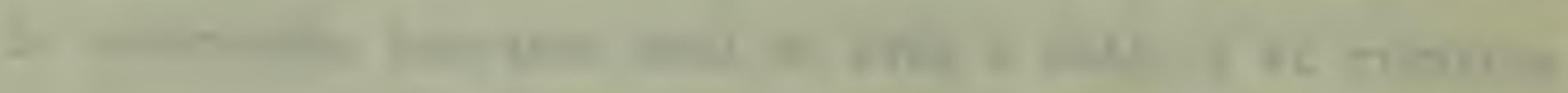

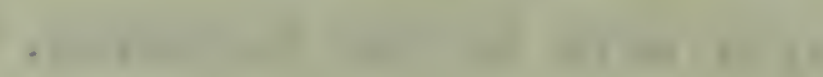

IIf

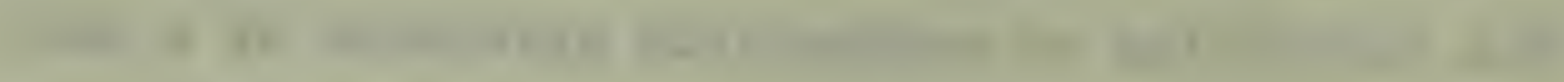

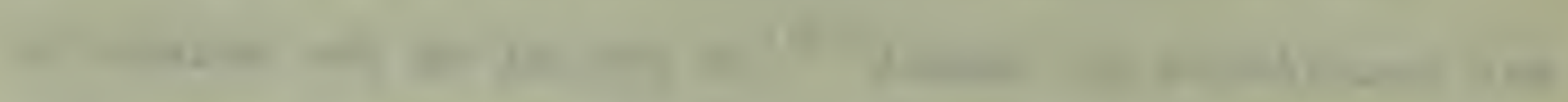

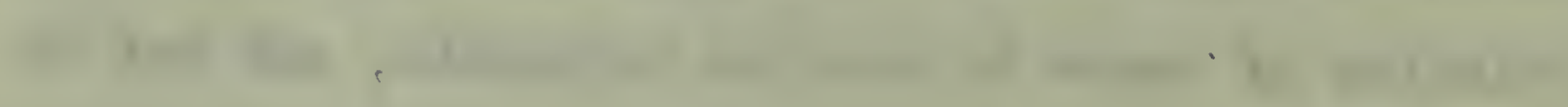

-

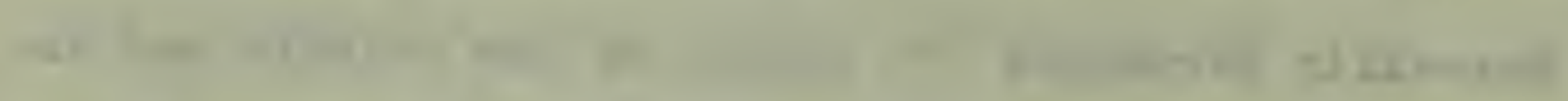

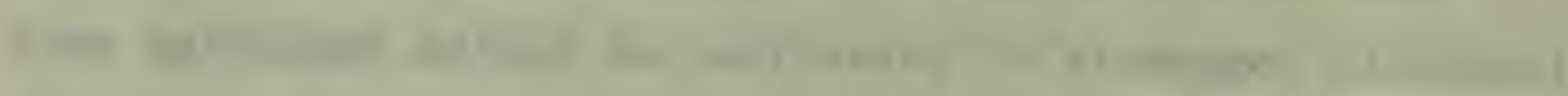

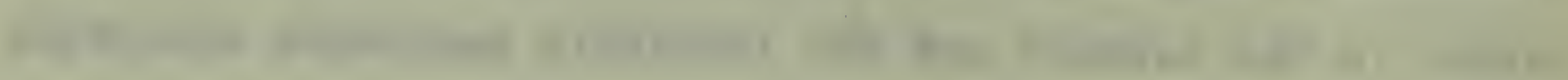

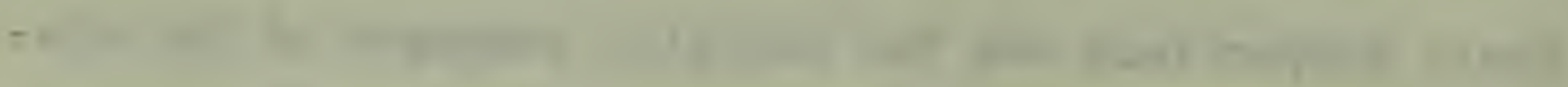

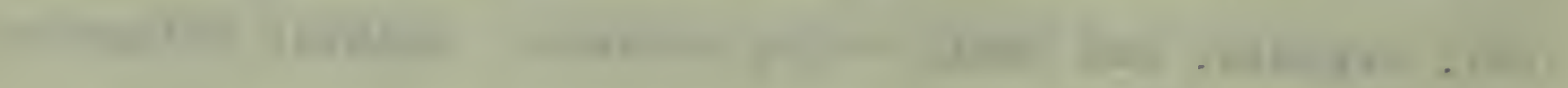

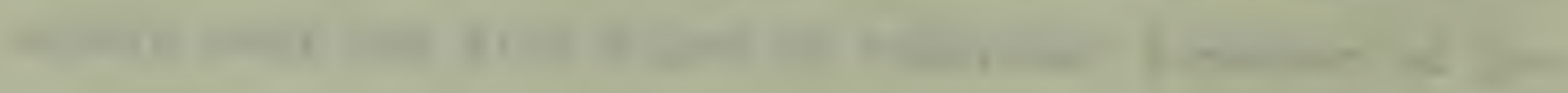

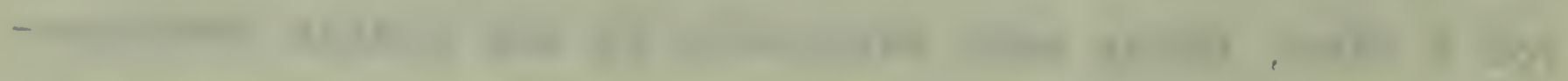

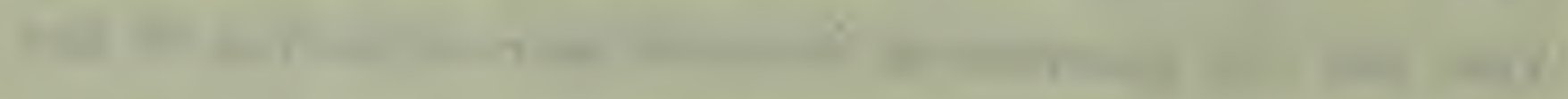

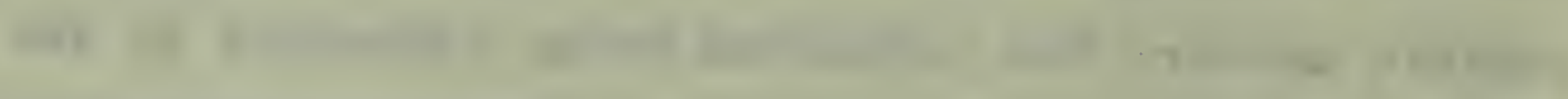

-

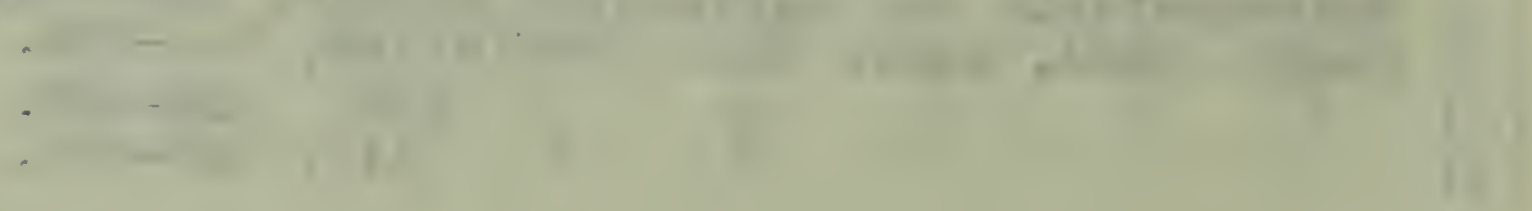


carbonate. Analogous changes occur in the soil at the expense of the calcium present as carbonate, silicate, sulphate, phosphate or humate.

Potassium and calcium are not directly appropriated by humic acid when they are in combination with strong acids. The displacement may however occur by the intervention of ammonia, by means of which the stronger acids are eliminated, coincidently amino-humic acids are formed which are capable of rendering the potassium insoluble. A. Dojarenko/(I) in summing up the results of the absorption of nitrogen from ammonium carbonate by neutral and artificial humic acias draws the following conclusions,-

1. "Absorption is more energetic where the humic acid is soluble in the ammonia salt used; less energetic when freshly precipitated humic acid is used with an ammonia salt in which it is not soluble; and least when dry humic acia reacts with a salt in which it is not soluble.

2. The energy of the absorption is expressed solely by the rapidity of the absorption; the amount of absorbed nitrogen being the same in all cases.

3. When the humic acid is not soluble in the ammonia salt used the rapidity of the absorption varies with the

(1) Exp. Sta. Record Vol. 13; 534. 


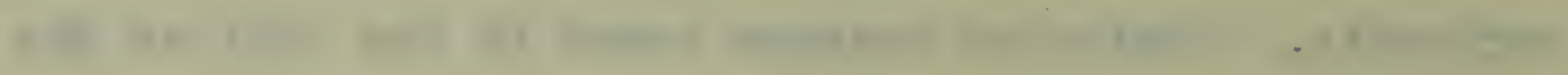

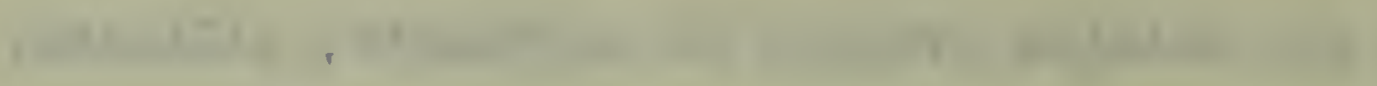

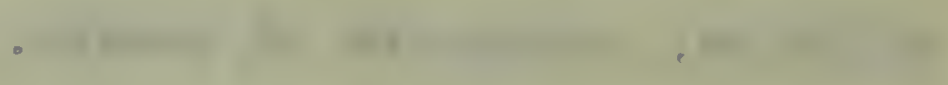

1

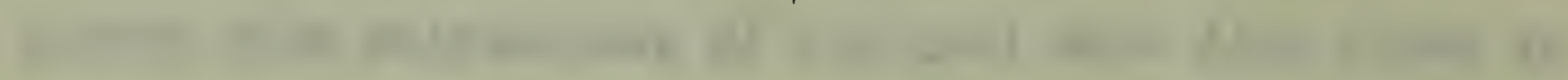

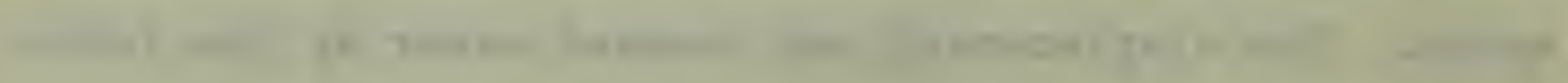

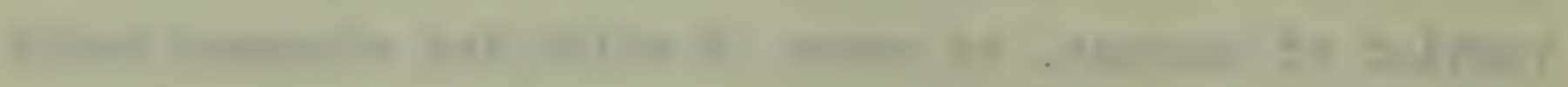

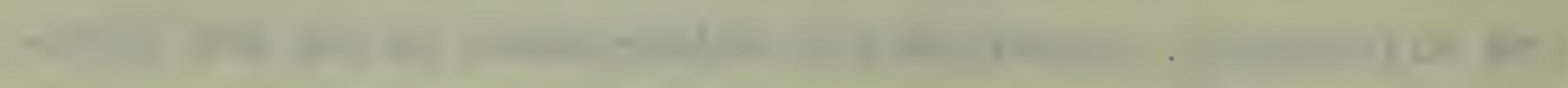

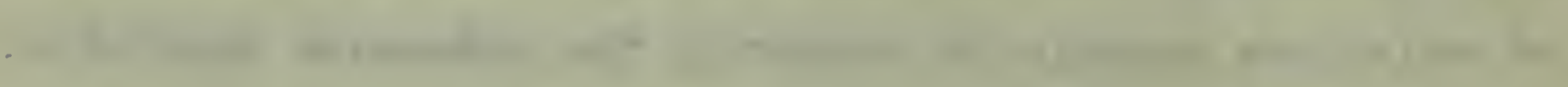

$-$

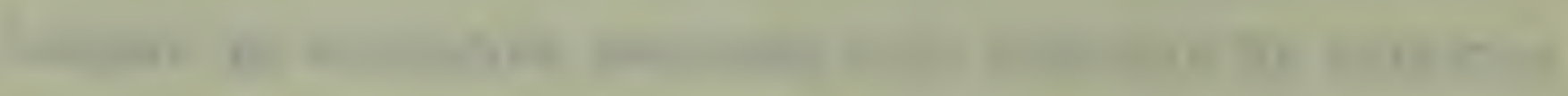

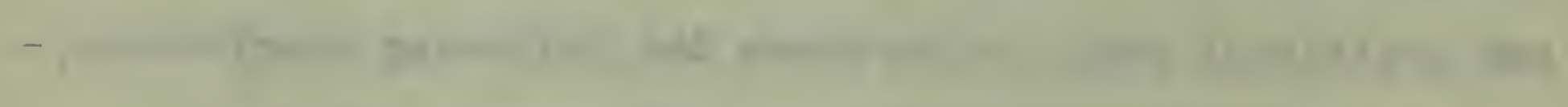

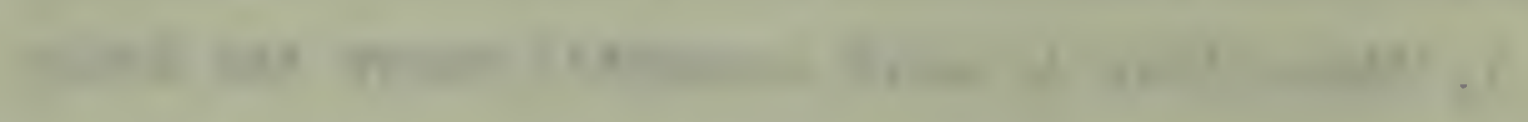

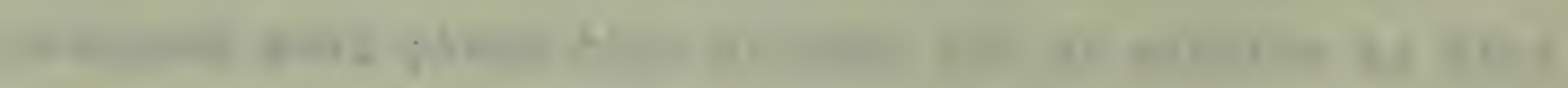

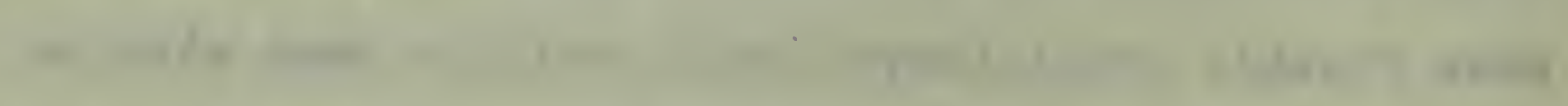

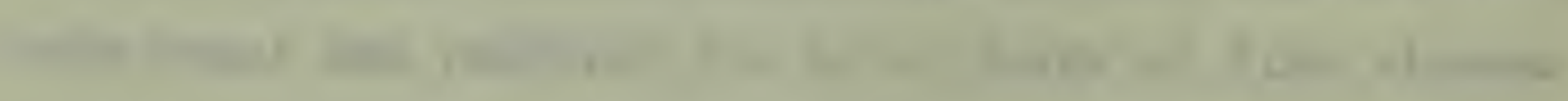

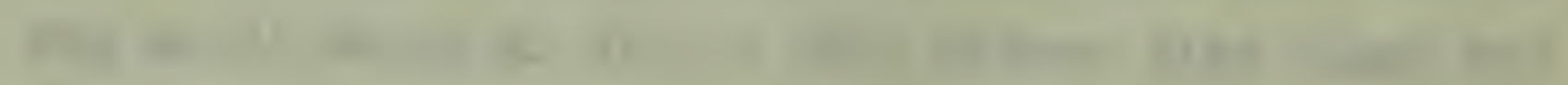

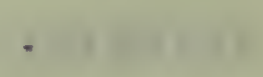

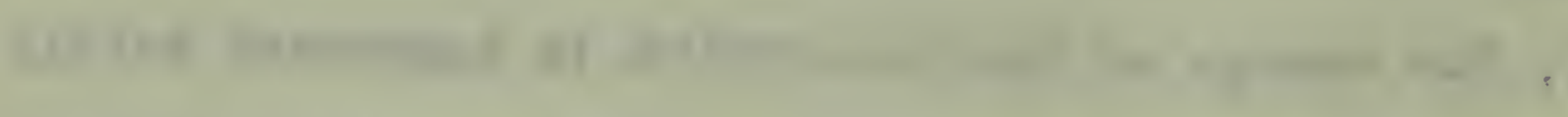

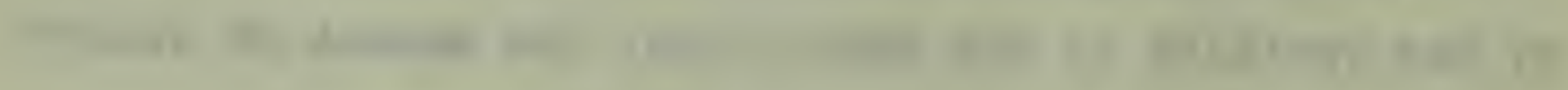

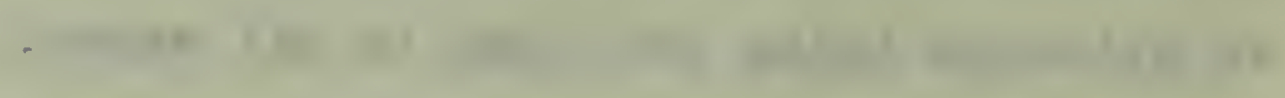

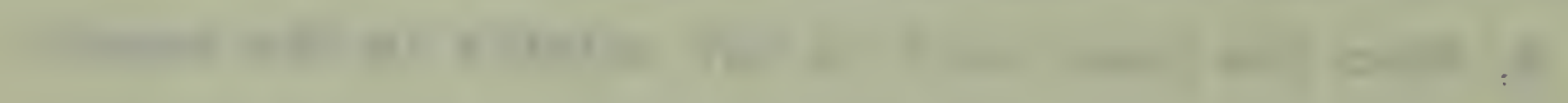

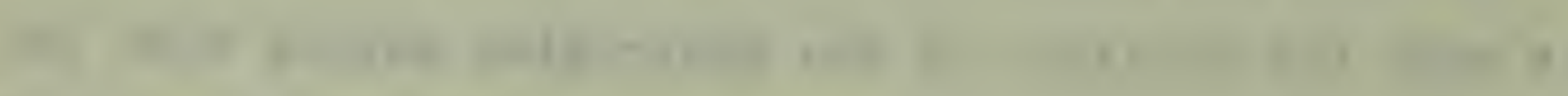

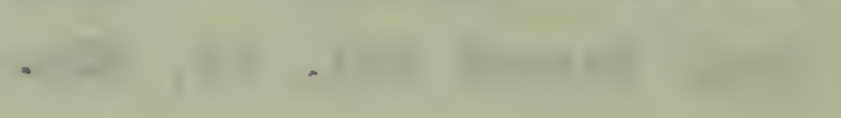


concentration.

4. The absorbed nitrogen gives rise to amids almost exclusively.

The literature cited was not chosen to represent the whole field of soil absorption. It shows that the organic matter present in the soil has both been used and ignored when investigators have dram conclusions as to the WHY of soil absorption. It is very plain that humus and humus forming substances do play a part in the absorption of salts by the soil. Humic acid, as it occurs in the soil is a mixture of sabstances and as eridenced by the chemical absorption of potassium which Bertholet speaks of, is a compound which not only absorbs substances but absorbs differently as it decays.

\section{Divisions of the Work.}

This investigation falls naturally into three divisions, the subjects of which are to study the absorption of certain radicals bj;-

(a) Freshly fallen leaves and leaf moulds in diffexent stages of decay.

(tb) Mixtures of a soil with leaves.

(c) Mixtures of the soil and leaves after they have started to decay together. 


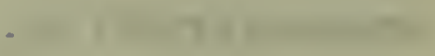

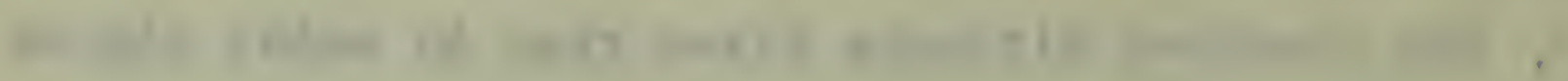

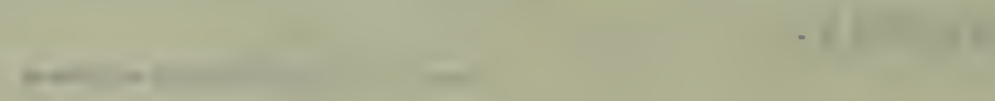

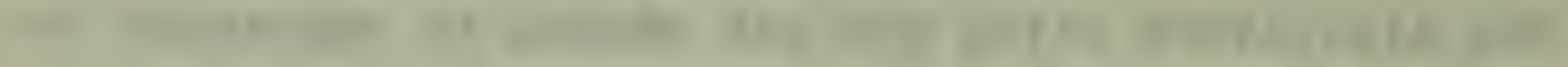

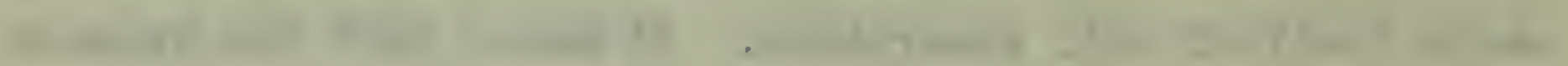

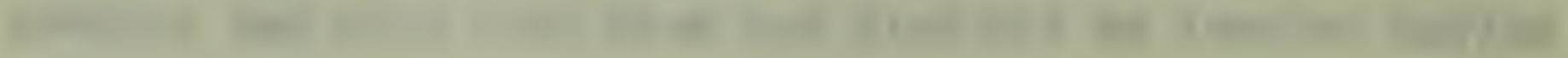

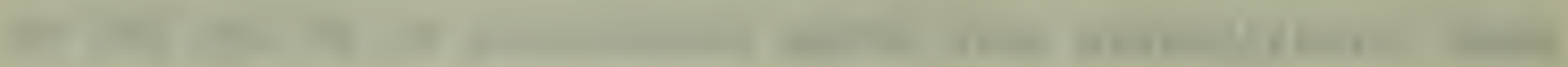

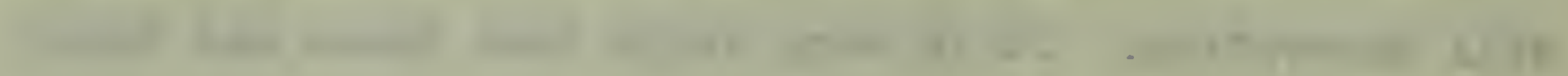

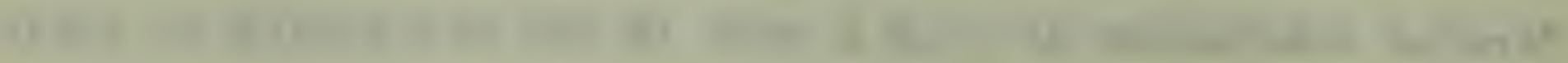

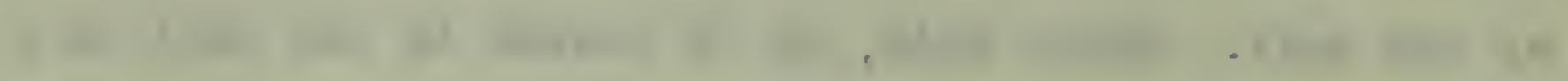

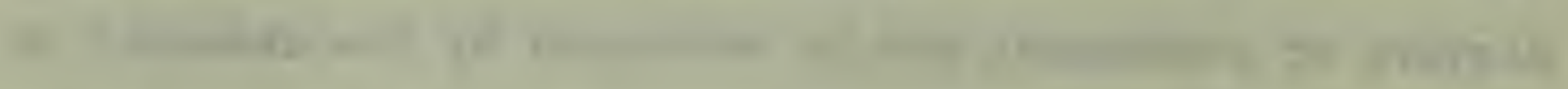

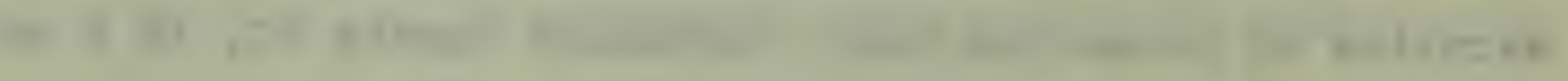
-

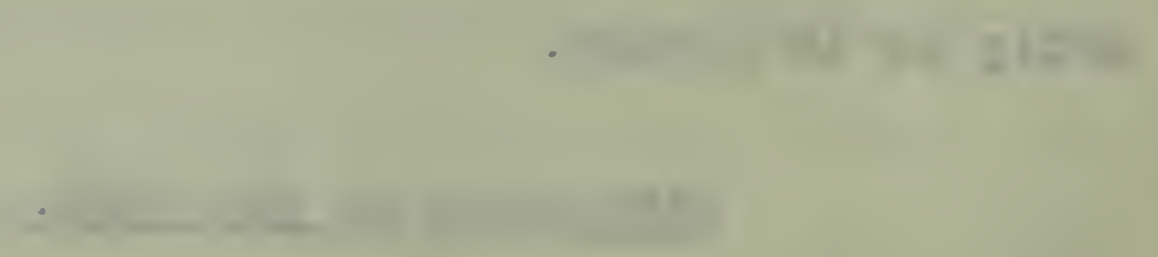

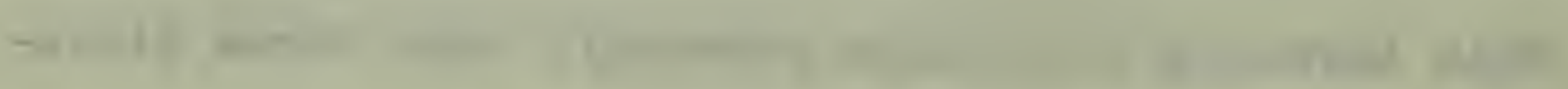

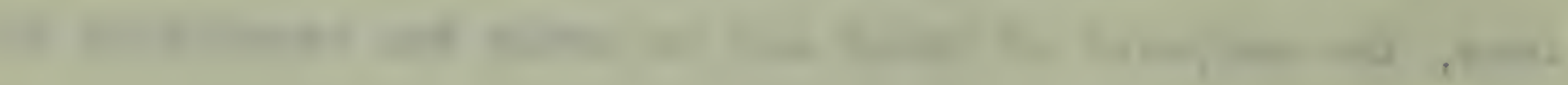

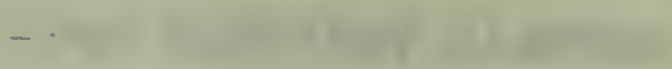

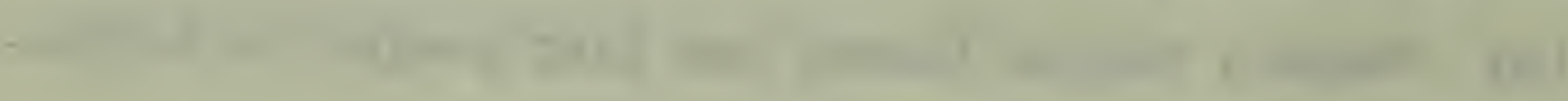

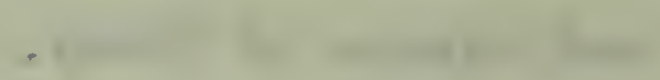

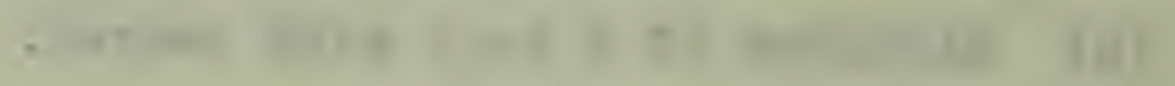

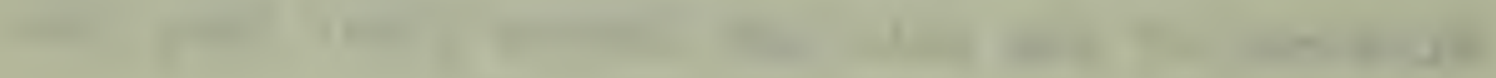

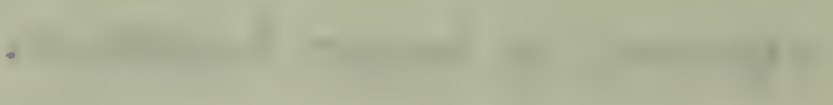


Materials used in the Investigation.

Freshly fallen leaves gathered from a lawn.

Two leaf moulds in aifferent stages of decay.

One sample (A) mas so decajed that the structure of the leaves was not discernable, while in the second sample (C) the moodt portions of the leares could still be discerned.

Brown silt loam, unfertilized for jears and perg low in organic matter.

A misture, containing ninetyfive percent, by weight of the brown silt loam, and five percent of the freshIJ fallen leaves.

A mixture, containing eighty percent by weight of the brom silt loam, and twenty percent of the freshly fallen leaves.

The freshly fallen leares after siz montis jeceg in the greenhouse.

Wixtures of the leares and loam, as abore, after siz months decry in the greeniouse.

Note;- The water holaing capacity of the freshly fallen leaves and the leaf-soil mixtures was determined and they were kept at one half the results of these determinetions while decrying. 


\section{$-$}

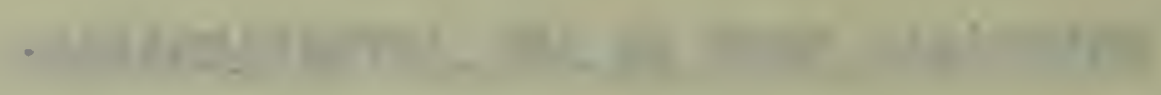

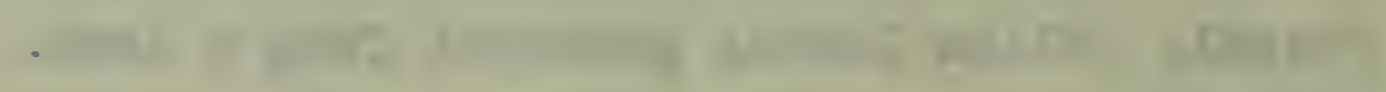

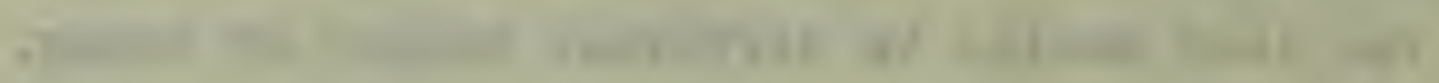

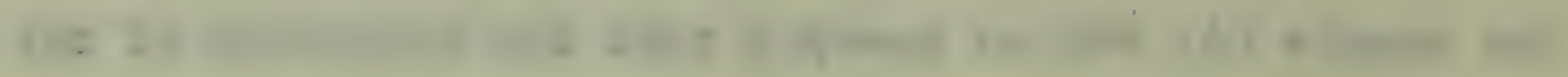

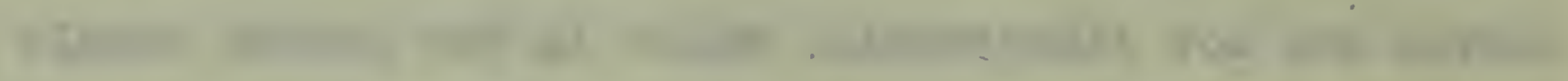

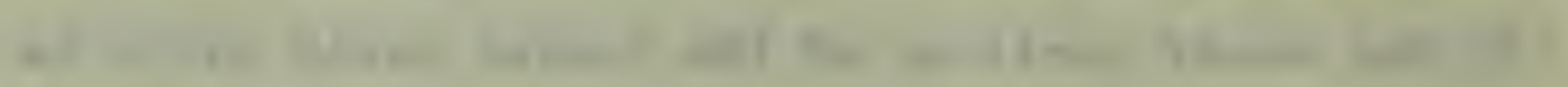
.

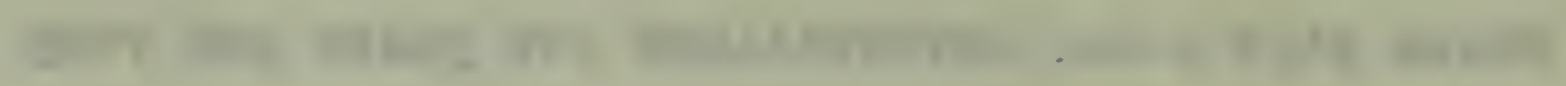

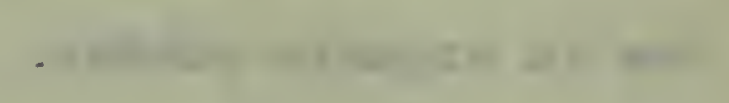

-

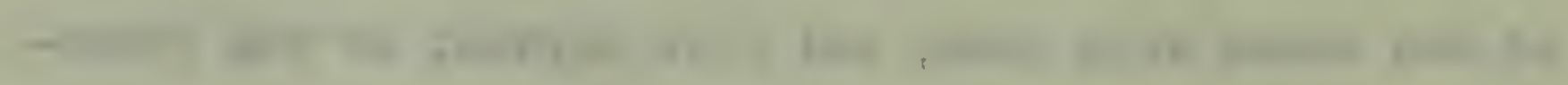

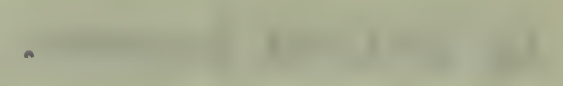

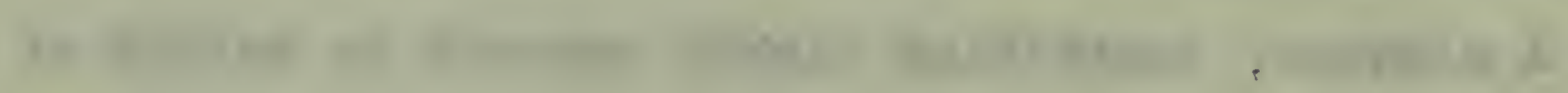

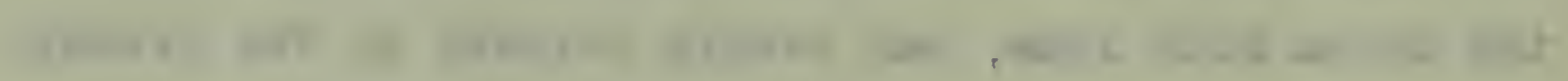

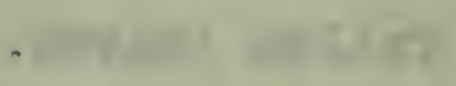

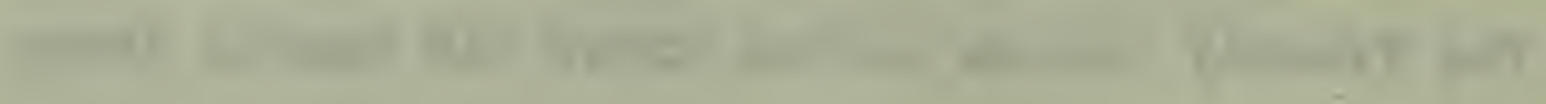

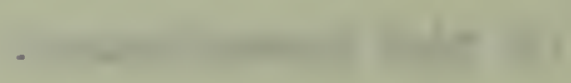

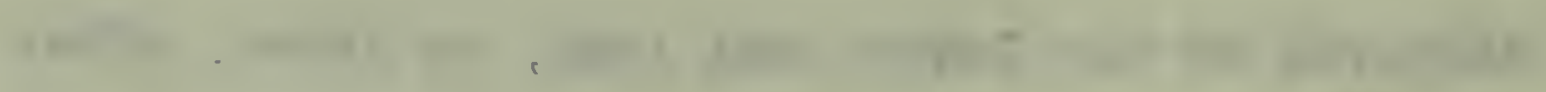

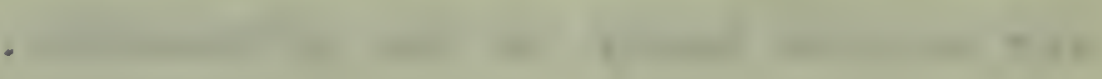

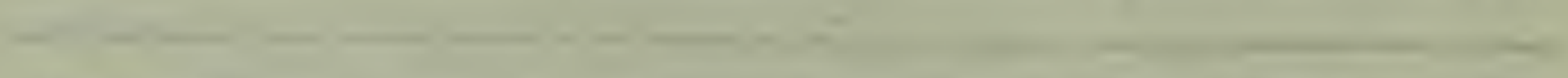

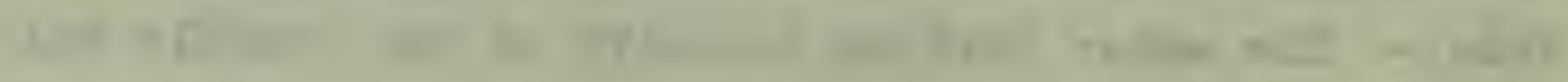

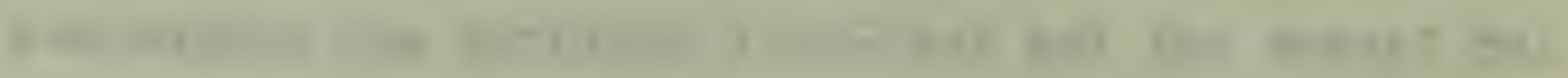

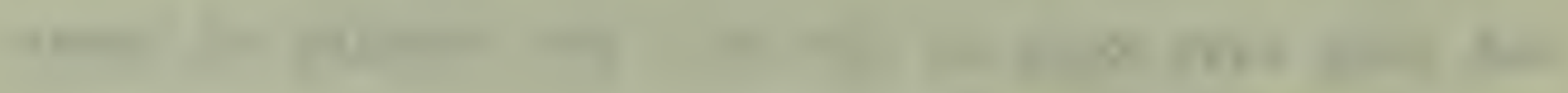

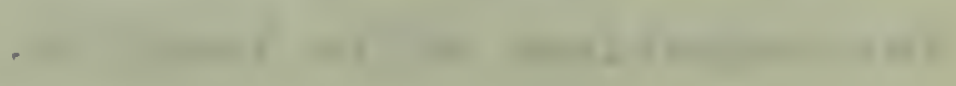




\section{Preparation of the Materials.}

All the materials were air aried, after which they were ground in a hand coffee mill. All ground well with the exception of the freshly fallen leaves. The ground material was fine enough to pass through a one millemeter sieve. (The woody portions of the leaves were sometimes in pieces one half a centimeter in length.

In most of the tests, the solutions that vere used were approximately tenthnormal. The salts used were-

Potassium bromide

Potassium chloride

Potassium iodide

Potassium nitrate
Calciumhyd rogen-phosphate

Calcium chloride.

Ammonium chloride

lagnesium sulphate

\section{Procedure.}

Thirty grams of the air aried material were placed in a twelve ounce salt-nouthed bottle with two hundred cubic centimeters of a vater solution of the salt containing the radical to be studied. The bottle was closed with a rubber stopper and shaken for ten minutes in a shaking machine, and then at intervals by hand. After about fifteen hours the contents were poured onto a folded filter and the filtrate was returned until the solution came through clear. Fifty to eighty cubic 


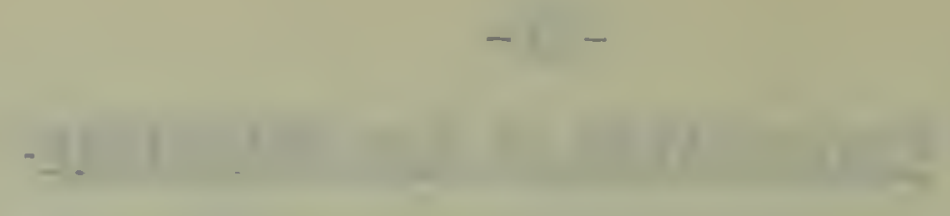

Conth

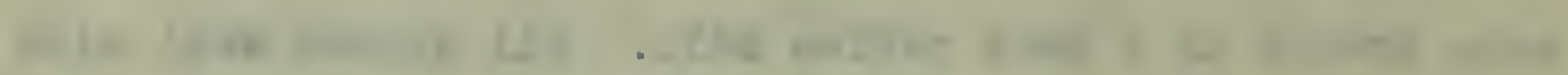

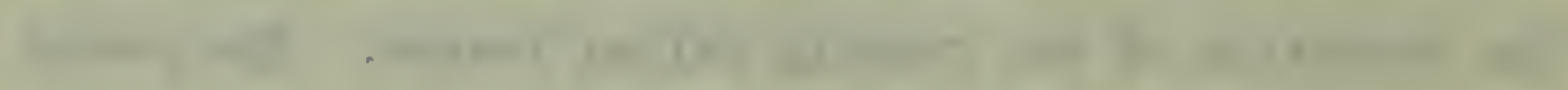

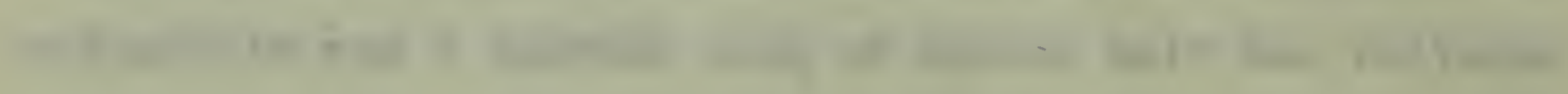

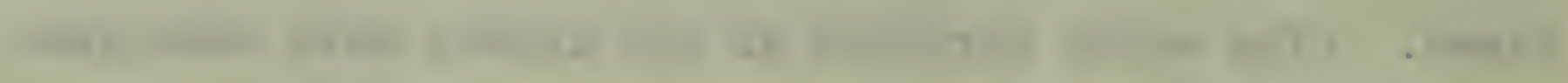

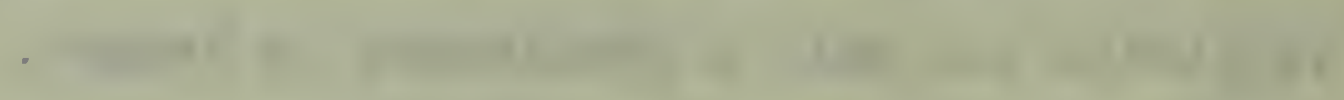

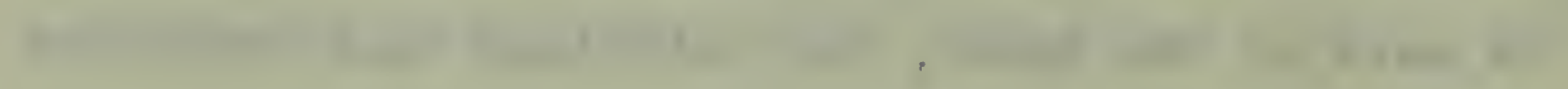

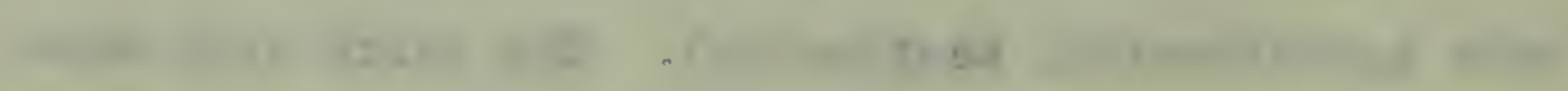

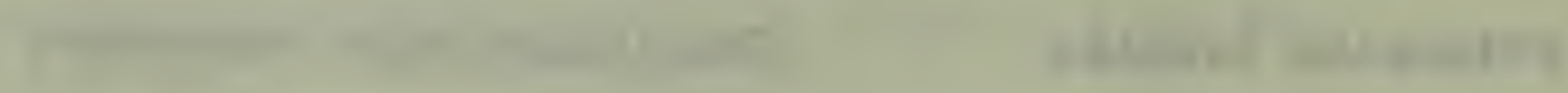

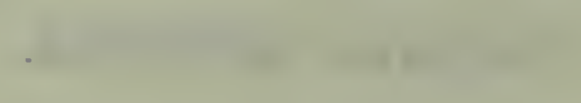

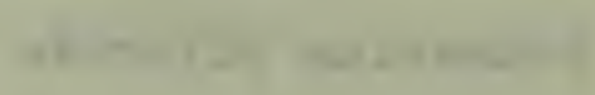

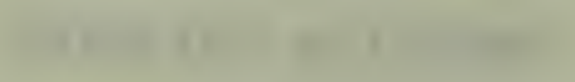

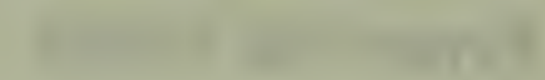

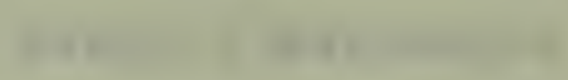

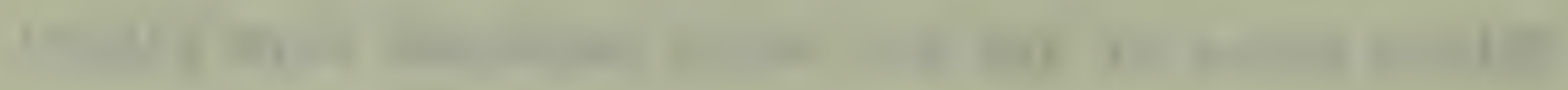

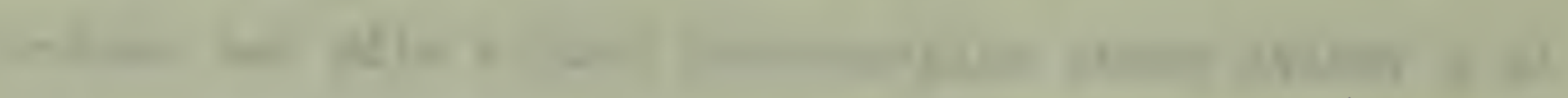

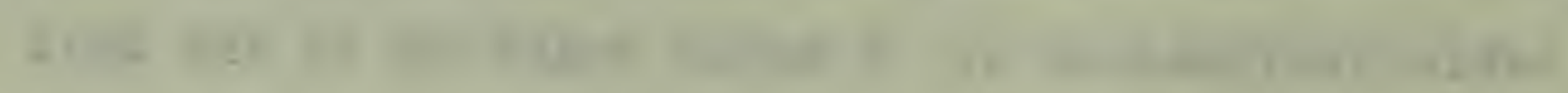

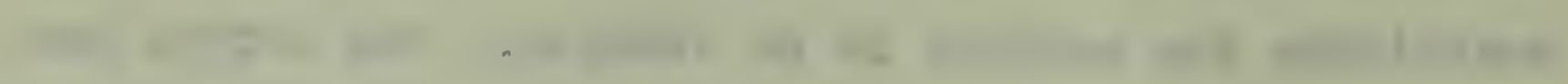

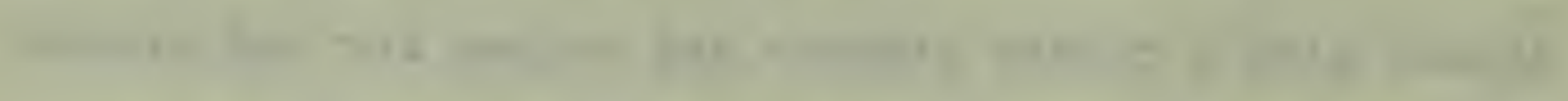

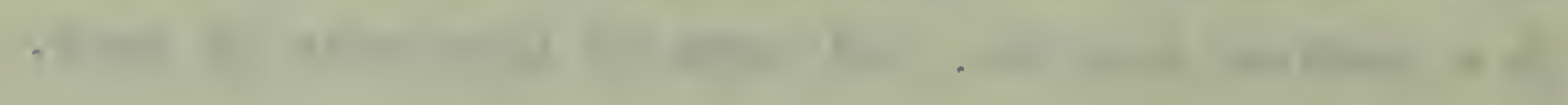

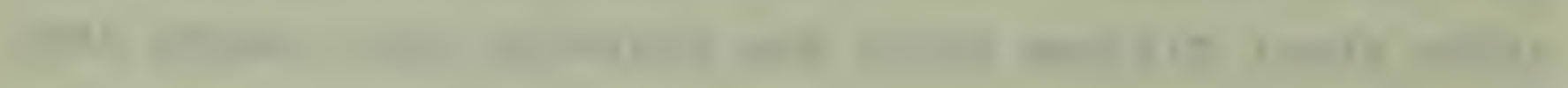

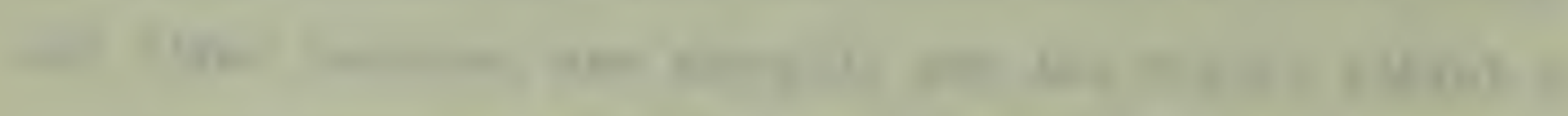

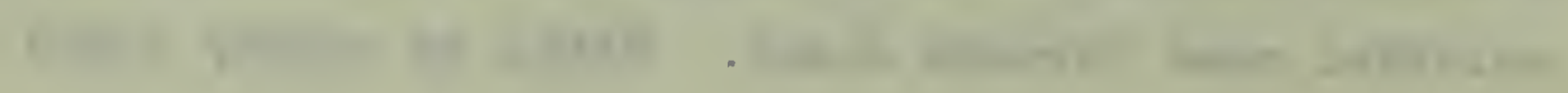


centimeters of the filtrate were collected in a small flask or glass stoppered bottle. These solutions were always analyzed within a few hours after they were prepared as moulds grew in them id they were allowed to stand for any length of time. Ten cubic centimeter portions of the solutions were taken and the determinations carried out by some standard method. No heat was applied to any of the solutions unless it was called for in the analytical method.

Water solutions of the materials were made up in the same manner, and these with aliquots of the solution containing the radical under investigation constituted the blank and check determinations.

\section{Analytical Methods.}

Chlorides, bromides and iodides were determined by titrating with silver nitrate using potassium chromate as the indicator.

Phosphoric acid was determined gravimetrically as magnesium pyrophosphate.

Ammonia was determined by ading strong caustic soda and distilling into standard acid.

Nitrates were determined by the Kjeldahl process modified to include nitrates,

Potassium was detemined gravimetrically aspotassium Chloropla ${ }^{t}$, inate. 


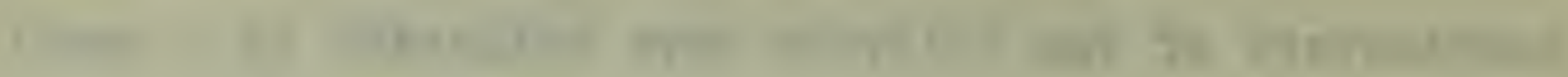

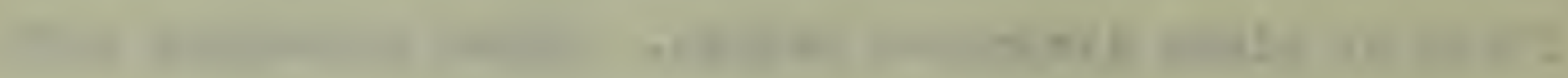

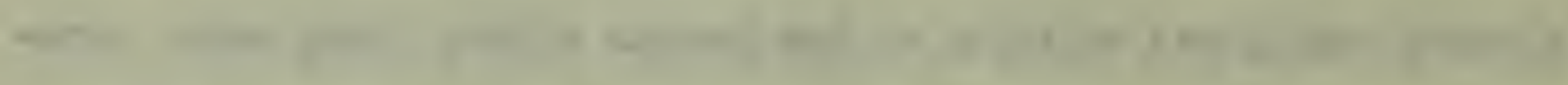

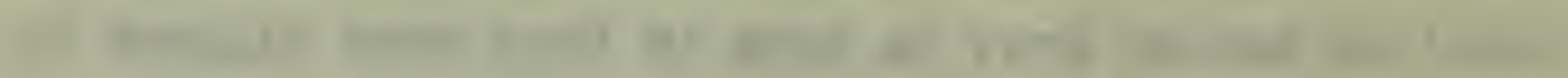

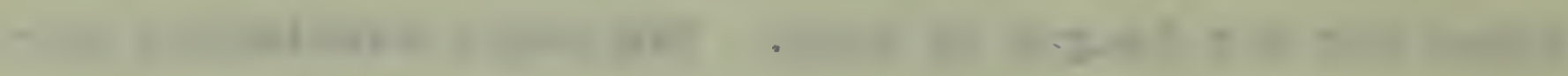

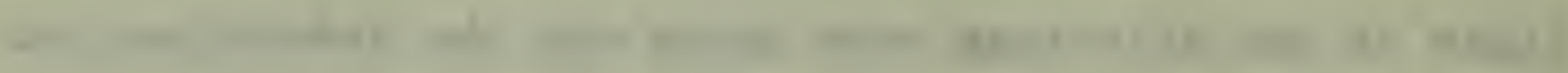

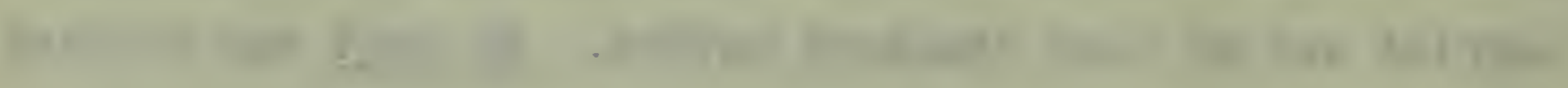

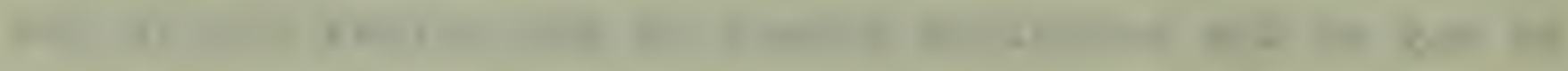
$-4+2+20$

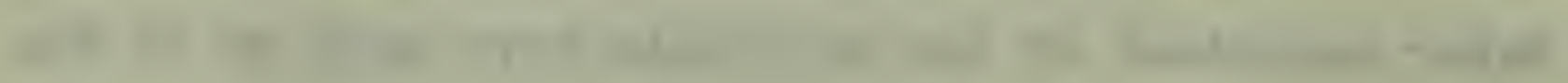

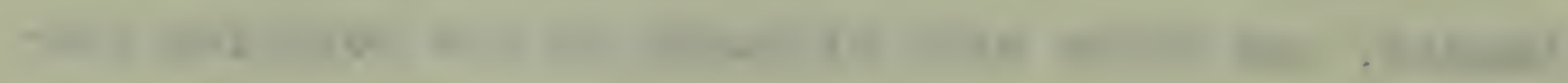

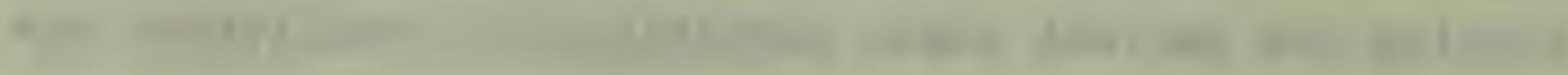

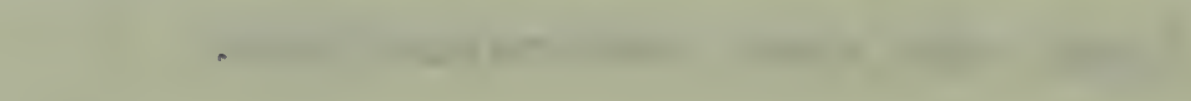

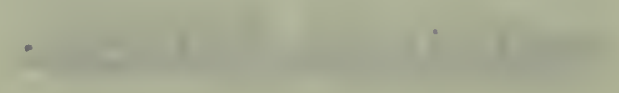

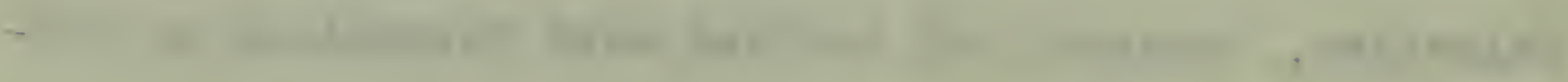

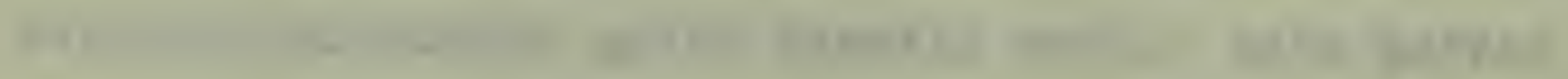

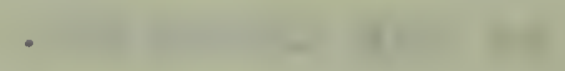

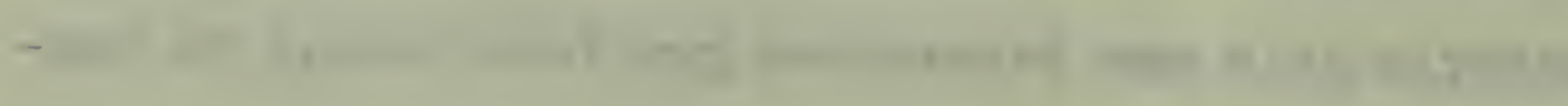

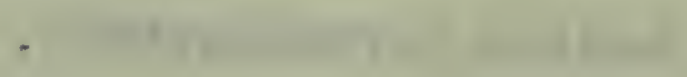

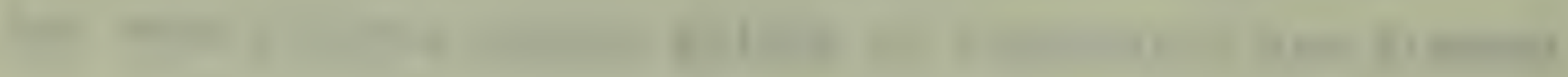

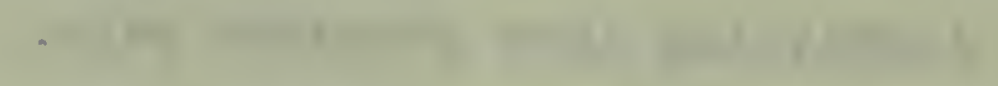

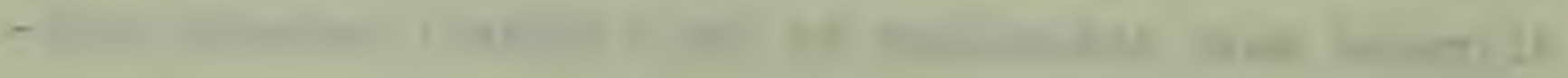
,

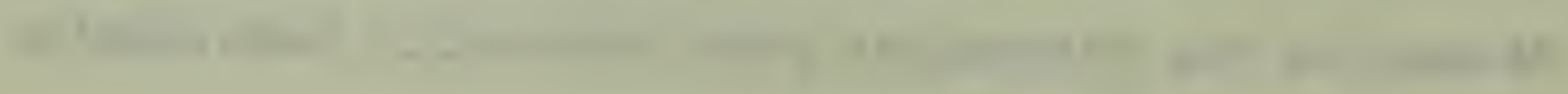

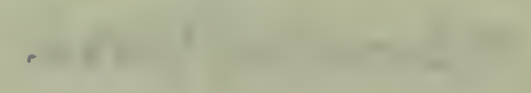


Calcium ras determined both volumetrically and gravimetrically; being precipitated in either case as the oralate, then titrated with standard potassium permanganate or ignited and weighed as the oxide. Magnesium was determined as the pyrophosphate. Sulphates were precipitated with barium chloride and weighed as barium sulphate.

\section{Results.}

The results of the blank determinations have been deducted in the following tables to add to the clearness of the tables.

Water solutions of all the materials investigated showed phosphates, sulphates, chlorides, and nitrates to be present in them.

At no place in the investigation were positive results on the absorption of chlorides, bromides or iodides obtained, and for this reason no results of determinations where these materials were used are given.

All results given are the average of at least three closely agreeing determinations. 


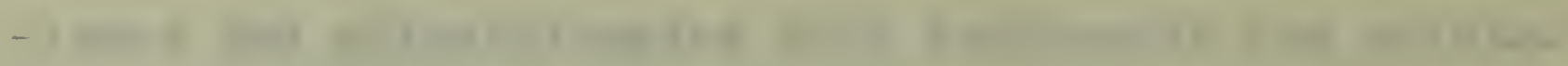

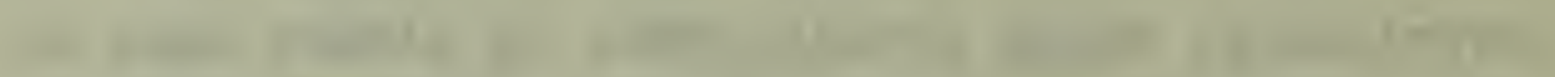

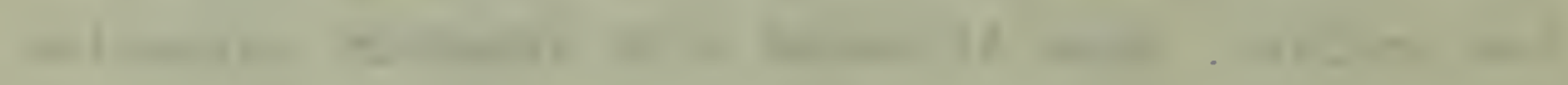

-

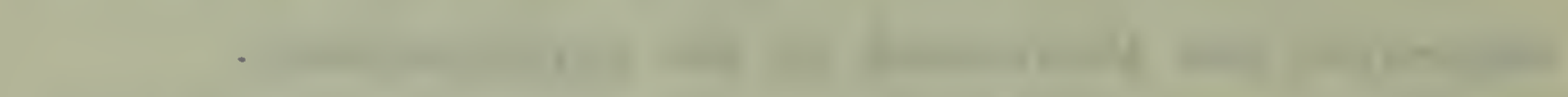

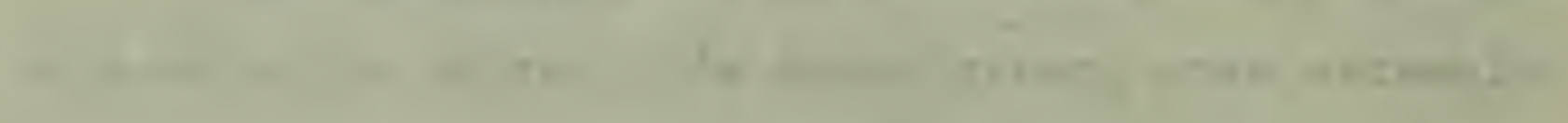

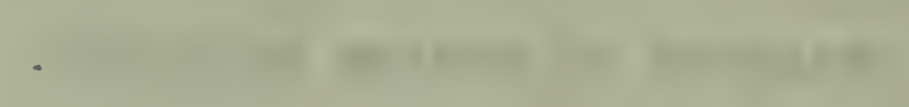

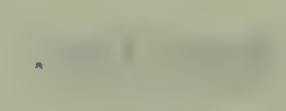

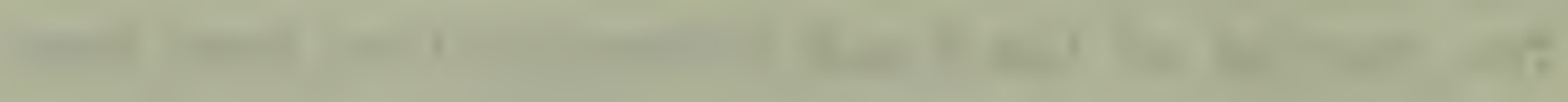

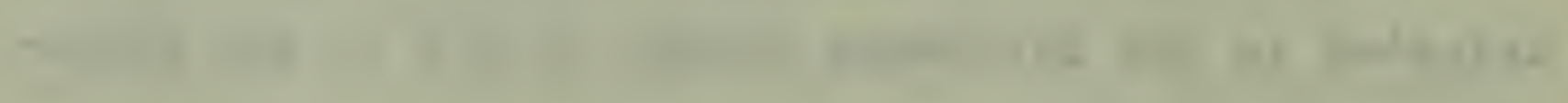

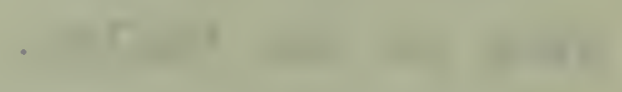

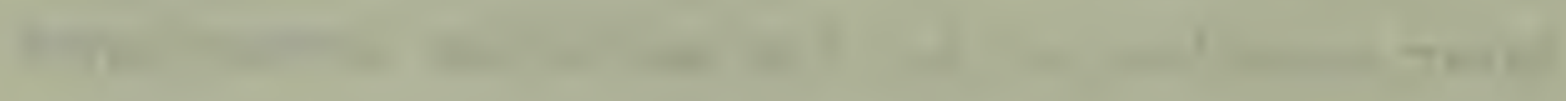

$$
\begin{aligned}
& \text { + }
\end{aligned}
$$

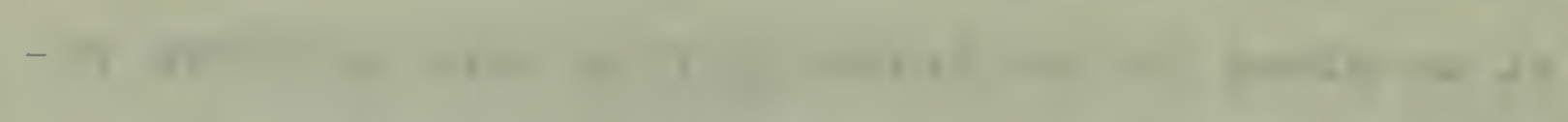

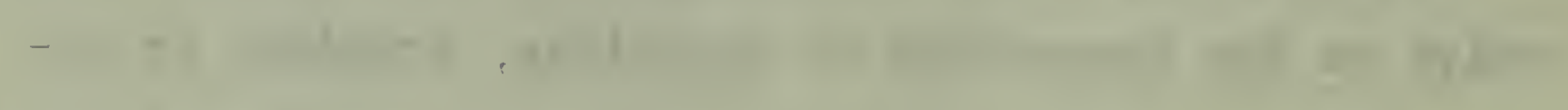

$$
\begin{aligned}
& \text { and }
\end{aligned}
$$

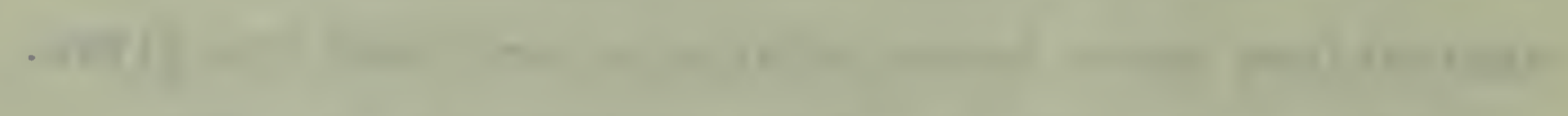

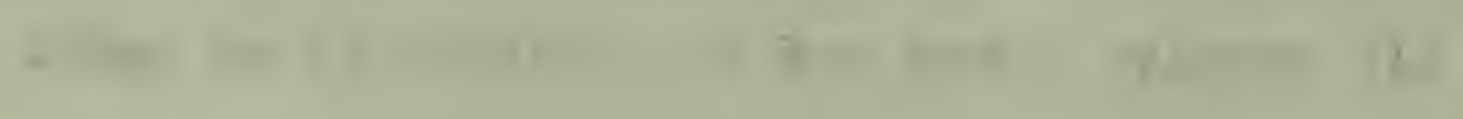

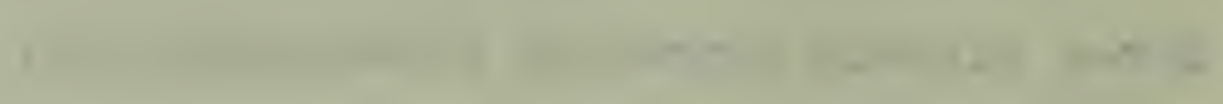

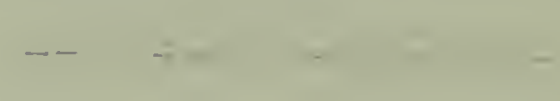


Division A.

Tables of determinations made on freshly fallen leaves and leaf moulds.

\section{Phosphate results.}

\begin{tabular}{|c|c|c|c|c|}
\hline & $\begin{array}{l}\text { iquot } \\
\text { ce. }\end{array}$ & $\begin{array}{l}\text { gms mat. } \\
\text { rep. }\end{array}$ & $\begin{array}{l}\text { gms. } \\
\text { sol. }\end{array}$ & $\begin{array}{l}\text { Ifgre } 207 \\
\text { alia. }\end{array}$ \\
\hline Freshly fallen leaves. & 10 & 1.5 & .0117 & .0116 \\
\hline $\begin{array}{l}\text { Freshly fallen leaves } \\
\text { after } 6 \text { mos. decay. }\end{array}$ & 10 & 1.5 & .0161 & .0150 \\
\hline Leaf mould C. & 10 & 1.5 & .0117 & .0087 \\
\hline Ieaf mould A. & 10 & 1.5 & .0117 & 050 \\
\hline
\end{tabular}

Ammonium chloride results.

Expressed in cc..0899 normal acid. aliquot gms mat. cc. ce. cc. rep. sol. alig.

Preshly fallen leaves

10

1.5

$12.43 \quad 10.73$

Freshly fallen leaves after 6 mos. decay.

10

1.5

10.40

8.45

Ieaf mould C.

10

1.5

$12.43 \quad 10.04$

Ieaf mould A.

10

1.5

$12.40 \quad 9.79$

cc. of 0.10 normal acia. 


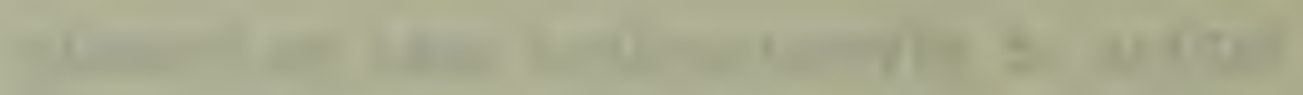

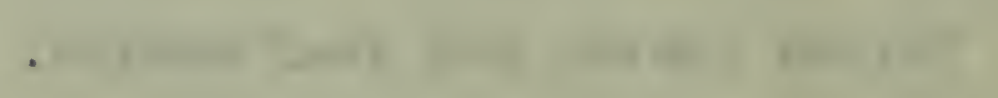

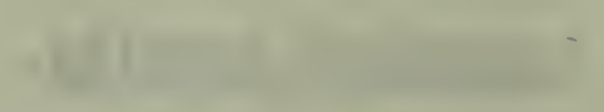

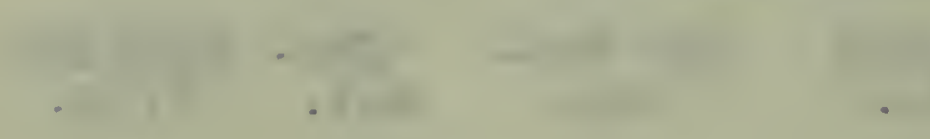

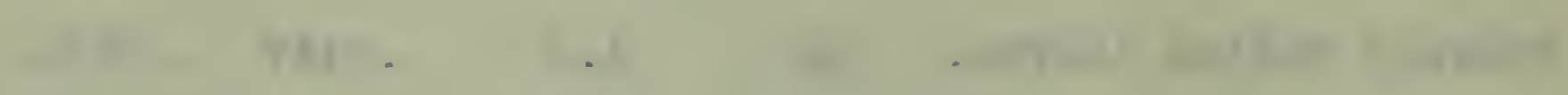

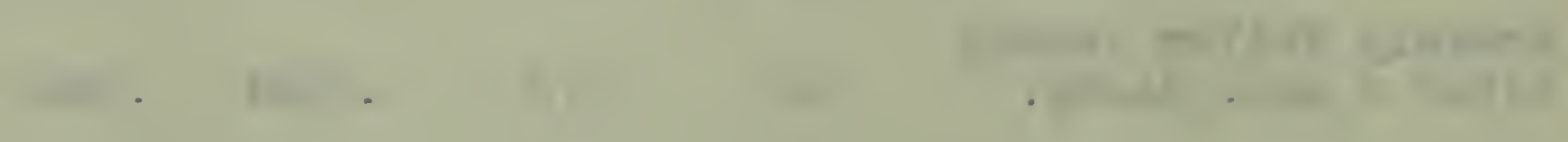

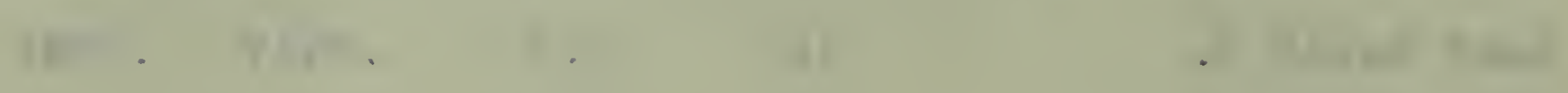

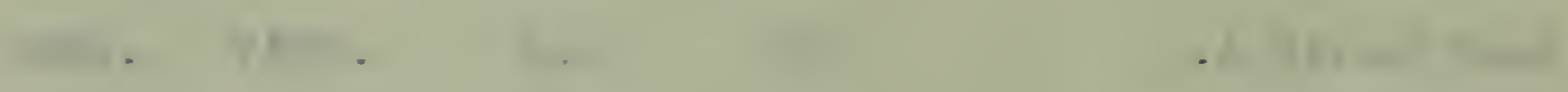

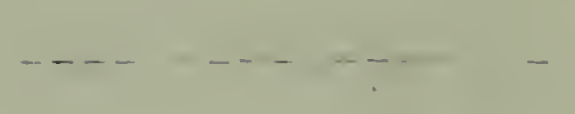

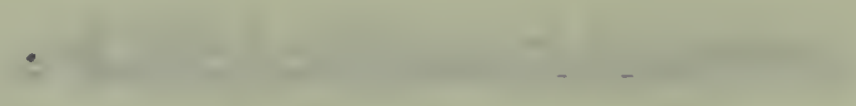

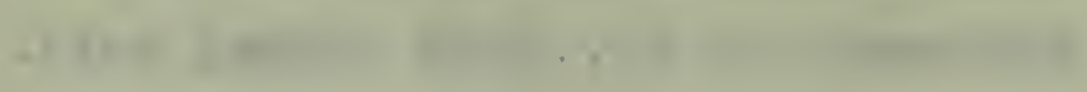

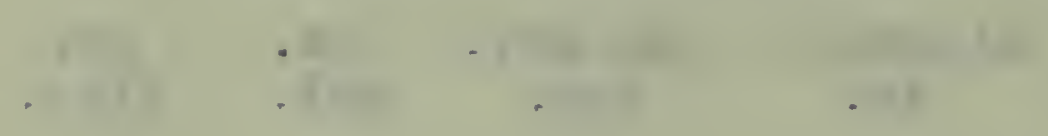

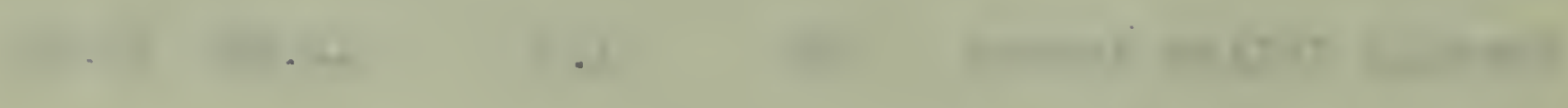

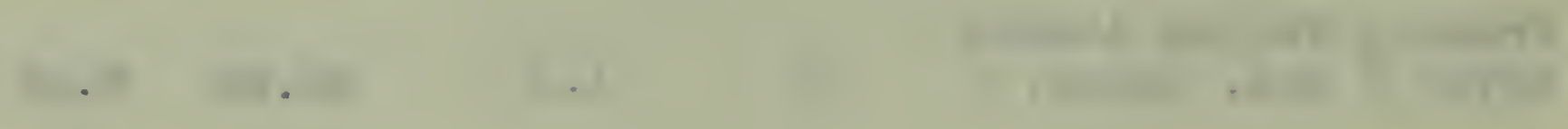

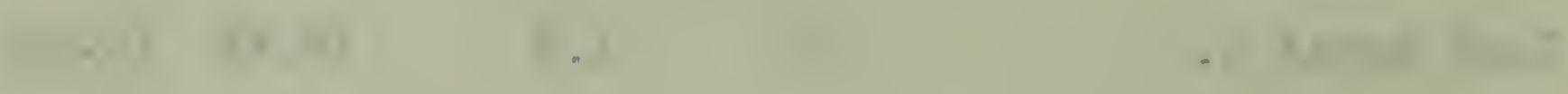

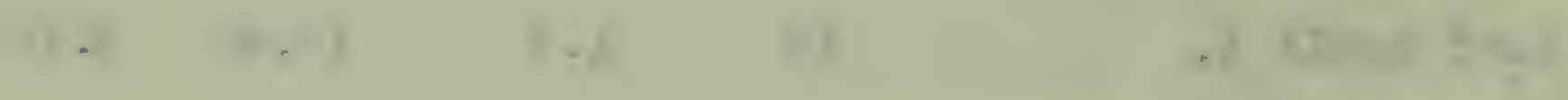

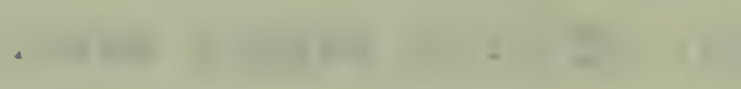


Potassium results.

Expressed as grams of potassium $\mathrm{K}_{2} \mathrm{PtCl}_{6}$.

$\begin{array}{cccc}\text { aliquot gms mat. } & \text { gms. } & \text { gms. } \\ \text { ce } & \text { rep. } & \text { sol. } & \text { aliq. }\end{array}$

\begin{tabular}{|c|c|c|c|c|}
\hline Freshly fallen leaves. & 10 & 1.5 & .2467 & .1989 \\
\hline $\begin{array}{l}\text { Freshly fallen leaves } \\
\text { after } 6 \text { mos. decay }\end{array}$ & 10 & 1.5 & .2459 & .2205 \\
\hline Leaf mould C. & 10 & 1.5 & .2467 & .2088 \\
\hline Leaf mould $A$. & 10 & 1.5 & .2467 & .2078 \\
\hline
\end{tabular}

Calcium results.

Expressed in cc. of .1206-normal $\mathrm{KMnO}_{4}$.

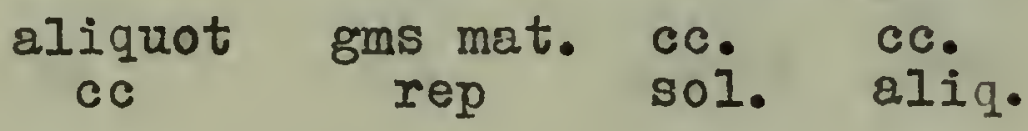

$\begin{array}{lllll}\text { Freshly fallen leaves. } & 10 & 1.5 & 8.10 & 8.14\end{array}$

Freshly fallen leaves after 6 mos. decay.

$1.5 * .0301 * .0271$

Leaf moula $\theta$.

10

1.5

$8.10 \quad 7.95$

Leaf mould $A$.

10

1.5

8.10

7.77

Grans of calcium oxide. 

Nitrate results.

Expressed in cc. of .0899 acid.

$$
\begin{array}{cccc}
\text { aliquot gms mat. } & c c . & c c . \\
\text { cc. } & \text { rep. } & \text { sol. } & \text { aliq. }
\end{array}
$$

$\begin{array}{lllll}\text { Freshly fallen leaves. } & 10 & 1.5 & 10.40 & 10.50\end{array}$

Leaf mould C.

10

1.5

$10.40 \quad 10.57$

Ieaf mould A.

10

1.5

$10.40 \quad 10.56$

\section{Hagnesium results.}

\begin{tabular}{|c|c|c|c|c|}
\hline & $\begin{array}{l}\text { aliquot } \\
\text { cc. }\end{array}$ & $\begin{array}{c}\text { gms mat. } \\
\text { rep. }\end{array}$ & $\begin{array}{l}\text { gms. } \\
\text { sol. }\end{array}$ & $\begin{array}{l}\text { gms. } \\
\text { aliq. }\end{array}$ \\
\hline Freshly fallen leaves & 10 & 1.5 & .0053 & .0053 \\
\hline $\begin{array}{l}\text { Freshly fallen leaves } \\
\text { after } 6 \text { mos. decay. }\end{array}$ & 10 & 1.5 & .0059 & .0059 \\
\hline Ieaf mould $c$. & 10 & 1.5 & .0053 & .0058 \\
\hline Ieaf mould $A$. & 10 & 1.5 & .0053 & .0057 \\
\hline
\end{tabular}

Expressed as grams of $\mathrm{Mg}_{2} \mathrm{P}_{2} \mathrm{O}$

Sulphate results.

Expressed as grams of barium sulphate. $\begin{array}{cccc}\text { aliquot gms mat. } & \text { gms. } & \text { gms. } \\ \text { cc. } & \text { rep. } & \text {, sol. } & \text { aliq. }\end{array}$

Freshly fallen leaves $10 \quad 01.5 \quad 0121 \quad .0123$

Freshly fallen leaves $\begin{array}{lllll}\text { after } 6 \text { mos. decay. } & 10 & 10 & .0121 & .0126\end{array}$

Ieaf mould C. 10

1.5

.0181 .0127

Ieaf mould A.

1.5

$.0121 \quad .0129$ 


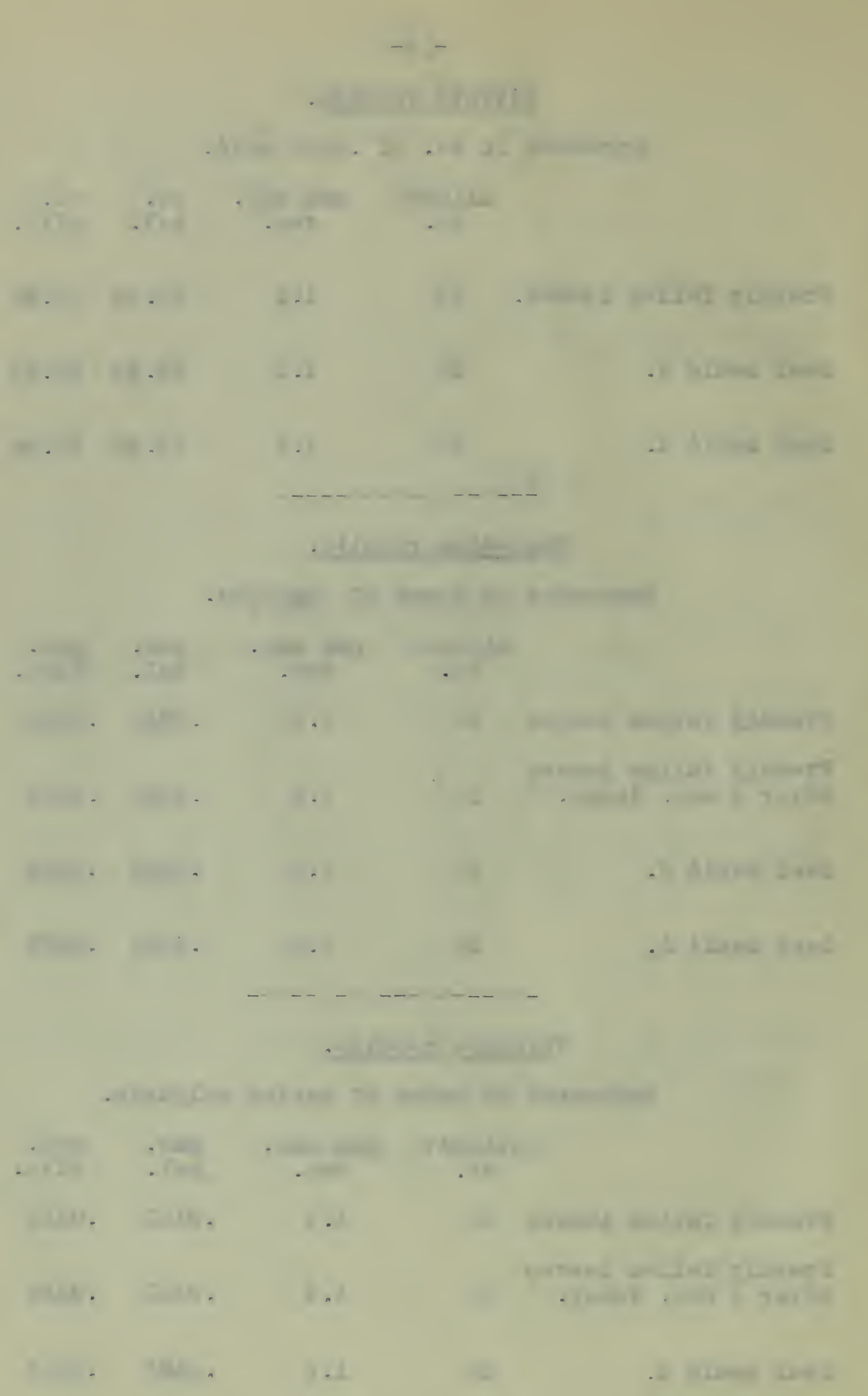


Compilation.

Absorption by freshly fallen leaves, and

leaves in three stages of decay.

(Calculated per gram of the material used.)

No absorption of the following radicals, -

chloride bromide iodide

nitrate sulphate magnesium.

Radical $\quad \mathrm{PO}_{4} \quad \mathrm{NH}_{4} \quad \mathrm{~K}$. Ca.

Freshly fallen leaves Vifight $.001835,006013$ No ab.

Freshly fallen leaves

$\begin{array}{llllll}\text { after } 6 \text { mos. decay } & .00047 & .002410 & .002740 & .00214\end{array}$

Leaf mould $C$.

$\begin{array}{llll}.00128 & .002559 & .004078 & .00005\end{array}$

Ieaf mould A.

$.00284 \quad .003141 \quad .004175 \quad .00011$

The table shows, -

That the absorption of $\mathrm{PO}_{4}$ increases as the decay proceeds.

That the absorption of $\mathbb{N H}_{4}$ increases as the decay proceeds.

That the absorption of potassium depends on the state of the material at the time that the test is made, tending to confirm the work of Bertbolet already quoted. 

The calcium absorption seems to increase as the decay proceeds.

\section{Special experiments.}

The freshly fallen leaves and the tro leaf moulds were treated with tenth normal benzoic acid in alcohol solution. The leares showed no absorption of the benzoic acid, while the leaf moulds showed absorption directly proportional to the decay.

Freshly fallen leaves were washed with distilled water. The washed leaves contained less sulphate, chloride and etc, but the washing had no effect on the absorption.

The hygroscopic moisture was determined in some of the materials with the result that it was proven that it did not account for the absorption.

Portions of the materials were reground and sieved, and the absorption of these sievings was compared with that of the original material with the result that it was determined that the absorption was in some cases slightly effected by the size of the particles. 


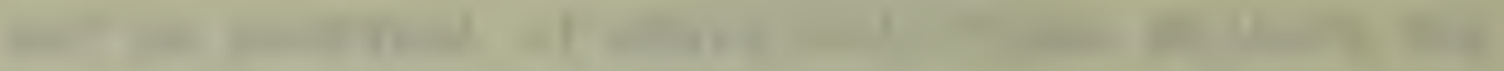

$$
\begin{aligned}
& \text { - Man an } \\
& -1---6 n-.
\end{aligned}
$$

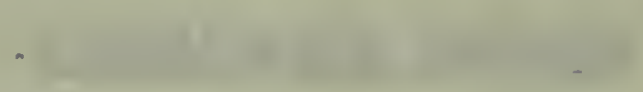

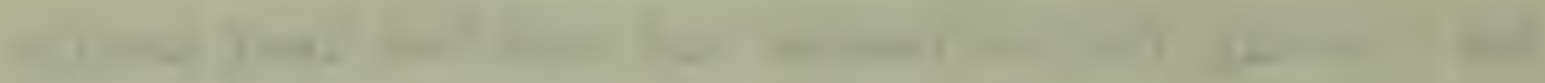

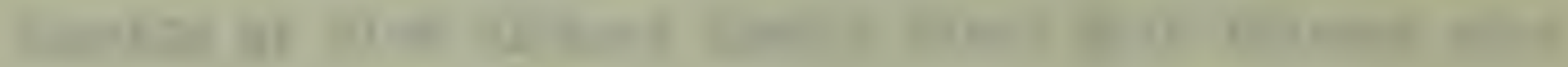

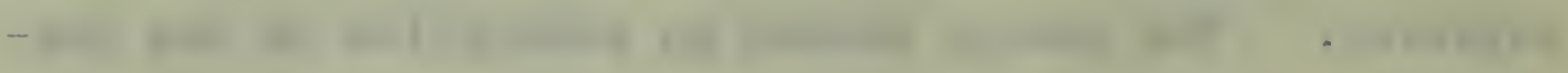

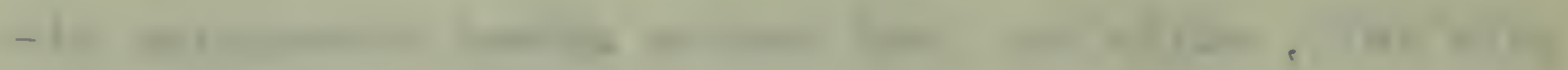

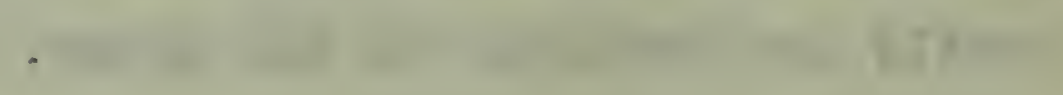

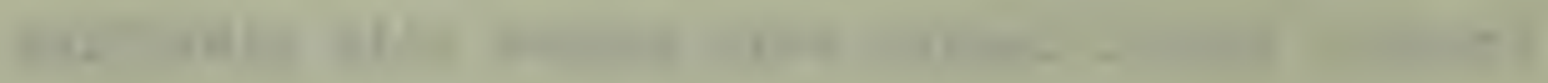

-

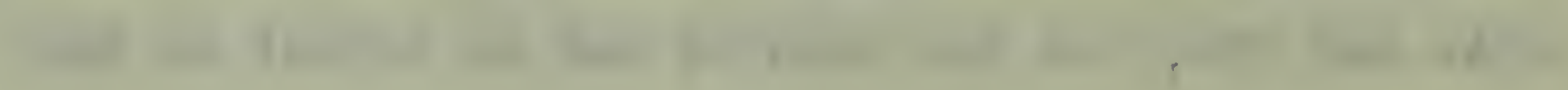

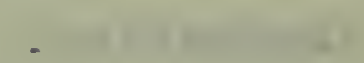

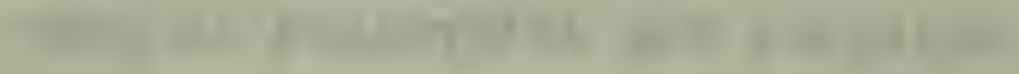

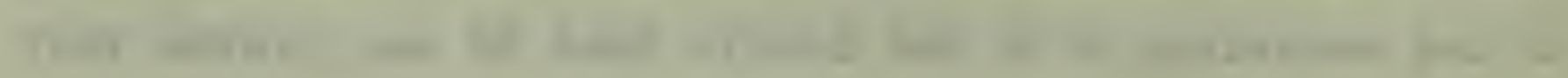

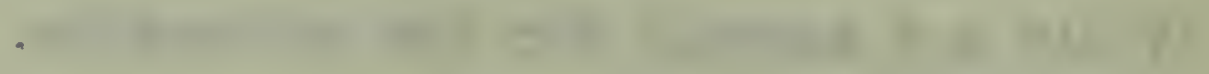

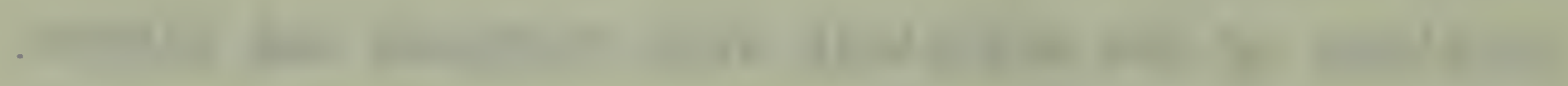

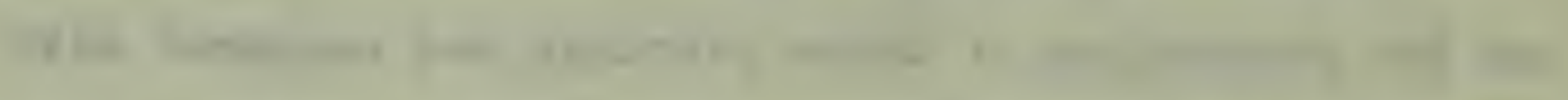

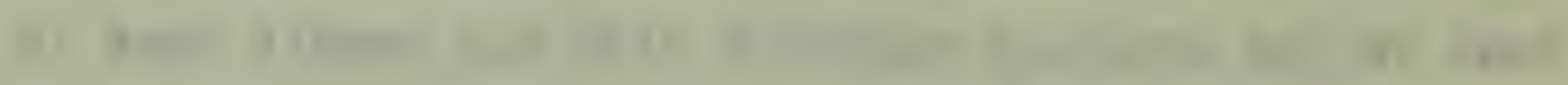

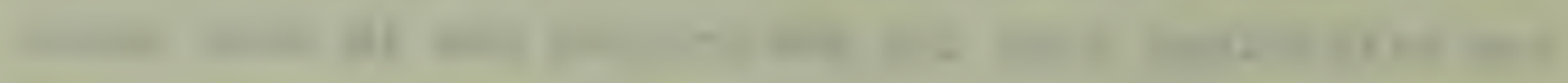

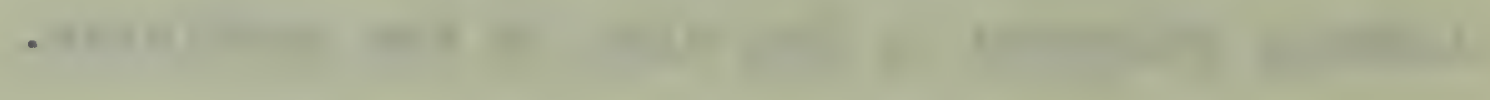

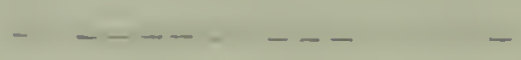


Division B.

Tables of the determinations made on freshly fallen leaves, a soil, and two mixtures of the soil and leaves.

The results of the determinations on freshly fallen leaves have already been given and will not be repeated in this division.

\section{Ammonium results.}

aliquot gms mat. cc .0899-N acia. cc. rep. sol. aliq.

Brown silt loam 10 1.5 $11.68 \quad 11.20$ 95\% loam 5\%leaf mix. 10 1. 5 $11.68 \quad 10.66$ $80 \%$ loam $20 \%$ leaf mix. 10 1.5 $11.68 \quad 10.68$

Phosphate results.

$\begin{array}{lcccc} & \begin{array}{c}\text { aliquot } \\ \text { ce }\end{array} & \begin{array}{c}\text { gms mat. } \\ \text { rep. }\end{array} & \begin{array}{c}\text { gms MgaP O } \\ \text { sol. }\end{array} \\ \begin{array}{lccc}\text { aliq. } \\ \text { Brown silt loam }\end{array} & 10 & 1.5 & .0113 & .0065 \\ 95 \% \text { loam 5\% leaf mix. } & 10 & 1.5 & .0113 & .0069 \\ 80 \% \text { lom 20\% leaf mix. } & 10 & 1.5 & .0113 & .0081\end{array}$




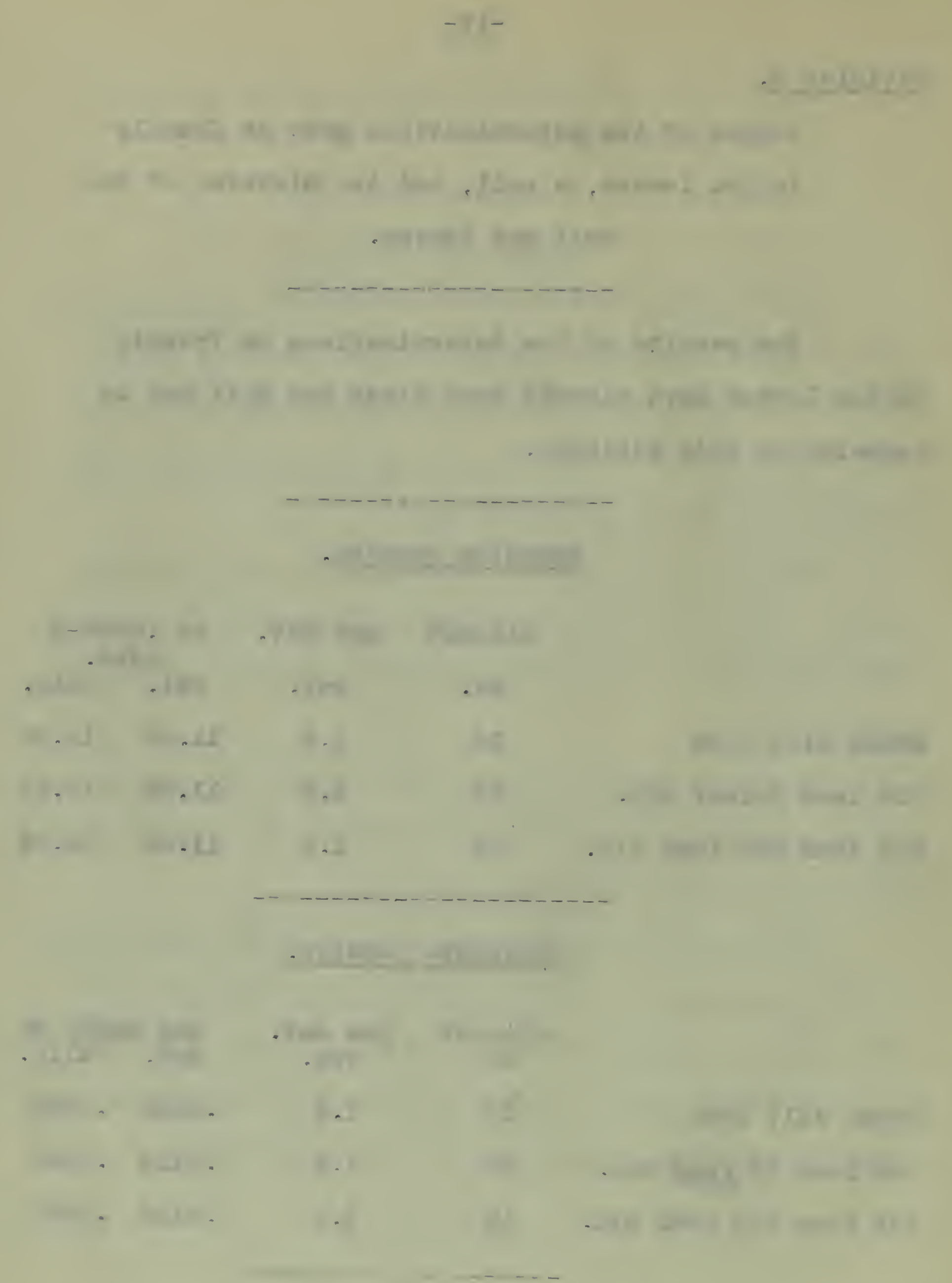


Potassium results.

Expressed in grams of potassium chloroplatinate.

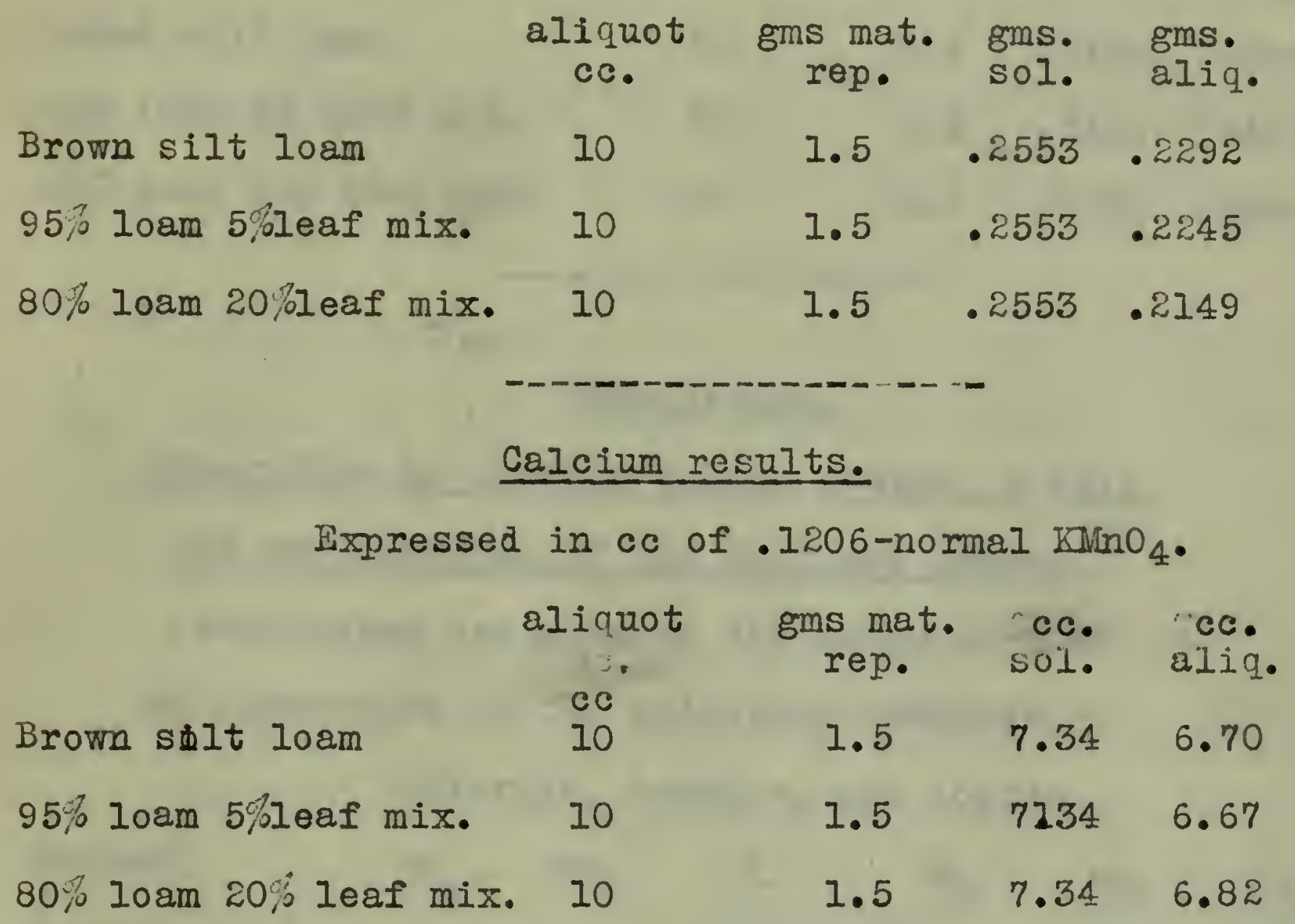

liagnesium results.

Expressed in grams of $\mathbb{M g}_{2} \mathrm{P} 2 \phi_{\eta}$.

aliquot gms mat. gms. gms. ce rep. sol. aliq.

$\begin{array}{lllll}\text { Brown silt loam } & 10 & 1.5 & .0559 & .0556\end{array}$

$95 \%$ loam $5 \%$ leaf mix. $10 \quad 1.5 \quad .0559 \quad .0555$

$80 \%$ loam $20 \%$ leaf mix. $10 \quad 1.5 \quad .0559 \quad .0557$ - 


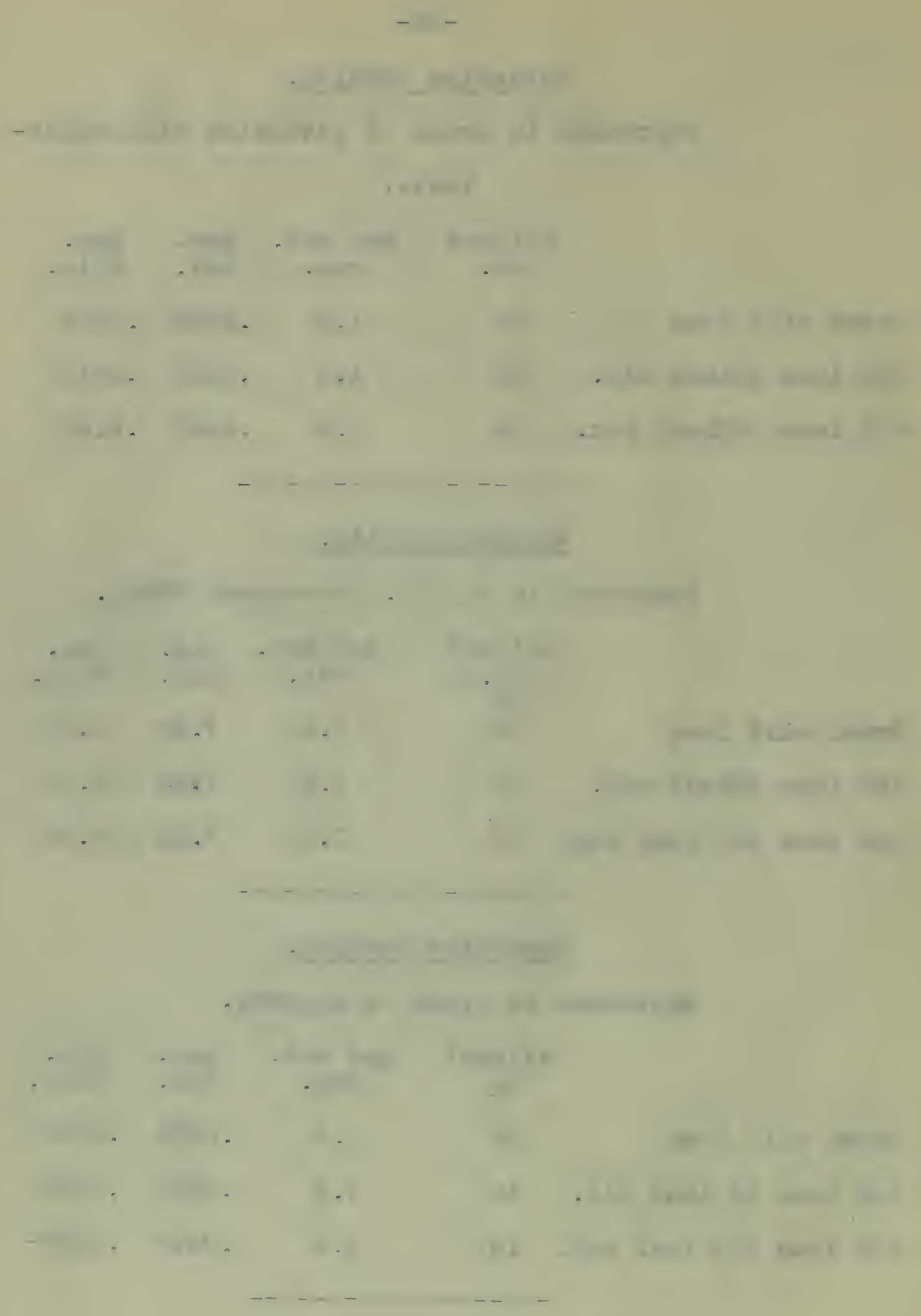


Sulphate results.

Expressed in grams of barium sulphote.

aliquot gms mat. gms gms.

cc. rep. sol. aliq.

Brown silt loam

10

$1.5 \quad .0126 \quad .0094$

$95 \%$ loam $5 \%$ leaf mix.

10

$1.5 \quad .0126 \quad .0102$

$80 \%$ loam $20 \%$ leaf mix.

10

$1.5 \quad .0126 \quad .0097$

\section{Compilation.}

Absorption by freshly fallen leaves, a soil,

and two mixtures of the soil and leaves.

(Calculated per gram of the material used)

No absorption of the following radicals,chloride, bromide, and iodide.

Radical

$\mathrm{PO}_{4}$
Very
slig

Freshly fallen

leaves.

slight .001835.006013 To ab. Iro ab. No ab.

Brown silt

Ioam.

.00273 .000520 .002805 .00021 .00007 .00086

$95 \%$ loam $5 \%$

leaf mixture. .00247 .001105.003305.00021 .00007.00066

$80 \%$ loam 20\%

leaf mixture.

.00179 .001137 .004352 .00013 .00006 .00078

The table shows, -

That the leaves are principaliy concerned with the absorption of the ammonium and potassium radicals. 


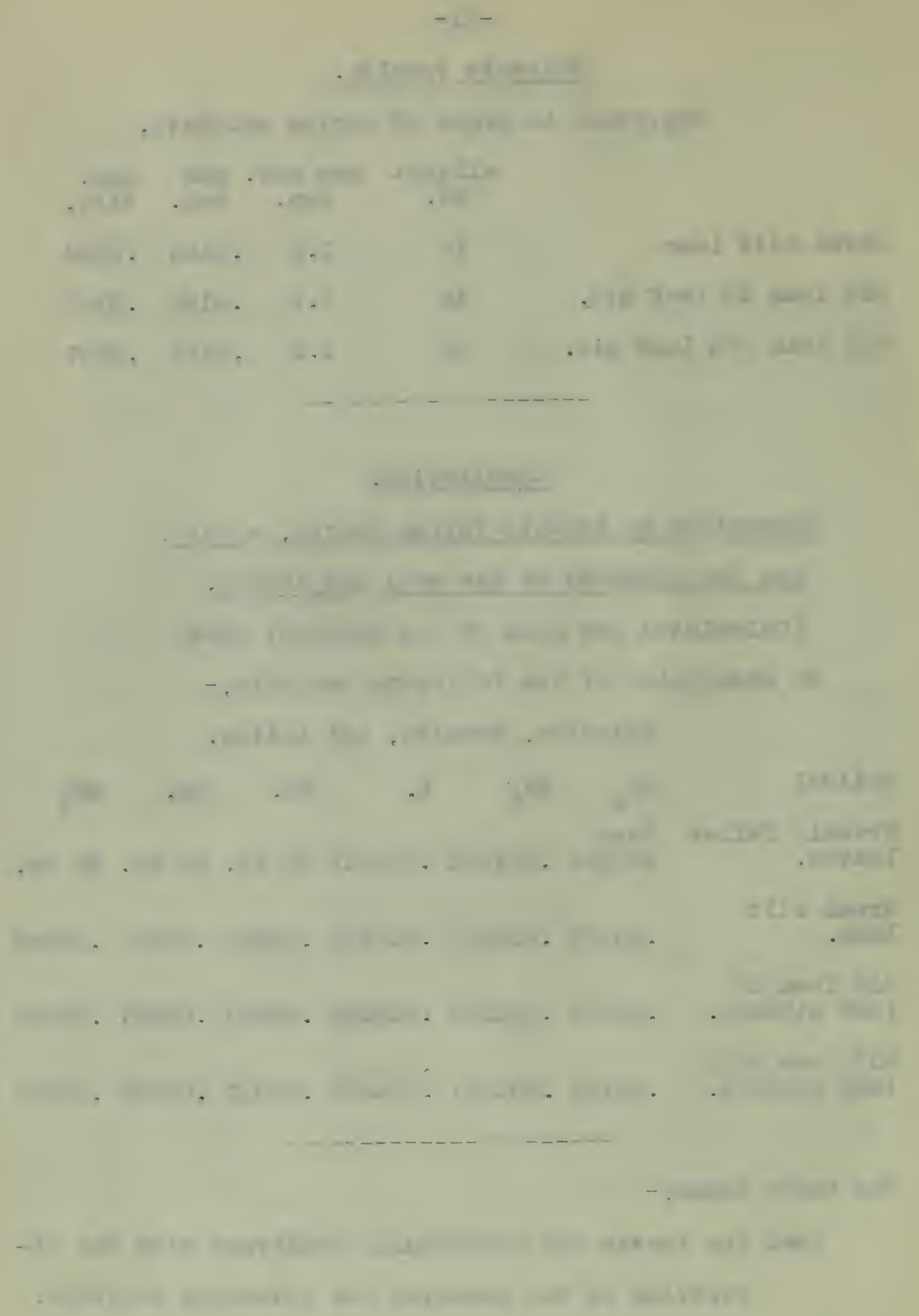


That the absorption of the phosphate, calcium. magnesium, and sulphate radicals is due more to the soil than to the leaves.

Division C.

Absorption by decaying leaves, a soil, and two mixtures of the soil and decaying leaves.

Previous tables give the results of the determinations made on the soil and the decaying leaves, therefore they are not given here.

\section{Results of determinations.}

I is $95 \%$ loam $5 \%$ leaf mixture after six month decay. II is $80 \%$ loam $20 \%$ leaf mixture after six months decay.

$$
\frac{I}{\text { sol. } \text { aliq. }} \frac{I I}{\text { sol. aliq. }}
$$

$\mathrm{PO}_{4}$ in grams $\mathrm{Mg}_{2} \mathrm{P}_{2} \mathrm{O}_{7}$

$\begin{array}{llll}.0161 & .0127 & .0161 & .0109\end{array}$

$\begin{array}{lllll}\mathrm{NH}_{4} \text { in ce tenth norm. acid } & 10.40 & 9.89 & 10.40 & 9.17\end{array}$

$\mathrm{K}$. in grams $\mathrm{K}_{2} \mathrm{PtCl}_{6}$.

$.2489 \quad .2247 \quad .2459 \quad .2173$

Ca. in grams EaO.

$.0301 \quad .0283 \quad .0301 \quad .0268$

$\mathrm{Mg}$. in grams $\mathrm{lig}_{2} \mathrm{P}_{2} \mathrm{O}_{7}$

$\begin{array}{llll}.0060 & .0057 & .0060 \quad .0058\end{array}$

$\mathrm{SO}_{4}$ in grams $\mathrm{BaSO}_{4}$

$\begin{array}{llll}.1207 & .1215 & .1207 & .1230\end{array}$ 


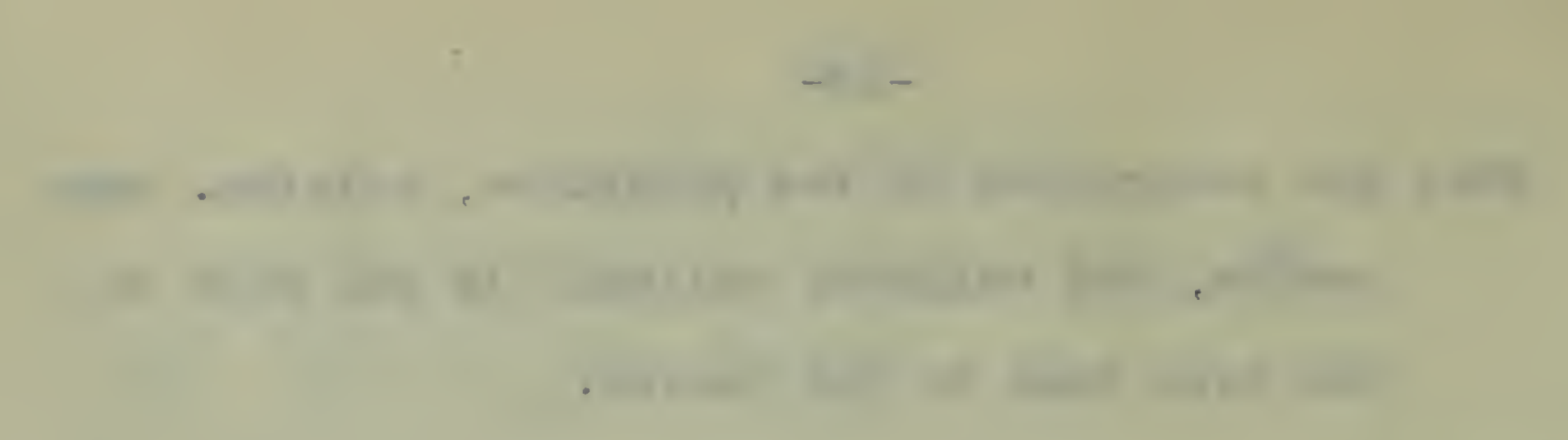

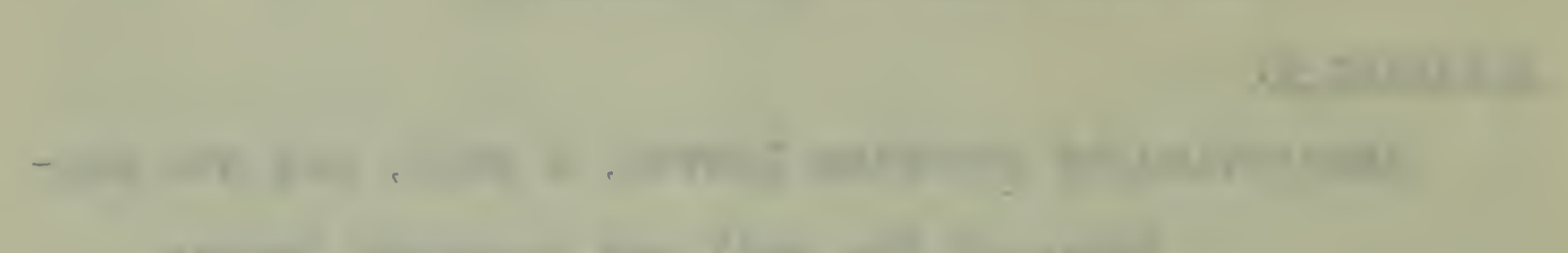

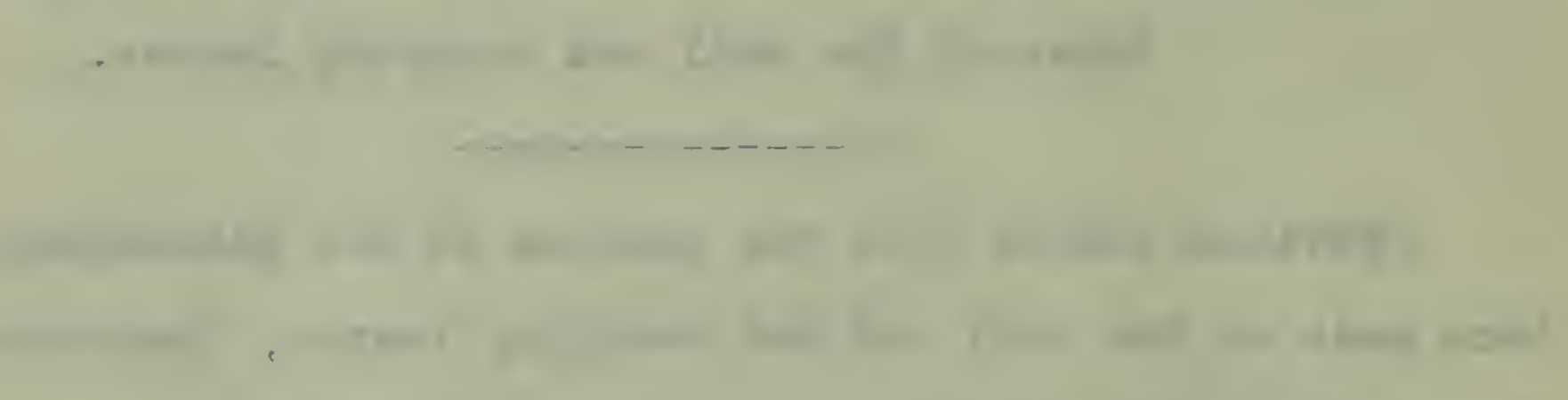

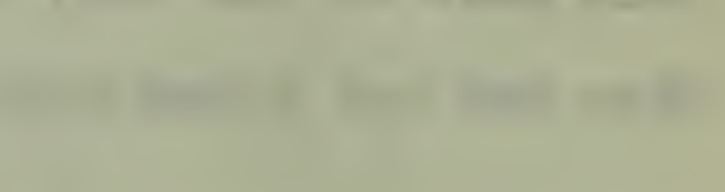

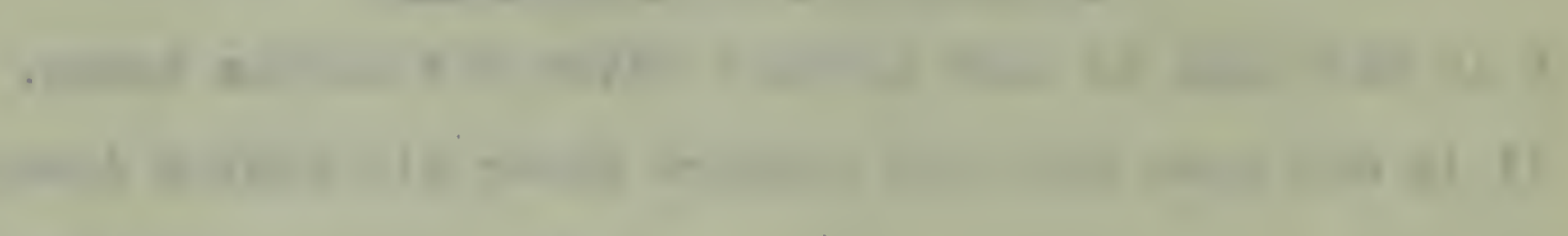

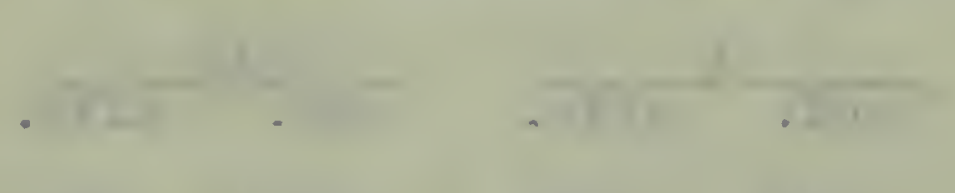


Compilation.

Absorotion by decaying leaves, a soil and two

mixtures of the soil and docazing leaves.

(Calculated per gram of the material used)

Ho absorption of the following radicals -

chloride, bromide, and iodide.

Explanation of table,-

I. is freshly fallen leaves after six months decay.

II. is brown silt loam.

III. is $95 \%$ loam $5 \%$ leaf mixture after six montis decay.

IV. is $80 \%$ loam $20 \%$ leaf mixture after six months decaj.

Radical $\mathrm{PO}_{4}$

$\mathrm{NH}_{4}$

K.

Ca.

Mg.

$\mathrm{SO}_{4}$

I. .00047 .00241 .00274 .00214 INo ab. No ab.

II. $\quad .00273 \quad .00052 \quad .00281 \quad .00021 \quad .00007 \quad .00086$

III. .00196 .00062 .00230 .00086 slight No ab.

IV. $.00299 .00148 \quad .00306 \quad .00157$ slight No ab. 

The table shows, -

That the sulphate and the magnesiurn which the soil would absorb are being supplied by the leaves. Irregularity, probably due to the different stages of decay that the materials are in for,-

a, The capillarity of the mixtures was observed to be different.

$b$, Bacterial decomposition could not have been the same because of differences in the pore space and water content of the materials.

That the absorption of the soil is increased by having decaying humus forming material in it.

\section{Conclusions.}

1. Leaves undecayed and in different stages of decay show absorption for certain radicals. This absorption. for the radicals studied, does not always increase with the decay.

2. The color of the solutions obtained by treating the same material with different salts is not the same. This indicates absorption rather than adsorption. 


$$
-
$$

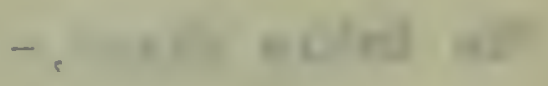

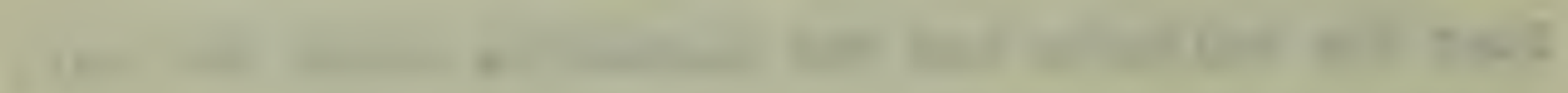

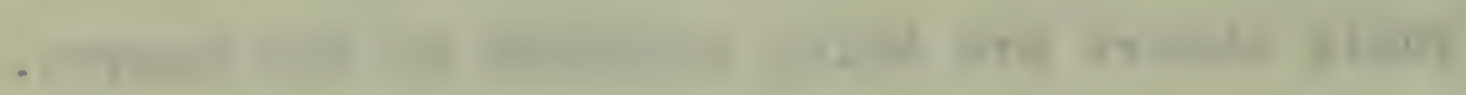

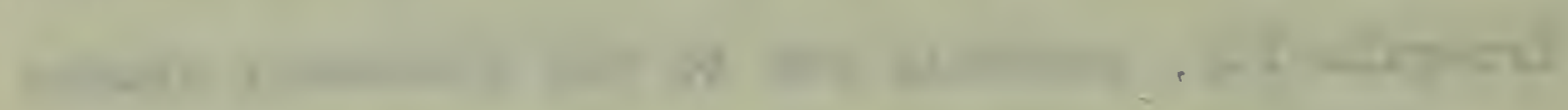

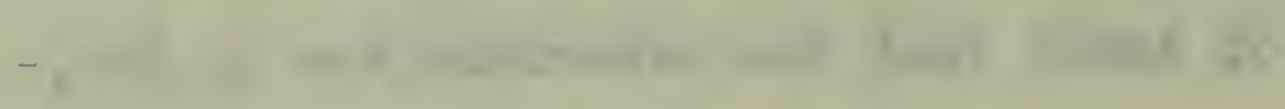

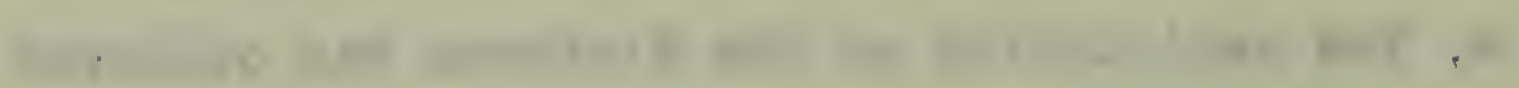

\section{-}

and

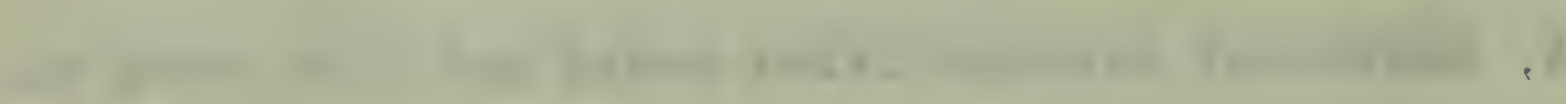

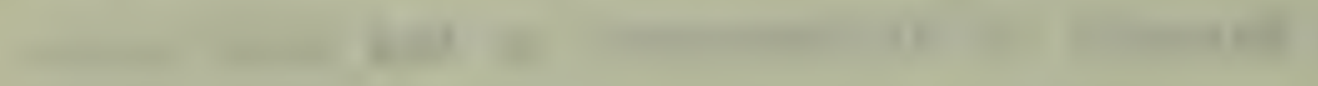

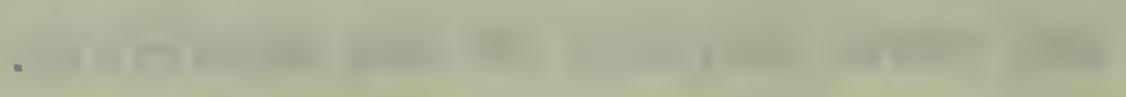

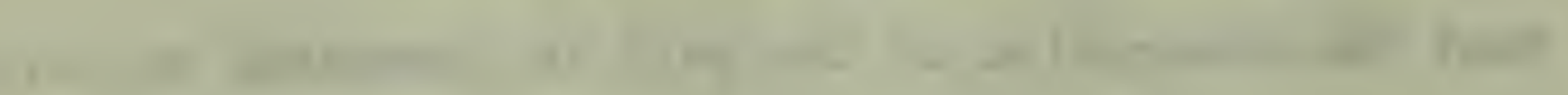

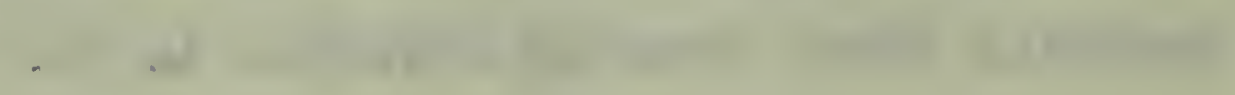

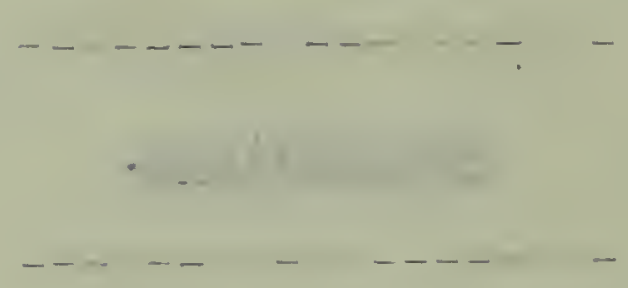

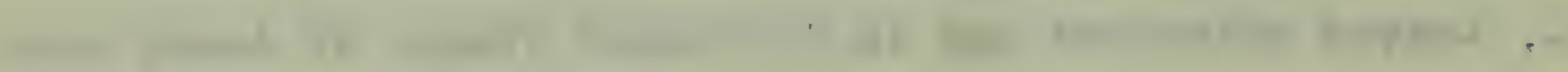

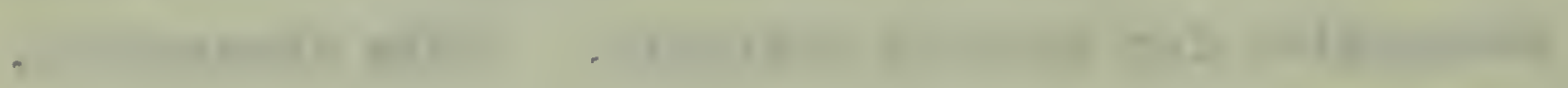

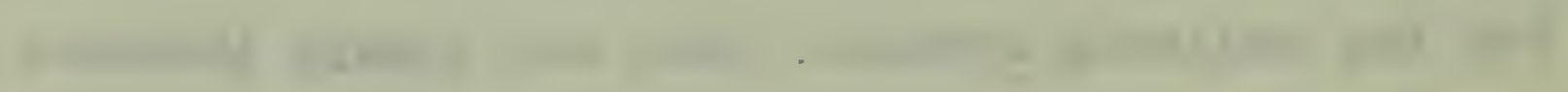

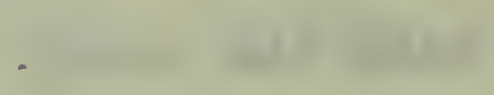

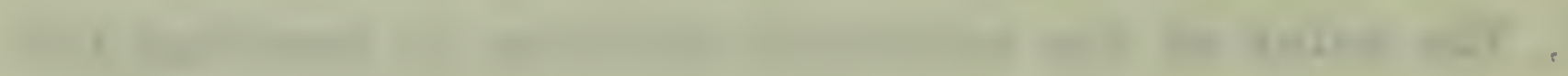
-

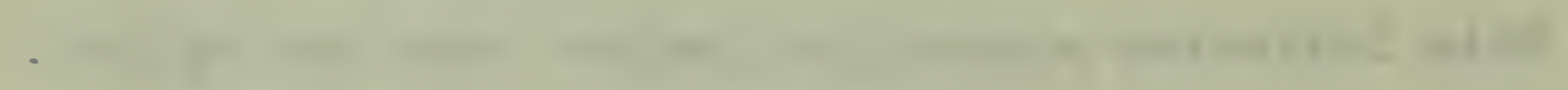


3, when soil is added to leaves there is absorption that is dependant on the absorptive power of both the leaves and the soil.

4, The mixtures of the soil and leaves both before and after decay has started do not absorb on the same basis that their constituents do.

5, (Summary) Hurnus forming substances such as leaves not only play a part in the absorption of salts by soils, but the part that they play is related to their decay.

This work was undertaken at the suggestion of Doctor Ernest Anderson, of the Department of General and Agricultural Chemistry, of the Massachusettes Agricultural College. 
ante

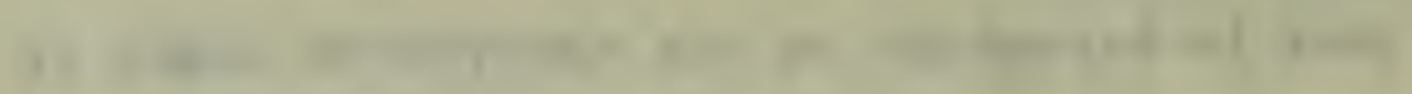

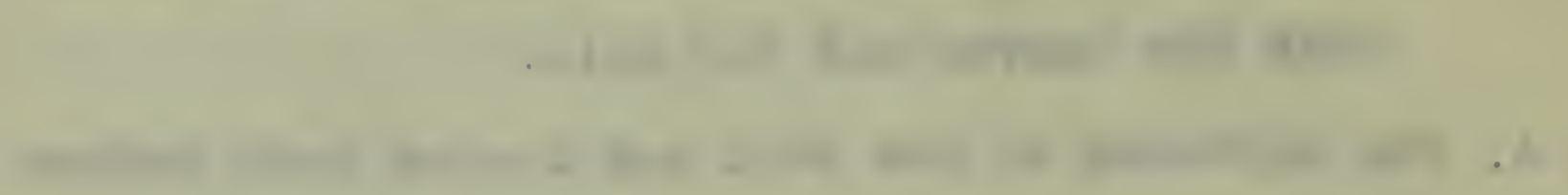

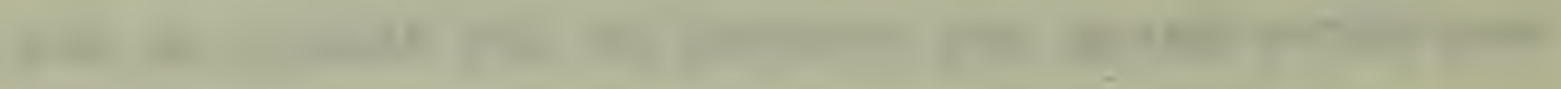

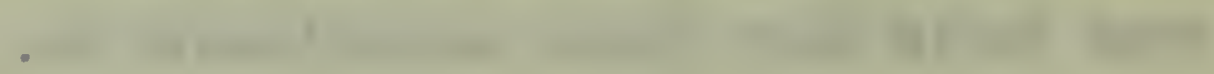

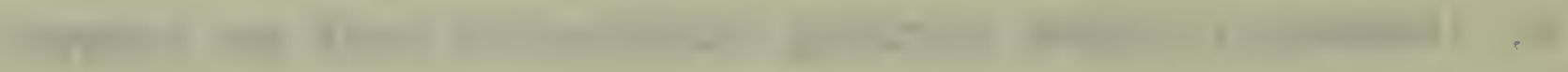

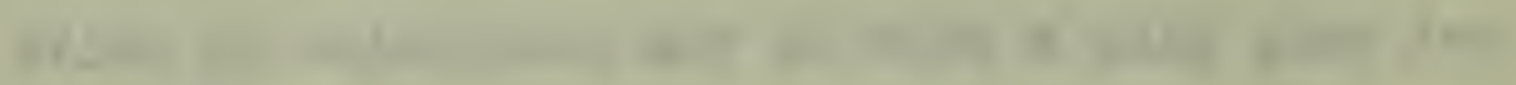
$+10$

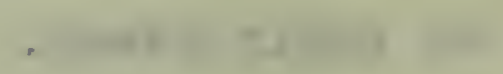

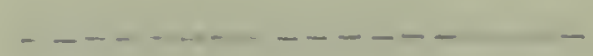

the

t

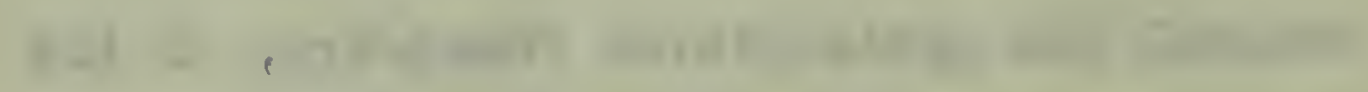

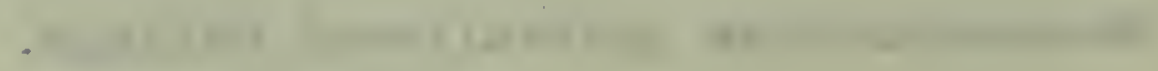

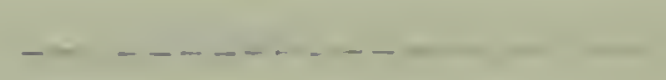








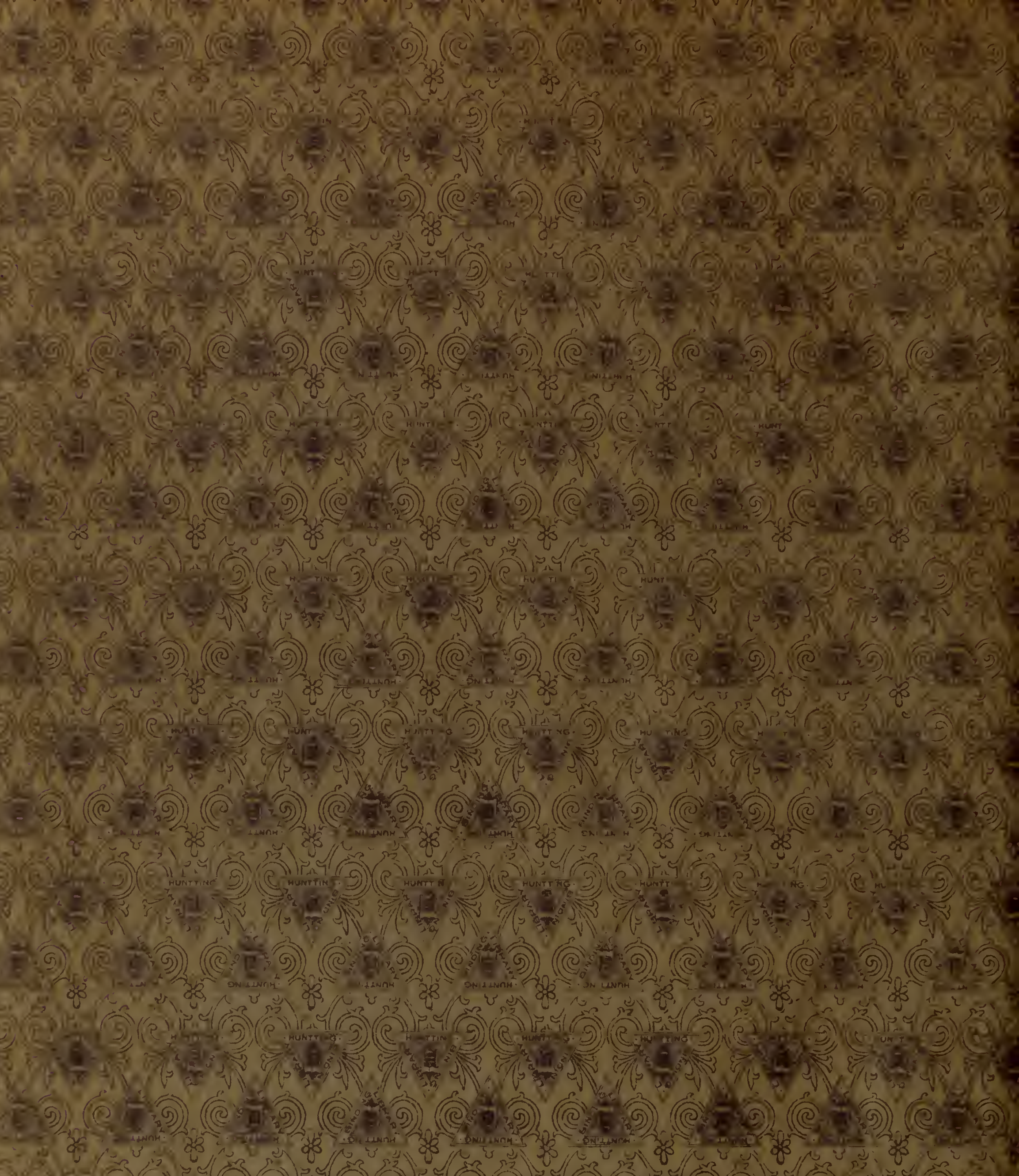


